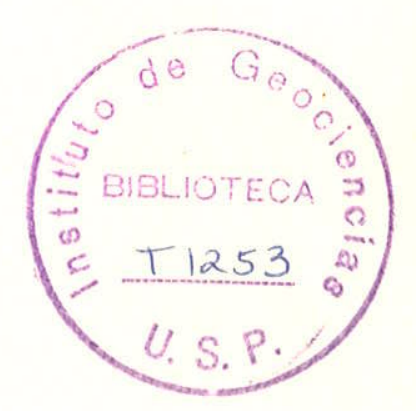

\title{
MÉTODOS DE DETERMINAÇÃO DE VAZÃO COM O EMPREGO DE TRAÇADORES RADIOATIVOS
}

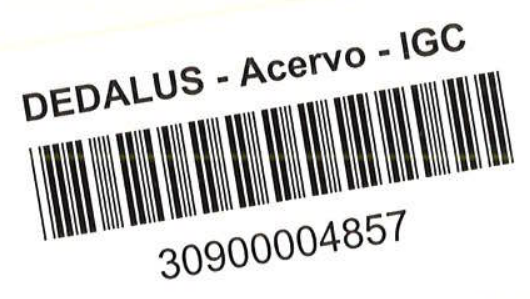




\section{AGRADECIMENTOS}

Expresso meus agradecimentos:

- ao Instituto de Energia Atômica (I.E.A.), na pessoa de seu Superintendente professor Dr. Rômulo Ribeiro Pieroni, pelo consentimento da realização deste trabalho;

- ao professor Dr. Nelson Ellert, meu orientador no campo de geociências, pelo incentivo e interessedemonstrado neste novo campo da ciência nuclear;

- ao professor Dr. Wladimyr Sanchez, diretor da Divisão de Aplicação de Radioisōtopos na Engenharia e Indústria (D.A.R.E.I.), a qual pertenço,pe1a orientação dada durante as experiências,assim como pela cuidadosa revisão dos textos aqui apresentados;

- ao professor Dr. Edmundo Garcia Agudo, pela ajuda e orientação durante e depois da realização dos ensaios;

- ao professor Dr. Antonio Carlos Gerônimo Castagnet pelas observações teóricas e práticas dos métodos empregados;

- ao Sr. Claudio Szulak pelos projetos da aparelha gem extra usada durante o transcorrer dos ensaios;

- ao geólogo Claudio Lisias Seignemartin pela ajuda nos trabalhos de campo;

- a física Barbara Maria Rzyski pelos excelentes de senhos e gráficos aqui apresentados; 
- aos meus colegas da Divisão que, direta ou indire tamente, contribuiram na realização deste traba 1 ho;

- as Srtas. Vera Lucia da Costa e Maria Luiza Frësca pela datilografia;

- ao Sr. Jayme Alves da Silva pelo trabalho de impressão e montagem desta dissertação. 
INDICE

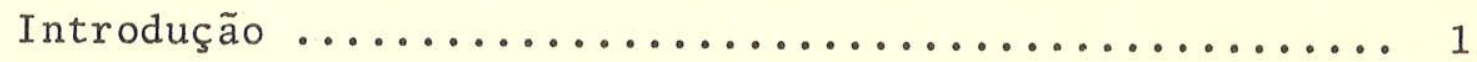

CAPITULO I - NOÇÕES DE RADIOATIVIDADE

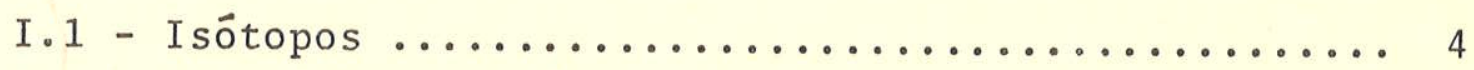

I.2 - Abundância Isotópica .......................6 6

I.3 - Radioisótopos Naturais e Séries Radicativas .... 6

I.4 - Desintegração dos Isótopos Naturais .......... 7

I.5 - Reação Nuclear .......................... 7

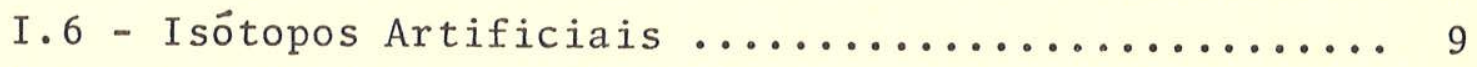

I.7 - Lei Fundamental da Radioatividade ............ 11

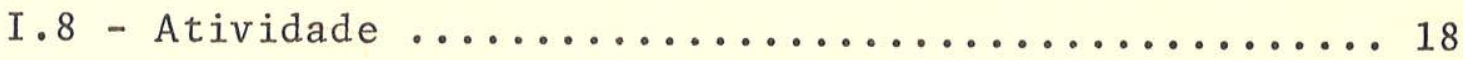

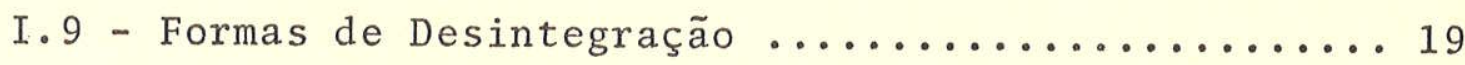

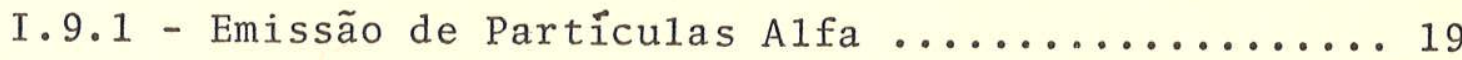

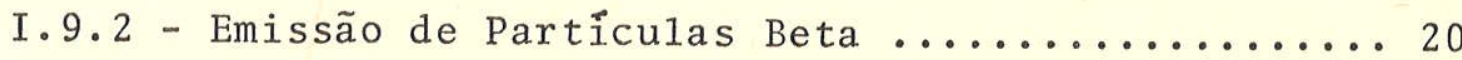

I.9.3 - Emissão de Raios Gama ..................... 21

\section{CAPITULO II -TRAÇADORES}

II.1 - Considerações Gerais .................... 23

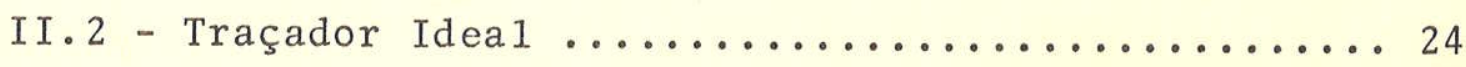

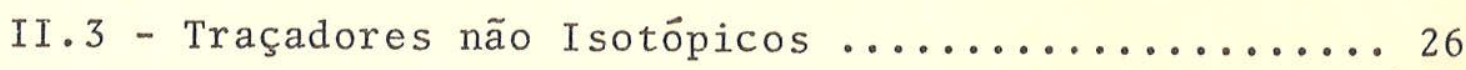

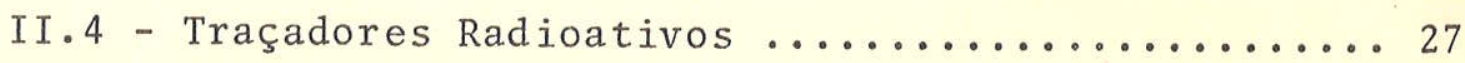

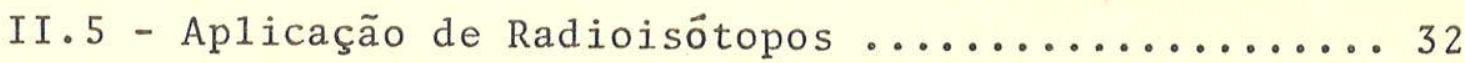

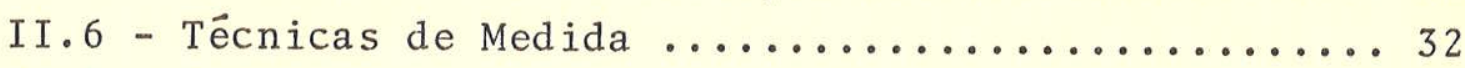

II.7 - Vantagens e Inconvenientes no uso de Traçadores

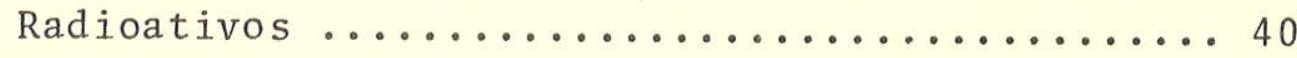

II.8 - Riscos Derivados do uso de Radioisótopos em Hi -

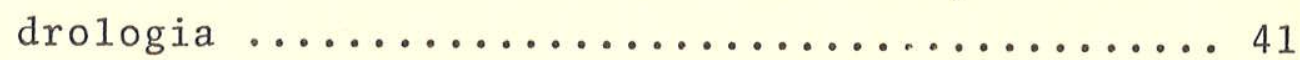

II.8.1 - Irradiação Externa ............... 42

II.8.2 - Irradiação Interna ................. 45

II.8.3 - Riscos Potenciais das Técnicas Isotópicas Utilizadas .......................... 51 
III.1 - Métodos Convencionais ................. 54

III.2 - Distância Mínima de Homogeneização .......... 57

III.3 - Verificação da Homogeneização (Latera1) .......61

III.4 - Tempo de Passagem da "Onda Radioativa"........62 62

III.5 - Mëtodos Radioisotöpicos ................ 64

III.5.1 - Método dos Dois Picos ................ 64

III.5.2 - Método da Contagem Tota $\ldots . . . . . . . . .69$

III.5.2.1 - Variantes do Mëtodo ................. 73

III.5.2.2 - Sistemas de Injeção ................ 75

III.5.2.3 - Correntes Divergentes ............... 75

III.5.2.4 - Constante de Proporcionalidade cu de Calibra

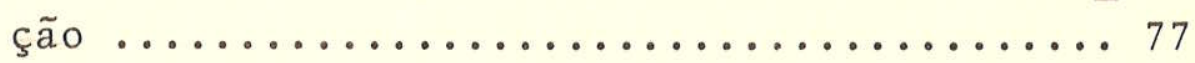

III.5.2.5 - Cảlculo da Atividade a Injetar .......... 79 III.5.3 - Método da Injeção Contínua ou da Diluição ... 81 III.5.3.1 - Cá1culo da Atividade a Injetar ..........84 III.6 - Comparação entre os Métodos Descritos ........ 84

CAPITULO IV - PARTE EXPERIMENTAL

IV.1 - Medidas de Vazão em Tubulações .............. 88

IV.1.1 - Mẻtodo da Contagem Tota $\ldots \ldots \ldots \ldots \ldots \ldots . \ldots 8$

IV.1.2 - Método dos Dois Picos .................. 94

IV.1.3 - Comparação entre os resultados obtidos ....... 97

IV.2 - Medidas de Vazão em Canalizações ............. 99

IV.3 - Medidas de Vazão em Rios ...................108

IV.4 - Conclusões e Observações ....................112

Bibliografia .................................... 14 
INTRODUÇÃO

A medida de vazão ê problema fundamental em muitos campos, notadamente em engenharia e hidräulica. Incansáveis buscas experimentais e teóricas sobre o problema desenvolve ram grande numero de soluções aproximadas. Para cada aplica ção em particular foi desenvolvida uma técnica, geralmente com sucesso limitado. Os mëtodos aqui desenvolvidos alem de serem aplicảveis nos casos em que os métodos convencionais não podem ser utilizados apresentam melhor resolução e ver satilidade.

Os apare1hos comumente usados nas medições de va zão em tubulações apresentam värias deficiencias. Por exemplo, um tubo de Pitot mede a velocidade linear na ponta do tubo. Para se medir volume torna-se necessärio considerar a seção transversal da corrente com o tubo Pitot, ou usar -se uma fórmula empírica, para cálculo do fluxo medio, por meio da integral dos pontos da ärea transversa1. Podem tambêm apresentar defeitos provocados pelas partículas em suspensão, que podem obstruir parcial ou totalmente a abertura do tu bo.

Placas com orificios tambëm servem à medição de vâ zão, mas elas dependem de formulas empíricas, com numerosos coeficientes. Quando um orificio estiver corroido ou houver incrustações, a precisão das medidas será prejudicada. As fórmulas usadas nos cálculos de vazão em tubulações, com es tes aparelhos, levam em conta um fator empírico, que depende da natureza da parede da tubulação.

Métodos de dissolução, proporcionam resultados pre cisos, quando usados em líquidos limpos, com aparelhagem mantidas em perfeitas condições de operação e frequentemente calibradas. Com estes métodos utilizam-se traçadores quí micos (cloreto de sódio fenóis, ảcido bórico, detergentes, etc...) e colorantes (fluoreceina, dicromato de potássio, rodamina $B$, eosina, roxo do congo, etc.), que alẻm de caros não são aplicâveis em medidas de grandes vazões. Podem pro vocar ainda contaminações duradouras sendo fisicamente afe 
tadas pelo meio em medição.

Vertedores tambem possibilitam medições de vazão,por meio de fórmulas semiempíricas. Quando as condições são anor malmente baixas ou altas, geralmente as fórmulas não conduzem a resultados precisos.

Normalmente, em medições de vazão de rios,utiliza-se - molinete. Este apare1ho, que necessita de cuidadosa manutenção após cada campanha de medidas, poderá proporcionar resulta dos insatisfatórios em decorrência de sua parte mecânica.Existe ainda a necessidade de se conhecer a seção transversal do escoamento ou "perímetro molhado", o que é trabalhoso, dada a quantidade de fatôres intervenientes.

Em estações fixas, de registro contínuo, os medidores convencionais são insubstituíveis, mas devem ser periodica mente calibrados. Geralmente as calibrações são realizadas por meio de métodos convencionais. Atualmente a técnica mais indicada para aferição das medições de vazão é a dos traçadores ra dioativos.

São värias as vantagens apresentadas pelas técnicas radioisotópicas de medição de vazão, e entre elas pode-se destacar a identidade entre o agente marcado e o marcador, que pode chegar ao nível atômico (um átomo do isótopo radioativo se comporta do mesmo modo que um átomo estável do mesmo elemen to). A deteção do radioisótopo tambēm pode alcançar níveis atô micos (os radioisótopos de vida curta, com periodos de 100 dias ou menos, podem ser detetados em quantidades pequenas co mo $10^{-16}$ ou $10^{-17}$ de gramas). Ainda como vantagens, a técnica possibilita medições "in situ" e vida limitada do radioisótopo, que pode ser escolhido de acôrdo com a duração prevista para a experiência.

Entre os métodos de medição de vazão descritos neste trabalho, utiliza-se com mais frequência o da."Contagem Total". Seu emprego possibilita obter valores com precisão da ordem de $1 \%$ e as medições independem do conhecimento da seção transversal do escoamento.

Foi D. E. Hu11, em 1957, que ao analisar medidas rea lizadas em um oleoduto, onde periodicamente se havia injetado 
determinado radioisótopo, adaptou o método dos traçadores quí micos aos traçadores radioativos. Com o método da Contagem To tal mede-se o fluxo em qualquer parte da corrente e em diversos tipos de corrente. Por meio de um detetor de radiação, fixo em uma seção a jusante, suficientemente distante para proporcionar completa mistura do traçador com o escoamento, registra-se a contagem da radiação emitida durante a passagem da nuvem radioativa. A relação entre a contagem total da radiação $N$, a atividade $A$ de traçador injetado no escoamento e a vazão volumétrica $Q$, é expressa por uma fórmula simples,

$$
Q=\frac{F \cdot A \cdot}{N}
$$

onde, F, chamado fator de calibração, é característico de cada radioisótopo, do detetor utilizado e da geometria de deteção.

Neste trabalho descreve-se com pormenores a parte teórica pelo fato de não existir ainda em nossa língua, ne nhum compêndio que trate do assunto e tambẻm porque os hidrólogos ou pessoas que trabalham no ramo, praticamente desco nhecem a utilização da radioatividade na hidrologia.

$\mathrm{Na}$ parte prática procurou-se realçar as vantagens dos métodos empregados, caracterizados pela simplicidade,eficiência, baixo custo, alta sensibilidade e ausência de perigo para a saúde dos técnicos.

Pretende-se mostrar, também, as facilidades do emprego de radiotraçadores em hidrologia de superfície, e conse quentemente melhor divulgação dos métodos empregados. 


\section{CAPITULO I}

\section{NOÇOES DE RADIOATIVIDADE}

\section{I-1 ISOTTOPOS}

A teoria atômica de Dalton postulava serem os ảto mos de um mesmo elemento inteiramente idênticos, no que concerne à massa, tamanho e demais propriedades. Durante muito tempo considerou-se os pesos relativos dos átomos como a propriedade fundamental dos elementos. Entretanto,Mendeleieff, em sua classificação periódica, dispunha certos elementos em posições que não as exatamente determinadas pela ordem dos pesos atômicos, talvez prevendo o aparecimento de outras proprie dades desses elementos. Realmente, os estudos posteriores sobre a estrutura do átomo demonstraram que as propriedades químicas dos elementos são determinadas pelo número de elétrons que envolvem os núcleos. Sendo o número de elétrons do átomo de um dado elemento numericamente igual à carga do núcleo respectivo, ele coincide com o número atômico do elemento. De acôrdo com a representação do núcleo que fornece o modêlo pro ton-nêutron, é perfeitamente possível admitir espécies atômicas com idênticas estruturas eletrônicas, diferindo apenas no tocante ao número de neutrons que entram na composição dos núcleos. A esta possibilidade corresponde o fenômeno da isotopia.

W. Crookes, em 1896, jả admitia a existência de isótopos, mas somente com a descoberta da radioatividade é que apareceram razões mais evidentes desta existência. Em 1906, B. B. Boltwood identificou o iônio como sendo um elemento radioativo. Verificou-se, então, que as propriedades químicas do iônio eram de tal forma idênticas às do tório que os compostos de iônio e tório eram quimicamente inseparáveis. Todavia,esses dois elementos apresentavam indiscutiveis diferenças de massa 
e propriedades radioativas. Posteriormente, A. S. Russel e R. Rossi (1912) observaram que os espéctros de arco do iônio e do tório eram iguais. Outros casos semelhantes haviam levado F. Soddy (1910) a considerar que um elemento, não obstante sua homogeneidade química, fosse constituido de uma mistura de várias espécies atômicas e que seu peso atômico seria a média ponderada das massas das espécies atômicas componentes.

Comprovou-se a suposição de Soddy quando J.J.Thomson (1912), investigando os raios positivos do neônio, constatou que este elemento continha átomos com número de massa 20 e 22 ainda que os átomos mais pesados representassem apenas uma pequena fração. A partir daí Soddy propôs o nome de isótopos para designar as espécies atômicas com idêntica carga nuclear e massa diferente, tomando em conta que tais espécies atômicas devem ocupar o mesmo lugar na classificação periódica.

Estudos posteriores, efetuados com o auxilio do espectrógrafo de massa, revelaram que a isotopia não é uma exceção, pois a maior parte dos elementos ocorrem na forma de misturas de isótopos. Como os isótopos de um elemento têm idêntica estrutura eletrônica, êles são quimicamente idênticos. 0 nú mero variảvel de neutrons é que diferencia os isótopos. É óbvio que as propriedades físicas dos elementos que dependem diretamente da massa atômica não são idênticas nos isôtopos. 0 efeito da diferença da massa é mais apreciável nos casos dos elementos mais leves, porque ela assume uma significação relativa maior. Neste particular, o exemplo extremo é o do hidrogê nio, que possui três isótopos: o hidrogênio leve $(H)$, o deutério $\left({ }^{2} \mathrm{H}\right)$ e o trítio $\left({ }^{3} \mathrm{H}\right)$, de números de massa 1,2 , e 3 , res pectivamente. Os isótopos do hidrogênio são os únicos que rece beram nomes específicos, em grande parte devido às apreciá veis diferenças do comportamento que exibem. Para se destinguir um isótopo de outro, usam-se notações que especificam o número de massa. Por exemplo, os isótopos de neônio com os números de massa 20 e 22 são representados por ${ }^{20} \mathrm{Ne}$ e ${ }^{22} \mathrm{Ne}$. 


\section{I-2 ABUNDÂNCIA ISOTÓPICA}

Alguns elementos, como o A1, P, etc., possuem sōmente um isótopo estável. Sem dúvida, a maior parte dos elementos têm dois ou mais isótopos (o Sn chega a ter dez). Quando ocorrem värios isótopos, a proporção com que cada um entra na for mação do elemento natural é definida e constante. Esta proporção recebe o nome de abundância isotópica e pode ser expressa em porcentagem, como por exemp1o:

- o H natural está formado por $99,985^{\circ}$ de ${ }^{1} \mathrm{H}$ e $0,01492 \%$ de ${ }^{2} \mathrm{H}$ (deutêrio).

- o C natural está formado por $98,893 \%$ de ${ }^{12} \mathrm{C}$ e $1,107 \%$ de ${ }^{13} \mathrm{C}$. $0,239 \%$ de ${ }^{18} 0$

- o o natural tem $99,759 \%$ de ${ }^{16} 0,0,0374 \%$ de ${ }^{17} 0$ e

\section{I-3 RADIOISÓTOPOS NATURAIS E SERIES RADIOATIVAS}

A maioria dos radioisótopos encontrados na natureza possuem cargas nucleares e números de massa elevados. Isótopos naturais com cargas nucleares mais baixas apresentam radiativi dade $\left({ }_{1}^{3} \mathrm{H},{ }_{6}^{14} \mathrm{C}, \quad{ }_{19}^{40} \mathrm{~K}\right)$. Com exceção do trítio, os isó topos radioativos naturais dos elementos leves possuem períodos de semidesintegração extremamente 1ongos. $0{ }^{3} \mathrm{H}$ e o ${ }^{14} \mathrm{C}$ são produzidos continuamente, pelo bombardeio do ${ }^{14} \mathrm{~N}$ existente na natureza, com nêutrons provenientes dos raios cósmicos. Os ra ios cósmicos chegam à Terra, provindos do espaço universal, e são formados por prótons de energia muito alta. A energia mé dia por partícula equivale a cêrca de $10.000 \mathrm{MeV}$, mas existem partículas com energias bem mais elevadas. Ao chocar com os nú cleos dos átomos dos componentes do ar, os prótons cósmicos originam processos secundários,desintegram os núcleos atômicos e formam milhares de partículas capazes de originar novas partículas.

os radioisótopos naturais pesados foram agrupados em 
três séries de desintegração, conhecidos como série do tório, do urânio e do actínio. Cada uma delas tem como membro-pai um isótopo radioativo de longo período de semidesintegração, que por sucessivas desintegrações originam os demais, até atingirse um produto final estável. Os produtos finais das três séries são isótopos do chumbo. A hipótese de existência de uma quarta série radioativa, encontrou confirmação com a descoberta dos elementos transurânios e a produção artificial de numerosos radioisótopos pesados. Com esses elementos foi possível traçar uma quarta série radioativa, a série do neptúnio.

\section{I-4 DESINTEGRAÇÃO DOS ISOTTOPOS NATURAIS}

0 fenômeno da radioatividade prende-se à existência de radioisótopos, constituỉdos de núcleos estáveis, que se desintegram expontâneamente. Os processos de desintegração são acompanhados da emissão de partículas alfa $(\alpha)$, beta $(\beta)$ e gama $(\gamma)$. Com a desintegração dos núcleos atômicos resultam produtos que diferem do original não sōmente quanto as proprie dades radioativas, mas também em relação às propriedades químí cas. Os processos radioativos envolvem, portanto, a transmutação dos elementos. No caso de radioisótopos naturais, geralmen te as espécies atômicas resultantes da desintegração também são radioativas. Estas, por sua vez, desintegram-se formando outros produtos, até que, finalmente, resultam espécies está veis e inativas. Tem-se, assim, tôda uma sucessão de produtos de processos radioativos encadeados, chamada série de desintegração.

\section{I-5 REAÇÃO NUCLEAR}

A radioatividade natural ẻ um processo expontâneo, que na maioria dos casos ocorre com elementos de massa compre- 
endidos entre 238 e 207 e números atômicos compreendidos entre 92 e 81.

A reação nuclear de um elemento naturalmente estáve1 foi conseguida, pela primeira vez, por E. Rutherford (1919), fa zendo incidir um feixe de partículas a emitidas pelo rảdio sôbre nitrogênio gasoso. Observou-se que o bombardeio das molécu las de nitrogênio pelas partículas a produzia pequeno número de novas partículas capazes de atravessar ate $40 \mathrm{~cm}$ de espessu ra de ar. A deflexão dessas partículas, por meio de um campo magnético, demonstrou que se tratava de prótons movendo-se com grande velocidade. Estes prótons seriam resultante de uma rea ção nuclear do tipo:

$$
{ }_{7}^{14} \mathrm{~N}+{ }_{2}^{4} \mathrm{He} \longrightarrow{ }_{8}^{17} \mathrm{O}+{ }_{1}^{1} \mathrm{H}+\mathrm{Q}
$$

onde $Q \vec{e}$ a energia de desintegração envolvida na reação.

Trabalhos posteriores de E. Rutherford e J. Chadwik

( 1919 e 1925 ) mostraram que todos os elementos compreendidos entre o boro e o potássio, com exceção feita ao carbono e oxigênio, são igualmente suscetíveis de desintegração e emissão de protons, por efeito do bombardeio com partículas $\alpha$.

0 poder de penetração dos prótons formados nas rea ções $(\alpha, p)$ depende do elemento bombardeado. 0 flúor emite par tículas com poder de penetração no ar, da ordem de $65 \mathrm{~cm}$, e o aluminio, de até $90 \mathrm{~cm}$. Os prótons são emitidos em tôdas as dị reções, o que prova que sua energia cinética provẻm principalmente da desintegração dos átomos. O número de desintegrações, provocadas pelo bombardeamento dos radioisótopos naturais com partículas alfa $(\alpha)$, è minimo, tendo-se constatado a formação de apenas dezenas de prótons por milhão de partículas a inci dentes. As partículas alfa possuem carga elétrica positiva e por isso ao se aproximarem de um núcleo, tendem a ser desvia das. A colisão destas partículas com um núcleo é tanto mais di fícil quanto maior for a carga nuclear do elemento alvo. Esta limitação ê superada, quando a partícula incidente possui alta energia, o que se consegue mediante utilização de aceleradores. Com particulas a aceleradas foram conseguidas novas desintegra ções do tipo $(\alpha, p)$. 
Os prótons e os dêuterons (núcleos do deutério) possuem cargas elétricas menores, e por isso foram admitidos como eventuais projéteis capazes de vencer a repulsão eletrotática dos núcleos com mais facilidade do que as partículas $\alpha$.

Os neutrons não possuem carga, daí sua possibilidade de colidir com os núcleos dos elementos é maior do que, por exemplo, as partículas duplamente carregadas. Em consequência as colisões inelásticas com neutrons, que provocam desintegrações de nücleos, ocorrem mais frequentemente do que nas irra diações com partículas $\alpha$. Os neutrons são emitidos com veloc $\underline{\underline{i}}$ dades da ordem de $1 / 10$ da velocidade da luz e energias de um milhão de elëtrons-volts aproximadamente. As colisões de neu trons rápidos (altas energias) provocam desintegrações de mu $\underline{i}$ tos núcleos. Os neutrons räpidos depois de sofrerem colisões perdem energia e se transformam em neutrons lentos ou têrmi cos. Em outras palavras, neutrons térmicos são aqueles cujas velocidades foram reduzidas nas colisões, a ponto de suas ener gias se tornarem equivalentes à energia de equilibrio de qua 1 quer outra partícula à mesma temperatura. O amortecimento da velocidade é alcançado mediante a passagem dos neutrons rápidos atravês de materiais contendo ao menos uma espécie de ätomos leves, chamados moderadores.

\section{$\underline{\text { I-6 ISOTTOPOS ARTIFICIAIS }}$}

A produção de isótopos artificiais foi iniciada por I. Curie e F. Joliot (1934). Submetendo alvos de boro, magnesio e alumínio ao bombardeio com partículas $\alpha$, constataram que os materiais bombardeados continuavam a emitir radiações mesmo depois de removida a fonte de partículas $\alpha$. As medidas de ionização e de deflexão magnêtica provaram que a radiação emitida pelos elementos bombardeados era constituída de posi trons. Observou-se, também, que a intensidade dos positrons di minuia exponencialmente com o tempo, da mesma forma que nos ca sos de isôtopos naturais. o casal Joliot-Curie explicou o fenô 
meno admitindo a formação de núcleos estáveis em reações do tí po $(\alpha, \eta)$, que, em seguida, se desintegravam com emissão de po sitrons. Em cada caso, foi medido o período de desintegração do processo.

Posteriormente, numerosos cientistas conseguiram pro duzir artificialmente grande nümero de outros isótopos, não só mediante bombardeio com partículas naturais, mas tambëm com prótons e dêuterons eletricamente acelerados e neutrons. Os neutrons se encontram entre as melhores partículas para o bom bardeio de elementos com vistas à obtensão de isótopos radioativos. As reações nucleares podem ser de värios tipos, conforme sejam os neutrons râpidos, epitêrmicos e térmicos.

Existem mais de uma düzia de tipos de reações nuclea res que dão origem a isótopos radioativos artificiais. A maioria dos isótopos radioativos artificiais são emissores de eletrons negativos (partículas beta), em vez de positrons. Há uma regra que, com poucas excessões,permite predizer o sinal da ra diação. Se o isótopo formado for mais pesado do que os isóto pos estáveis do elemento, êle será um emissor de partículas $\beta$ negativas; se mais leve, geralmente serä emissor de positrons. Menos frequentemente o nücleo deste elemento pode capturar um eletron das camadas mais próximas. De cada um dos elementos co nhecidos, pode se produzir vârios isótopos. Em geral, um dado isótopo pode ser obtido por meio de mais de uma reação nuclear.

Métodos práticos para a produção artificial de radio isótopos são os baseados no bombardeamento com ions eletrica mente acelerados (protons, deuterons e núcieos de hêlio, com velocidades controladas, produzidas em ciclotron) ou com neu trons räpidos e lentos. Presentemente, a mais importante fonte de produção de radioisótopos artificiais é o reator nuclear , que é capaz de fornecer um intenso feixe neutrônico, que permi te irradiar facilmente qualquer elemento. 


\subsection{LEI FUNDAMENTAL DA RADIOATIVIDADE}

O decaimento radioativo ê uma propriedade do núcleo e só depende do seu estado. O decaimento de todos os radioisó topos é caracterizado pela seguinte regularidade: em dado isótopo o número de núcleos que se desintegra, por unidade de tempo, representa uma fração definida do número total de nú cleos remanescentes. A fração dos núcleos desintegrados varia de elemento para elemento, dependendo da instabilidade de cada um deles. Matematicamente a lei do decaimento radioativo po de ser expressa pela relação:

$$
-d N=\lambda \cdot N \cdot d t
$$

isto $\hat{e}$, o número de åtomos $\mathrm{dN}$, que se desintegra durante um curto período de tempo $d t$, é proporcional ao número total inicial de átomos N. O fator $\lambda$ é chamado constante de desinte gração e determina o número de âtomos desintegrados por unida de de tempo. A constante é expressa em segundos ${ }^{-1}$ dias $^{-1}$, anos -1 e tem valor definitivo para cada radioisôtopo. 0 sinal negativo que precede $\mathrm{dN}$ indica que o processo de desintegração é acompanhado pelo decréscimo do nủmero de átomos radioativos.

A lei básica do decaimento radioativo pode ser dedu zida como se segue:

a) multip1icamos a expressão (1)por -1

$$
\begin{aligned}
(-1) \cdot(\text { ndN }) & =(-1) \cdot(\lambda \cdot N \cdot d t) \\
d N & =-\lambda \cdot N \cdot d t
\end{aligned}
$$

b) dividimos (2)por $\mathrm{N}$

$$
\frac{\mathrm{dN}}{\mathrm{N}}=\frac{-\lambda \cdot N \cdot d t}{\mathrm{~N}} \therefore \frac{\mathrm{dN}}{\mathrm{N}}=-\lambda \mathrm{dt}
$$

c) integramos (3)para obter a totalidade dos ātomos desintegrados durante o tempo $t$

$$
\int_{N_{0}}^{N} \frac{d N}{N}=-\int_{0}^{t} \lambda d t
$$

as integrais variam de $N_{0}$ (número inicial de átomos) no ins tante $t=0$ até $N$ (número final de átomos) no instante $t$ 


$$
\begin{aligned}
\left.\ln N\right|_{N_{0}} ^{N} & =-\lambda \cdot t \\
\ln N-\ln N_{0} & =-\lambda \cdot t \\
\frac{N}{N_{O}} & =e^{-\lambda \cdot t} \\
N & =N_{0} \cdot e^{-\lambda \cdot t}
\end{aligned}
$$

onde ê ê a base dos logarítimos naturais.

Chama-se meia vida ou, período de semidesintegra ção, o intervalo de tempo $\mathrm{T}_{1 / 2}$, necessário para que a ativida de de radioisótopo seja reduzida exatamente pela metade. Fa zendo $N=N_{0} / 2$ e $t=T_{1 / 2}$, na equação (4) temos

$$
\lambda \mathrm{T}_{1 / 2}=1 \mathrm{n} 2=0,693
$$

Portanto, a meia vida de um radioisótopo é calculada pela e quação:

$$
\mathrm{T}_{1 / 2}=0,693 / \lambda
$$

As meias vidas dos raioisótopos variam dentro de grandes limites (tabela I).

De acôrdo com a lei exponencial de desintegração, o número de ätomos radioativos presentes em uma amostra se re duz à metade depois de transcorrido o tempo T. No fim de um tempo 2T, restará um quarto dos ātomos radioativos originais e assim por diante. A desintegração exponencial significa que determinado átomo possui, em dado instante, uma probabilidade definida de sofrer a desintegração, probabilidade essa que é proporcional ao número de átomos radioativos presentes no momento. Portanto, a vida de um ätomo radioativo pode estenderse entre valôres de tempo que vão desde zero até infinito. Ex plica-se assim, a gradual redução da intensidade da radiação, pois do conträrio, todos os ätomos se desintegrariam ao mesmo tempo. Frequentemente se menciona, entre as caracteristicas ' dos radioisótopos, o período de vida mëdia de um átomo radioa tivo. Pode-se demonstrar que a vida média de um ätomo radioativo, $\tau$, è igual à recíproca de sua constante de desintegra 
T A B E L A I

CARACTERISTICAS DOS PRINCIPAIS RADIOISŐTOPOS

\begin{tabular}{|c|c|c|}
\hline $\begin{array}{l}\frac{{ }_{\mathrm{H} \mathrm{T}_{1 / 2}}^{\mathrm{H}^{-} 0,018 \mathrm{MeV}}}{{ }^{3} \mathrm{He}} \\
\mathrm{E}_{\text {max }}=12,62 \mathrm{a} \\
\mathrm{E}_{\text {med }}=5,5 \mathrm{keV}\end{array}$ & $\begin{array}{l}\text { Alcance para } E_{\max } \\
\text { No ar }=4,5 \mathrm{~mm} \\
\mathrm{Na} \text { ägua }=6 \mu\end{array}$ & $\begin{array}{c}\text { Origem Natural } \\
{ }^{1{ }^{4} \mathrm{~N}\left(\mathrm{n}^{3} \mathrm{H}\right)} \\
\text { Produção Artificial: } \\
{ }^{6} \mathrm{Li}(\mathrm{n}, \alpha)^{3} \mathrm{H} \\
\text { Förmula }{ }^{3} \mathrm{H} \mathrm{HO} \\
\text { Unidade } \\
1 \mathrm{UT}=\frac{1 \text { atomo }{ }^{3} \mathrm{H}}{10^{18} \text { atomos } \mathrm{H}}= \\
=7,1 \times 10^{-3} \text { des } / \mathrm{min} \mathrm{cm}^{3} \text { ägua }\end{array}$ \\
\hline $\begin{array}{l}\frac{{ }^{1{ }^{4} \dot{C} \mathrm{~T}_{1 / 2}}=5760 \mathrm{a}}{\beta^{-} 0,159 \mathrm{MeV}} \\
\mathrm{E}_{\text {max }}=159 \mathrm{keV} \\
\mathrm{E}_{\text {med }}=50 \mathrm{keV}\end{array}$ & $\begin{array}{l}\text { Alcance para } E_{\max } \\
\text { No } \mathrm{ar}=19,3 \mathrm{~cm} \\
\mathrm{Na} \text { água }=250 \mu\end{array}$ & $\begin{array}{r}\text { Origem Natural } \\
{ }^{14} \mathrm{~N}(\mathrm{n}, \mathrm{p}){ }^{1{ }^{4} \mathrm{C}}\end{array}$ \\
\hline $\begin{array}{c}\frac{1}{{ }^{32} \mathrm{~S}} \\
\mathrm{E}_{\max }=1,71 \mathrm{MeV} \\
\mathrm{E}_{\text {med }}=700 \mathrm{keV}\end{array}$ & $\begin{array}{l}\text { Alcance para } E_{\max } \\
\text { No ar }=603 \mathrm{~cm} \\
\mathrm{Na} \text { ägua }=8 \mathrm{~mm}\end{array}$ & $\begin{array}{l}\text { Processo de Produção } \\
{ }^{31} \mathrm{P}(\mathrm{m}, \gamma){ }^{32} \mathrm{P} ; \sigma=0,19 \text { barns } \\
\text { Atividade Produzida } \\
\quad\left(10^{12} \mathrm{n} / \mathrm{cm}^{2} / \mathrm{s}\right) \\
1 \text { semana }=25 \mathrm{mCi} / \mathrm{g} \text { de } \mathrm{P}\end{array}$ \\
\hline 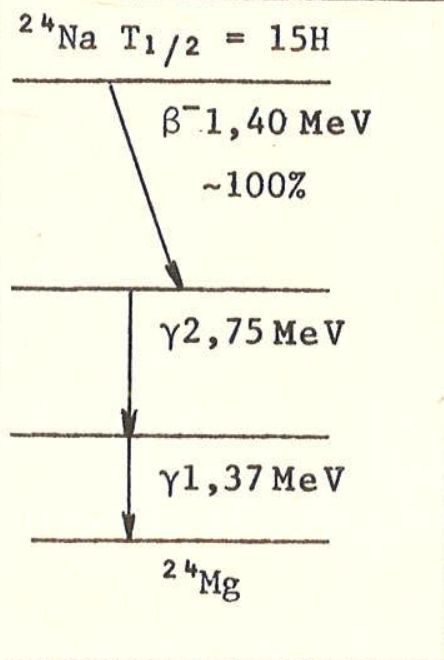 & $\begin{array}{l}\mathrm{E}_{\gamma}: 1,84 \mathrm{mR} / \mathrm{h}: 1 \mathrm{~m}: 1 \mathrm{~m} C_{i} \\
\mathrm{Na} \text { ägua: } \\
\mu_{01}=0,05 \mathrm{~cm}^{3} / \mathrm{g} \\
x_{1 / 2}=13,6 \mathrm{~cm} ; X^{\prime}{ }_{1 / 2}=20 \mathrm{~cm} \\
\frac{\mu_{\mathrm{al}}}{\rho}=0,024 \mathrm{~cm}^{2} / \mathrm{g}\end{array}$ & $\begin{array}{l}\text { Processo de Produção } \\
\qquad{ }^{23} \mathrm{Na}(\mathrm{n}, \gamma)^{24} \mathrm{Na} ; \\
\sigma=0,54 \text { barns } \\
\text { Atividade Produzida } \\
\quad\left(10^{12} \mathrm{n} / \mathrm{cm}^{2} / \mathrm{s}\right)\end{array}$ \\
\hline
\end{tabular}




\begin{tabular}{|c|c|c|}
\hline $\begin{aligned}{ }^{35} \mathrm{C} 1 \\
E_{\max }=167 \mathrm{keV} \\
E_{\text {med }}=49 \mathrm{keV}\end{aligned}$ & $\begin{array}{l}\text { Alcance para } E_{\max } \\
\text { No ar }=27 \mathrm{~cm} \\
\mathrm{Na} \text { ägua }=250 \mu\end{array}$ & $\begin{array}{c}\text { Processo de Produção } \\
{ }^{35} \mathrm{C} 1(\mathrm{n}, \mathrm{p})^{35} \mathrm{~S} ; \\
\sigma=0,30 \text { barns } \\
{ }^{34} \mathrm{~S}(\mathrm{n}, \gamma)^{35} \mathrm{~s}: \\
0,011 \text { barns } \\
\text { Atividade Produzida } \\
\left(10^{12} \mathrm{n} / \mathrm{cm}^{2} / \mathrm{s}\right) \\
\text { semana }=6,3 \mathrm{mCi} / \mathrm{g} \mathrm{C} 1 \\
\text { L semana }=0,26 \mathrm{mCi} / \mathrm{g} \mathrm{s}\end{array}$ \\
\hline 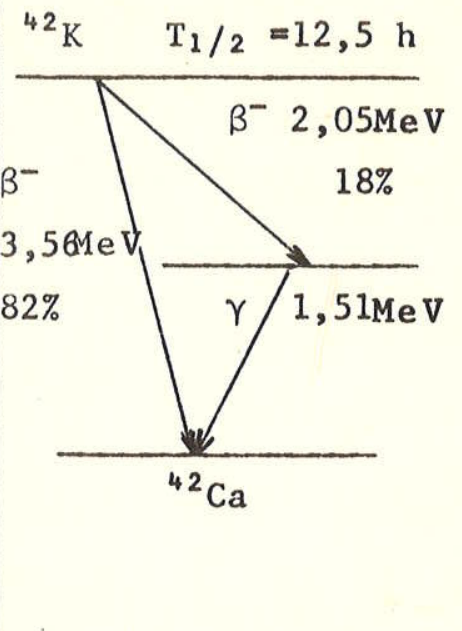 & $\begin{array}{l}\mathrm{E}_{\gamma}: 0,14 \mathrm{mR} / \mathrm{h} ; 1 \mathrm{~m} ; 1 \mathrm{mCi} \\
\frac{\mu_{01}}{\rho}=0,058 \mathrm{~cm}^{2} / \mathrm{g} \\
X_{1 / 2}=12,4 \mathrm{~cm}: X_{1 / 2}^{\prime}=17,8 \mathrm{~cm} \\
\frac{\mu_{\text {al }}}{\rho}=0,028 \mathrm{~cm}^{2} / \mathrm{g}\end{array}$ & $\begin{array}{l}\text { Processo de Produção } \\
\qquad{ }^{41} \mathrm{~K}(\mathrm{n}, \gamma)^{42} \mathrm{~K} \text {; } \\
\text { Atividade Produzida } \\
\qquad\left(10^{12} \mathrm{n} / \mathrm{cm}^{2} / \mathrm{s}\right) \\
24 \text { horas : } 27 \mathrm{mCi} / \mathrm{g} \mathrm{K}\end{array}$ \\
\hline$\frac{\int^{\gamma 0,89 \mathrm{MeV}}}{{ }^{46} \mathrm{Ti}}$ & $\begin{array}{c}\mathrm{E}_{\gamma}: 0,14 \mathrm{mR} / \mathrm{h}(\mathrm{a} 1 \mathrm{~m}, \mathrm{p} / \mathrm{lmCl}) \\
\text { EM ĀGUA } \\
\mu_{01} / \rho=0,058 \mathrm{~cm}^{2} / \mathrm{g} \\
\mathrm{X}_{1 / 2}=10 \mathrm{~cm}: \mathrm{X} 1 / 2=14,4 \mathrm{~cm} \\
\mu_{\mathrm{a} 1} \rho=0,028 \mathrm{~cm}^{2} / \mathrm{g}\end{array}$ & $\begin{array}{l}\text { Processo de Produção } \\
{ }^{45} \mathrm{Sc}(\mathrm{n}, \gamma)^{46} \mathrm{Sc} \\
\sigma=22 \text { barns } \\
\text { Atividade Produzida } \\
\quad\left(10^{12} \mathrm{n} / \mathrm{cm}^{2} / \mathrm{s}\right) \\
1 \text { semana }=0,38 \mathrm{Ci} / \mathrm{g} \mathrm{Sc}\end{array}$ \\
\hline 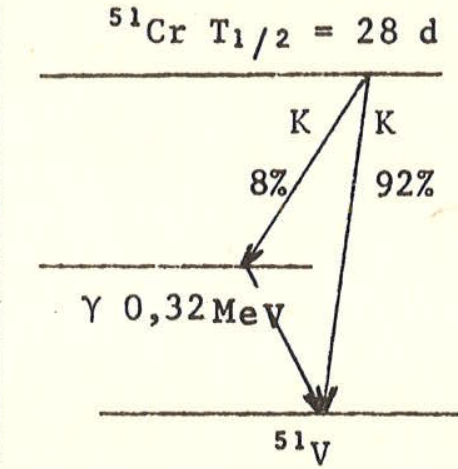 & 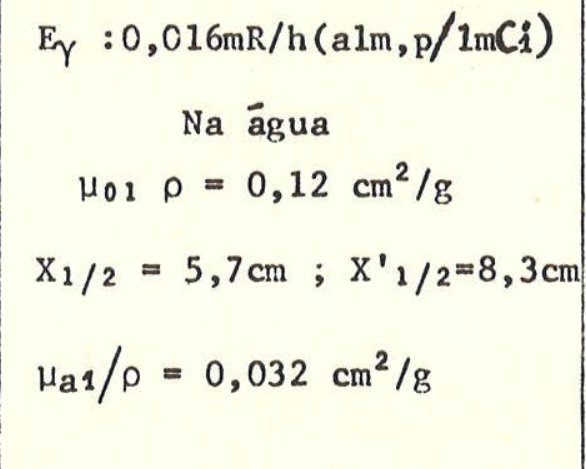 & $\begin{array}{l}\text { Processo de Produção } \\
\qquad{ }^{50} \mathrm{Cr}(\mathrm{n}, \gamma)^{51} \mathrm{Cr} \\
\sigma=0,69 \text { barns } \\
\text { Atividade Produzida } \\
\quad\left(10^{12} \mathrm{n} / \mathrm{cm}^{2} / \mathrm{s}\right) \\
1 \text { semana }=30 \mathrm{mCi} / \mathrm{g} \mathrm{Cr}\end{array}$ \\
\hline
\end{tabular}


CONTINUAÇÃO $\quad$ T A

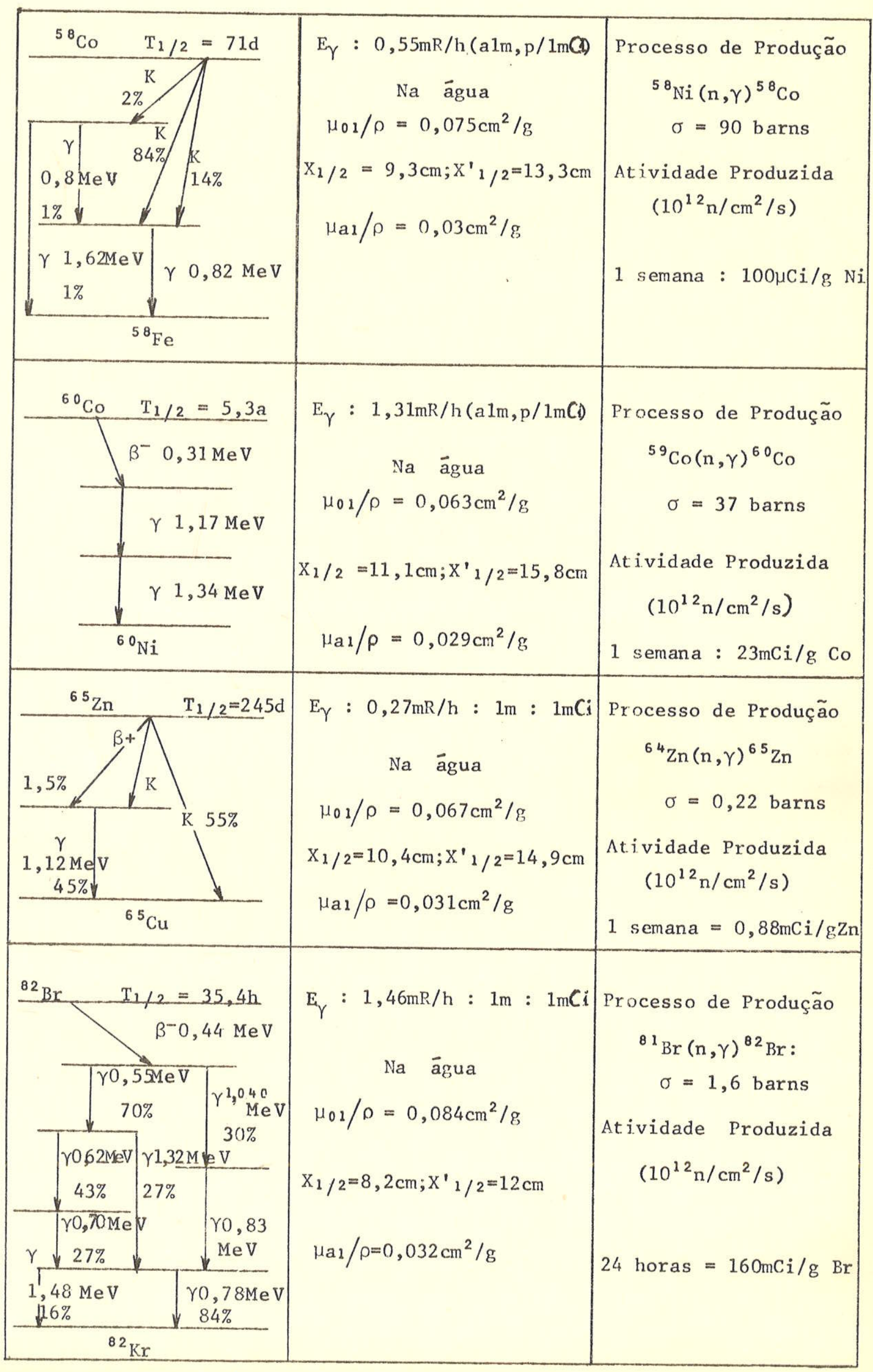


CONTINUAÇ̃̃̃O T A B E L A I

\begin{tabular}{|c|c|c|}
\hline 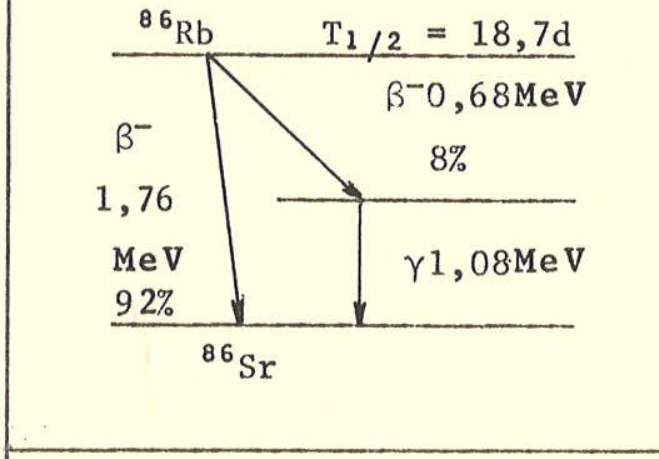 & $\begin{array}{l}\mathrm{E}_{\gamma}=0,05 \mathrm{mR} / \mathrm{h}: 1 \mathrm{~m}: 1 \mathrm{mCi} \\
\mathrm{Na} \text { ägua } \\
\mu_{01} / \rho=0,072 \mathrm{~cm}^{2} / \mathrm{g} \\
\mathrm{X}_{1 / 2}=9,8 \mathrm{~cm} ; \mathrm{X}_{1 / 2}^{\prime}=14 \mathrm{~cm} \\
\mu_{\mathrm{al}} / \rho=0,031 \mathrm{~cm}^{2} / \mathrm{g}\end{array}$ & $\begin{array}{c}\text { Processo de Produção } \\
{ }^{85} \mathrm{Rb}(\mathrm{n}, \gamma){ }^{86} \mathrm{Rb}: \\
\sigma=0,66 \text { barns } \\
\text { Atividade Produzida } \\
\quad\left(10^{12} \mathrm{n} / \mathrm{cm}^{2} / \mathrm{s}\right) \\
1 \text { semana } 25 \mathrm{mCi} / \mathrm{g} \mathrm{Rb} \\
\end{array}$ \\
\hline 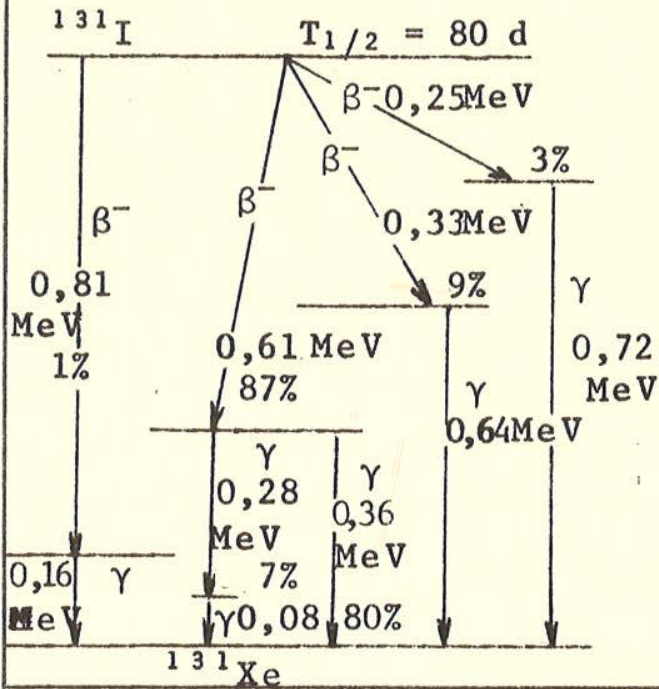 & $\begin{array}{l}E_{\gamma}=0,22 \mathrm{mR} / \mathrm{h}: 1 \mathrm{~m}: 1 \mathrm{mCl} \\
\text { Na ägua } \\
\mu_{01} / \rho=0,11 \mathrm{~cm}^{2} / \mathrm{g} \\
x_{1 / 2}=6,3 \mathrm{~cm} ; x_{1 / 2}^{\prime}=9 \mathrm{~cm} \\
\mu_{\mathrm{al}} / \rho=0,03 \mathrm{~cm}^{2} / \mathrm{g}\end{array}$ & $\begin{array}{l}\text { Processo de Produção } \\
{ }^{30} \mathrm{Te}(n, \gamma)^{131} \mathrm{Te} \beta^{131} \mathrm{I}\end{array}$ \\
\hline $\begin{array}{l}{ }^{110} \mathrm{Ag} \\
\text { Energia dos fotons } \varepsilon \% \\
\gamma_{1}=1,52-15 \% \\
\gamma_{2}=1,39-25 \% \\
\gamma_{3}=0,86-78 \% \\
\gamma_{4}=0,81-6 \% \\
\gamma_{5}=0,76-21 \% \\
\gamma_{6}=0,71-16 \% \\
\gamma_{7}=0,68-10 \% \\
\gamma_{8}=0,66-99 \%\end{array}$ & $\begin{array}{l}\mathrm{E}_{\gamma}=1,43 \mathrm{mR} / \mathrm{h}: 1 \mathrm{~m}: 1 \mathrm{nCi} \\
\mathrm{Na} \text { ägua } \\
\mu_{01} / \rho=0,075 \mathrm{~cm}^{2} / \mathrm{g} \\
\mathrm{x}_{1 / 2}=9,3 \mathrm{~cm} ; \mathrm{X}_{1 / 2}^{\prime}=13,3 \mathrm{c} \\
\mu_{\mathrm{a} 1} / \rho=0,03 \mathrm{~cm}^{2} / \mathrm{g}\end{array}$ & $\begin{array}{l}\text { Processo de Produção } \\
{ }^{109} \mathrm{Ag}(\mathrm{n}, \gamma){ }^{110} \mathrm{Ag} ; \\
\sigma=1,56 \text { barns } \\
\text { Atividade Produzida }\end{array}$ \\
\hline $\begin{array}{l}{ }^{192} \text { Ir } \\
\text { Energia dos fotons } \varepsilon \% \\
\gamma_{1}=0,61-7 \% \\
\gamma_{2}=0,60-12 \% \\
\gamma_{3}=0,46-57 \% \\
\gamma_{4}=0,32-85 \% \\
\gamma_{5}=0,31-30 \% \\
\gamma_{6}=0,30-25 \% \\
\gamma_{7}=0,20-4 \%\end{array}$ & $\begin{array}{c}\mathrm{E}_{\gamma}=0,48 \mathrm{mR} / \mathrm{h}: 1 \mathrm{~m}: 1 \mathrm{~m} C_{1} \\
\mathrm{Na} \text { ägua } \\
\mu_{01} / \rho=0,105 \mathrm{~cm}^{2} / g \\
\mathrm{X}_{1 / 2}=6,6 \mathrm{~cm} ; X_{1 / 2}^{\prime}=9,6 \mathrm{~cm} \\
\mu_{\mathrm{a}_{1} / \rho} / \rho=0,033 \mathrm{~cm}^{2} / g\end{array}$ & $\begin{array}{l}\text { Processo de Produção } \\
{ }^{191} \operatorname{Ir}(\mathrm{n}, \gamma)^{192} \mathrm{Ir} \\
\sigma=370 \text { barns } \\
\text { Atividade Produzida } \\
\quad\left(10^{12} \mathrm{~m} / \mathrm{cm}^{2} / \mathrm{s}\right) \\
1 \text { semana }=1,7 \mathrm{mCi} / \mathrm{g} \text { Ir }\end{array}$ \\
\hline
\end{tabular}


CONTINUAÇÃO $\quad$ T A B E E L A

\begin{tabular}{|c|c|c|c|c|c|}
\hline${ }^{198} \mathrm{Au}$ & $\begin{array}{r} \\
0,961 \\
99 \% \\
\gamma 0 \\
\end{array}$ & 411 & $\begin{array}{l}\frac{2=65 \mathrm{~h}}{29 \mathrm{MeV} 1 \%} \\
\begin{array}{l}\gamma 0,68 \mathrm{MeV} \\
1 \% \\
\mathrm{MeV}\end{array}\end{array}$ & $\begin{array}{c}\mathrm{E}_{\gamma}=0,23 \mathrm{mR} / \mathrm{h}: 1 \mathrm{~m}: 1 \mathrm{mCl} \\
\text { Na ägua } \\
\mu_{01} / \rho=0,103 \mathrm{~cm}^{2} / \mathrm{g} \\
x_{1 / 2}=6,6 \mathrm{~cm} ; X_{1 / 2}^{\prime}=9,8 \mathrm{~cm} \\
\mathrm{a}_{1} / \rho=0,033 \mathrm{~cm}^{2} / \mathrm{g}\end{array}$ & $\begin{array}{l}\text { Processo de Produção } \\
{ }^{192} \mathrm{Au}(\mathrm{n}, \gamma)^{196} \mathrm{Au} ; \\
\sigma=98 \text { barns } \\
\text { Atividade Produzida } \\
\quad\left(10^{12} \mathrm{n} / \mathrm{cm}^{2} / \mathrm{s}\right) \\
1 \text { semana }=6,2 \mathrm{mCi} / \mathrm{g} \mathrm{Au}\end{array}$ \\
\hline $\mathrm{mR} / \mathrm{h}, \mathrm{n}$ & $\begin{array}{l}\mathrm{E}_{\max } \\
\mathrm{E}_{\text {med }} \\
\text { des } \\
\text { mCi } \\
\mu_{01} \\
\mu_{1} \\
\rho \\
x_{1 / 2}\end{array}$ & $=$ & $\begin{array}{l}\text { ABREVI } \\
\text { ENERGTA } \\
\text { ENERGIA } \\
\text { DESTNTEG } \\
\text { MILIROEN! } \\
\text { COEFICIEN } \\
\text { A ENERGIA } \\
\text { COEF TCIEN } \\
\text { DENSTDADR } \\
\text { ESPESSURA } \\
\text { DUZ RADTA } \\
\text { ESPESSURA } \\
\text { PRIMARIA } \\
\text { META VIDA } \\
\text { NEUTRONS } \\
\text { SEÇÃO DE }\end{array}$ & 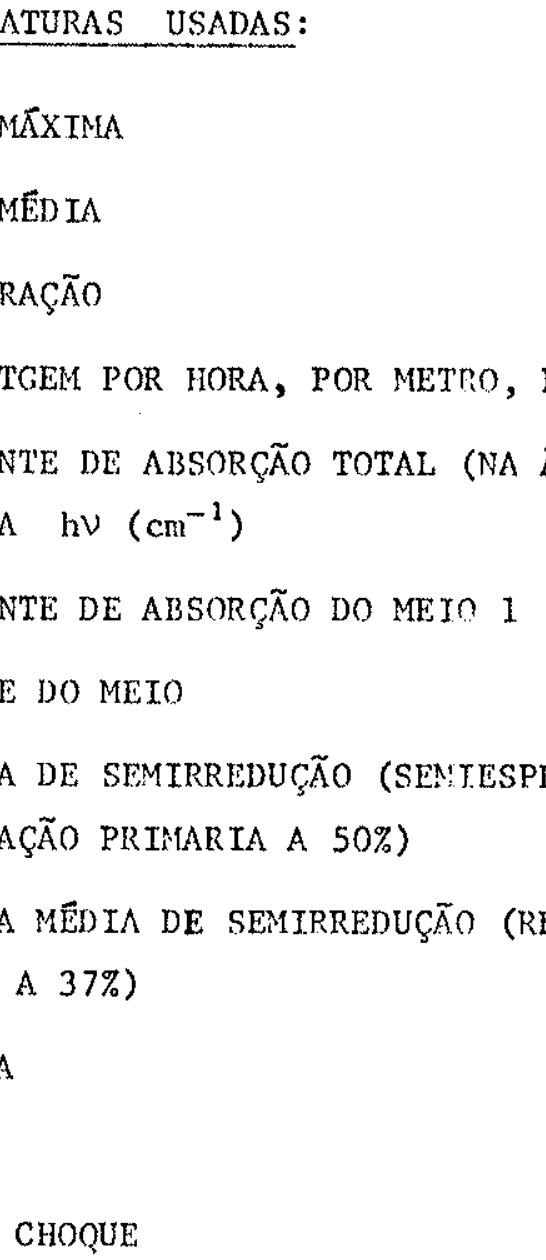 & $\begin{array}{l}\text { POR MILICURIE } \\
\text { AGUA) E PARA } \\
\text { PESSURA) (RE- } \\
\text { (EDUZ RADIAÇÃO }\end{array}$ \\
\hline
\end{tabular}


ção:

$$
\tau=\frac{1}{\lambda}
$$

Quando se utiliza isōtopos radioativos na solução de problemas hidrológicos, a meia vida è um dos fatôres que 1imita sua escolha. A meia vida deve ser compativel com o período entre a produção do raioisötopo e o fim do trabalho. No computo deste tempo temos: irradiação, fracionamento, diluições, marcação, transporte ao lugar onde se realiza o trabalho e duração do mesmo. Este ültimo valor nem sempre é passível de câl culo quando se estuda āguas subterrâneas.

Segundo os dados da tabela I, quando o tempo trans corrido entre a calibração e a medição for superior a 5 ou 6 meias vidas, a atividade residual se reduz a 3,12 e $1,56 \%$ respectivamente, da atividade inicial. Nestas condições, se a diluição do traçador, no ponto de amostragem for grande, torna se difícil detetá-1a.

Quando se realizam experiências em äguas subterrâneas com traçadores radioativos, ë preciso conhecer pelo menos a or dem de magnitude do tempo gasto entre a injeção e a deteção, isto é, a duração do ensaio, para que se possa selecionar o' traçador radioativo. Utilizando-se as conhecidas fórmulas de D'Allen Hazen, Zunker, Darcy, etc., calcula-se a permeabilidade $K$ do meio e estima-se o tempo de trânsito do traçador entre dois pontos. De acôrdo com a expressão de Darcy

$$
v_{1}=\frac{\Delta l}{\Delta t}=\frac{K}{m_{e}} \cdot \frac{d h}{d l}
$$

onde $\Delta t \vec{e}$ o tempo de trânsito do traçador entre dois pontos, $\Delta \ell$ é a distância entre os dois pontos considerados, $m_{e} \vec{e}$ a porosidade efetiva,

dh/dl ë o gradiente hidräulico

\section{I.8 ATIVIDADE}

A atividade de uma substância ê caracterizada pelo 
nümero de desintegrações radioativas que ocorre na unidade de tempo. Portanto podemos escrever

$$
A=-d N / d t
$$

onde dN é o número de ātomos radioativos desintegrados no intervalo de tempo dt. A atividade $A \vec{e}$ igual ao produto da cons tante de desintegração $\lambda$, multiplicada pelo nümero total de ătomos radioativos $\mathrm{N}_{\mathrm{O}}$

$$
A=\lambda N_{0}
$$

De acôrdo com a equação (4), a variação da ativi dade, no tempo $t$ considerado, pode ser calculada pela equação

$$
A_{t}=A_{o} \cdot e^{-\lambda t}
$$

Muitas vêzes se deseja não a atividade remanescente, mas o valor percentual ou fração da atividace inicial. Usa-se então a expressão

$$
A_{t} / A_{0}=e^{-\lambda t}
$$

onde $A_{t} / A_{0} \vec{e}$ a relação entre a atividade residual e a ativida de inicial, ou seja a fração da atividade encontrada depois de um pexíodo de tempo $t$.

A unidade de atividade ê o Curie (Ci), que represen ta a desintegração de $3,7.10^{10}$ átomos por segundo. Como submültiplos empregam-se o milicurie $(\mathrm{mCi})$ e o microcurie ( $\mu \mathrm{C} i)$.

$$
1 \mathrm{Ci}=10^{3} \mathrm{mCi}=10^{6} \mu \mathrm{Ci}
$$

\section{I.9 FORMAS DE DESINTEGRACAO}

\section{I.9.1 EMISSÃO DE PARTICULAS ALFA}

O estudo dos desvios sofridos pelas partículas alfa $(\alpha)$, sob a ação combinada de campos magnêtjcos e elëtricos, demonstrou que a relaçäo entre a carga e massa das partículas 
alfa ë a mesma, qualquer que seja a fonte emissora.

$$
\mathrm{e} / \mathrm{m}=4,813 \mathrm{u} \cdot \mathrm{e} \cdot \mathrm{m} \text {. por } \mathrm{g} \text {, ou } 5,2727 \cdot 10^{17} \mathrm{e} \cdot \mathrm{s} \cdot \mathrm{u} \cdot \mathrm{g}^{-1} \text {, }
$$

onde u.e.m. $\vec{e}$ a unidade elëtrica de massa e

e.s.u.g $\mathrm{g}^{-1}$ è a carga específica do eletron.

Para se determinar a massa da partícula $\alpha$, foi pre ciso conhecer a carga transportada por um nümero definido de particulas. Determinou-se que a carga positiva de uma partícu la $\alpha$ é equivalente a duas vêzes a carga eletrônica. A massa da particula alfa $\ddot{e}$ igual a $6,62 \cdot 10^{-24} \mathrm{~g}$, que $\vec{e}$ aproximadamente quatro vêzes maior que a do ätomo de hidrogênio. Formulouse, assim, a hipötese de que a partícula alfa seria um ätomo de hëlio duplamente ionizado. De fato, E. Rutherford e F. Royds (1906) confirmariam, experimentalmente, por anälises espectroquímicas, que o gás emitido pelas substâncias radioati vas emissoras de partículas alfa era o hẻlio.

As particulas a movem-se através dos gases em $1 \dot{i-}$ nha reta, causando a ionização das molëculas do meio. Depois de percorrerem certa distância, não se pode identificar mais qualquer efeito provocado pelas partículas $\alpha$. As particulas alfa emitidas pelos diferentes radioisótopos se caracterizam por possuir distintos pođêres de penetração. Chama-se percurso à distância de penetração, em centímetros, através do ar sêco, a $15^{\circ} \mathrm{C}$ e $760 \mathrm{~mm}$ de pressão. Em geral, as partículas $\alpha$ emitidas por dado elemento radioisótopico possuem idêntica ve locidade inical, mas seu percurso varia com a naturea do meio atravessado.

\section{I.9.2 EMISSÃO DE PART ICULAS BETA}

As partículas beta ( $\beta$ ) são constituidas de ele trons emitidos diretamente pelos nücleos, durante os proces sos de desintegração radioativa. As partículas $\beta$ não possuem energias discretas. A velocidade das particulas beta varia continuamente dentro de certa faixa, sendo que as de maior conteüdo energëtico possuem velocidades pröximas à da luz. Es tas particulas são emitidas segundo um espectro contínuo de 
energias.

As partïculas $\beta$ também provocam fenômenos de ioniza ção. Para iguais distâncias percorridas, a ação ionizante das particulas $\beta \hat{e}$ bem menor do que a das partículas $\alpha$. As partí culas $\beta$ mais râpidas produzem, ao atravessar o ar à pressão atmosfërica, 50 a 100 pares de ions por $\mathrm{cm}$ percorrido, ao pas so que as partículas $\alpha$ de mesma energia chegam a produzir 20.000 pares de ions. Em compensação, o percurso desenvolvido pelas particulas beta, no mesmo meio, $\vec{e}$ bem maior, podendo alcançar algumas dezenas de centimetros no ar. Tal como no caso das particulas $\alpha$, a ação ionizante das partículas $\beta$ aumenta à medida que diminuem suas velocidades, atingindo um mäximo para valôres da ordem de $3.10^{8} \mathrm{~cm} / \mathrm{s}$. Abaixo deste valor, a ionização torna-se menor e desaparece para velocidades ainda mais fracas.

A absorção das particulas $\beta$ ocorre de maneira diferente à das partículas $\alpha$. Enquanto estas sofrem uma atenuação brusca, as partículas $\beta$ atenuam-se gradualmente, em parte por absorção e em parte pelos desvios de sua trajetória retilinea. Quando as particulas Batravessam um meio absorvente, a intensidade I da radiação primária obedece a equação expo nencial

$$
I=I_{0} \cdot e^{-\mu x}
$$

onde $I_{0} \ddot{e}$ a intensidade de radiaçäo antes de penetrar no meio absorvedor,

$\mu \vec{e}$ um fator de proporcionalidade chamado coeficiente de absorção que depende da natureza do material absor vente e da energia das particulas $\beta$,

$x \quad \vec{e}$ a espessura do absorvedor atravessada pela particula,

e ê a base dos logarítimos naturais.

\section{T.9.3 EMISSATO DE RATOS GAMA}

Em muitos casos, nas desintegrações onde existem emissores de partículas $\alpha$ e $\beta$, estas podem vir acompanhadas 
por raios $\gamma$, de natureza eletromagnëtica. Istes raios possuem comprimento de onda menor que os dos raios $X$ e poder $d e$ penetração superior ao das partículas $\alpha$ e $\beta$.

Sōmente certosradioisötopos emitem radiação $\gamma$. Eila tanto pode acompanhar uma desintegração $\alpha$ quanto uma desintegração $\beta$. Isso acontece quando, na emissão de uma partícuia aou $\beta$, o nücleo resultante fica em estado excitado e seu excesso de energia $\vec{e}$ então emitido em forma de um quantum de radiação eletromagnëtica, de frequência muito alta. Como o nü cleo pode assumir estados energëticos definidos e discretos, a passagem de um estado de maior conteüdo energetico a outros mais baixos se processa pela emissão de um quantum de energia hv, correspondente à diferença de energia entre os estados energëticos envolvidos. Assim, os raios $\gamma$ emitidos por um ra m dioisötopo têm comprimentos de onda definidos e característicos.

os raios $\gamma$, ao atravessarem uma camada de gases, provocam a ionização das suas molêculas de modo diferente ao que ocorre com as partículas $\alpha$ e $\beta$. Estas $\vec{u} 1$ timas formam, ao longo do seu percurso, uma continua sucessão de íons, e, gradualmente, perdem sua energia inicial. Os raios $\gamma$ conservam suas energias atê o momento em que, colidindo com os elêtrons dos ätomos, transferem a eles energia suficiente para expulsä los das ôrbitas. 
CAPITULO II

\section{TRACADORES}

\section{1 CONSIDERACOES GERAIS}

Com o nome de traçador designa-se, geralmente, qual quer produto que, incorporado na massa de una substância, per mite investigar seu comportamento en determinado processo fi sico ou químico.

0 uso de traçadores em Hidrologia ê muito antigo. Fo ram utilizados os mais diferentes tipos de traçadores, algumas vêzes adicionados diretamente na ägua, e em outras, aprovei tando-se determinadas substâncias nela incorporadas, como con sequência de processos naturais ou de derramamentos aciden tais. Baseando-se no comportamento destes traçadores pode -se deduzir determinados parâmetros hidrológicos. porém, para eles, é condição fundamental que seu comportamento seja igual, ao menos, muito parecido ao da ägua.

os traçadores não isotöpicos mais utilizados, con sistem em determinados compostos químicos solüveis em ägua e fäcilmente identificâveis, principalmente compostos iônicos e colorantes. Em alguns casos, a simples anälise dos ions transportados pela ägua, como consequência da dissolução de matexiais do meio ou de contaminações acidentais, pode propor cionar informações valiosas. Porēm a interpretação destes re sultados deve ser feita com grande prudência, principalmente quando a ägua percorre meios de composição litolögicas dife rentes. 


\section{2 TRACADOR IDEAL}

o traçador ideal para usos hidrológicos deve cumprir as seguintes condições:

1. O comportamento do traçador no processo que se pretence investigar deve ser idêntico ao da água, que dizer, o traçador e a ägua devem difundir-se com a mesma velocidade (f delidade do marcado). Esta condição, exige por sua vez, outras a saber:

- o traçacor não deve realizar com a água reações que venham interferir em sua icientificação posterior;

- não deve provocar reação química com os materiais do meio;

- não deve ser absorvido e/ou absorvido pelos materiais sôlidos do meio;

- no caso de traçadores ionicos, não devem ser produzidos fenômenos de troca com os âtomos do mesmo tipo, existentes no meio;

- a quantidade de traçadox a ser utilizado em uma experiência não deve modificar de forma significa tiva, a densidade, viscosidade ou temperatura da ăgua, para não provocar alterações no fluxo naturail

- os fenômenos de dispersão e difusão do traçador devem ser iguais que os correspondentes às molécu las de ägua.

2. No caso do traçador ser adicionado à ägua, esta não deve conter nada do mesmo, ou somente uma concentração tão baixa, que não interfira nos resultados.

3. Quando se aproveita como traçador uma substância. existente na ăgua, como consequência de um processo natural ou acidentai alheio ao hidrölogo, sua concentração deve manter-se constante durante o estudo do fenômeno, sem interação com os materiais sôlidos do meio. 
4. Deve ser facilmente solüvel em ägua.

5. Permitir fatôres de điluição bastante elevados, isto $\vec{e}$, com uma quantidade de traçador razoavelmente pequena, marcar volumes muito grandes de ägua.

6. En muitos casos, é condiçãó importante que o tra çador possa ser medido "in situ", quer dizer, sem que seja ne cessärio fazer-se amostragem.

7. Não deve contaminar o meio por períodos muito grandes, evitando-se interferências em outras experiências fu turas.

8. Deve ser de baixo custo, de fäcil manipulação e inöcuo para os sêres vivos.

Não existe um traçador que cumpra com perfeição todas essas condições, porêm uns se aproximan delas mais que outros. Devido a grande diversidade de problemas para os que utilizam traçadores, não é possível selecionar um traçador universal que se adapte satisfatóriamente a todos eles. Em 1 i nhas gerais, podem-se distinguir duas situações distintas, se gundo se trate de âguas superficiais ou de äguas subterrâneas. No primeiro caso as condições exigidas do traçador são mais suaves, devido ao escasso contato existente entre a ägua e os materiais sölidos do meio, as facilidades existentes para as tomadas de amostras, e, em alguns casos, as altas velocidades do fluxo, acarretando curta duração dos ensaios. São numero sos os traçadores, isotôpicos e não isotöpicos que proporcionam bons resultados em äguas superficiais.

Ao conträrio, quando se trata de äguas subterrâneas que circulam atravës de meios porosos seguindo trajetörias si nuosas, as condições exigidas ao traçador são mais severas, pelas seguintes razões:

1. A possibilidade de retenção do traçador pelos ma teriais sôlidos do meio $\vec{e}$ muito elevada, provocadas não somen te pelo intimo contato da água com estes materiais, como pela baixa velocidade dos fluxos existentes. 
2. As mudanças de velocidade da ägua devido a dis tribuiçáo desigual do tamanho dos poros e das forças de atrito no interior dos mesmos, ocasionam uma dispersão longitudinal e transversal do traçador, que não coincide exatamente com a experimentada pelas molëculas de água. Isto provoca diferen ças no transporte dos dois produtos, que podem chegar a ser significativas quando o fluxo da ägua é pequeno.

3. Diferenças de transporte são devidas tambêm a di fusão molecular e osmötica do traçador.

\section{3 TRACADORES NAO TSOTÖPICOS}

Entre os traçadores não isotópicos mais utilizados, diferenciam-se dois tipos:

- traçadores denominados químicos, não colorantes, tais como cloreto de sódio, fenöis, äcido börico, detergentes, etc.;

- colorantes, entre os quais podemos citar a fluoresceina, dicromato de potässio, rodamina $B$, eosina, roxo do Congo, azul de metileno, anilina e ou tros.

Nos casos de investigação em äguas subterrâneas, es ses traçadores podem provocar contaminações duradouras. A úni ca forma que o traçador tem para sair do meio é por meio das correntes de ägua. Na realidade, sö os traçadores radioativos de meia vida relativamente curta, são autoestinguiveis.

Entre os traçadores quimicos, o que maior interesse oferece $\vec{e} o$ ion cloreto. Sua retenção pelos materiais sölidos do meio ë praticamente inexistente, pelo que, neste sentido, constitue um traçadox ideal. Sua determinaçio analitica em amostras de água ë simples, podendo ser medido "in situ" por têcnicas conductimëtricas. Apresenta por sua vez, o inconve niente de encontrar-se sempre presente na ägua, dificultando, assim, a anä1ise dos resultados. Quando sua concentração natu 
ra1 é elevada, torna-se necessârio juntar grandes quantidades de traçador, alterando-se consideravelmente a densidade da $\vec{a}-$ gua e, provocando o risco derivado da formação de fluxos anômalos. Por outro lado, sua determinação por medidas de conduc tividade não é um método seletivo deste ion.

Quanto aos colorantes, o dicromato de potässio $\vec{e}$ utilizado com certa frequência para medir correntes, superfi ciais. Mediante a têcnica colorimétrica, baseada na reação com a difeni1-carbacida, podem-se determinar concentraçōes de dicromato da ordem de $2.10^{-3} \mathrm{ppm}$ (mg/1itro); apresenta o risco de ser parcialmente reduzido a cromo trivalente pelas substân cias redutoras da ägua. A fluoresceina $\vec{e}$ o colorante majs empregado. Sem aparelhagem especial, podem ser detetadas concen trações de $0,1 \mathrm{ppm} e$, com fluorimetros, concentrações inferiores a $2 \cdot 10^{-3} \mathrm{ppm}$. Tem o inconveniente de decompor-se com certa facilidade pela ação das argilas, matéria orgânica e óxido de ferro.

No geral, os colorantes tem aplicação muito limitada quando se trata de äguas subterrâneas. Não podem ser medidos "in situ" e interagem facilmente com os materiais sólidos do meio. Sua limitada solubilidade na ägua exige o uso de grandes volumes de solução traçadora.

A sensibilidade relativa de deteção dos traçadores fluorescentes e salinos é mostrada nas tabelas II e III.

\section{IT.4 TRACADORES RADIOATIVOS}

Em termos gerais, o método de traçadores ẻ uma tẻcnica para obter informação de um sistema ou de suas partes, mediante a observação do comportamento de uma substância espe cifica, agregada ao sistema, o traçador. Geralmente o método implica em marcar uma fase especifica ou parte do sistema com - traçador, para tornä-la facilmente identificâve1.

Existem dois requisitos fundamentais na escolha do traçador: 
TA B E L A II

TRACADORES FLUORESCENTES USADAS MM UTDROLOGIA

\begin{tabular}{|c|c|c|c|}
\hline PROPRIEDADES & URANINA & RHODAMINA $B$ & $\begin{array}{l}\text { SULFORHODAMINA } \\
\qquad * \text { e G** }\end{array}$ \\
\hline $\begin{array}{l}\text { SENSTBIL TDADE DE } \\
\text { DETEÇÃO (VALORES } \\
\text { RELATIVOS; } \\
\text { "IN SITU") }\end{array}$ & $\begin{array}{c}\text { ELEVADA } \\
1\end{array}$ & $\begin{array}{c}\text { ELEVADA } \\
1\end{array}$ & $\begin{array}{l}B O A \\
0,5\end{array}$ \\
\hline $\begin{array}{c}\text { RUTDO DE FUNDO NA } \\
\text { DETEÇÃO } \\
\text { ("BACKGROUND") }\end{array}$ & 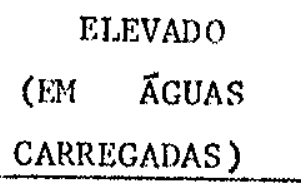 & REDUZIDO & REDUZTDO \\
\hline DEGRADAÇÃO NA LUZ & MUTTO ELEVAIJA & ELEVADA & NULA \\
\hline $\begin{array}{l}\text { INELUENCIA DA TEM } \\
\text { PERATURA SOBRE A } \\
\text { MED IÇÃO (VARIAÇÃOO } \\
\text { POR }{ }^{\circ} \mathrm{C} \text { ) }\end{array}$ & $\begin{array}{l}\text { REDUZIDA } \\
-0,36 \%\end{array}$ & $\begin{array}{l}\text { ELEVADA } \\
-2,7 \%\end{array}$ & $\begin{array}{r}* \text { ELEVVADA } \\
-2,9 \% \\
* * \text { NULA } 0 \% \\
\end{array}$ \\
\hline RETENÇÃO EM SOLOS & MUTTO BAIXA & MUITO ELEVADA & REDUZIDA \\
\hline SOLUBIL IDADE & $\begin{array}{c}\text { ALTA } \\
300 \mathrm{~g} / \ell\end{array}$ & $\begin{array}{l}\text { REDUZIDA } \\
\sim 10 \mathrm{~g} / 2\end{array}$ & $\begin{array}{l}\text { REDUZ IDA } \\
\sim 10 \mathrm{~g} / \ell\end{array}$ \\
\hline
\end{tabular}

A SOLUBILIDADE DA RHODAMINA $B$, DA SULFORHODAMINA B E $G$ PODE SER MELHORADA COM SOLVENTES ORGÂNICOS 
TABELA III

TRACADORES CONVENCIONATS USADOS EM HIDROLOGTA

\begin{tabular}{|c|c|c|c|c|c|c|}
\hline PROPRIEDADES & $\mathrm{Cr}_{2} \mathrm{O}_{7}$ & $\mathrm{NaI}$ & $\mathrm{NaC1}$ & $\mathrm{MgSO}_{4}$ & $\mathrm{NaNO}_{3}$ & LiC1 \\
\hline SOLUBILIDADE $(\mathrm{g} / \ell)$ & 600 & $>1.500$ & $300 \mathrm{a} 400$ & 500 & 75 & 600 \\
\hline \multirow{2}{*}{$\begin{array}{l}\text { CONCENTRAÇÃO MI } \\
\text { MA DETETĀVEL } \\
(\text { POR AMOSTRAGEM) }\end{array}$} & $\begin{array}{l}0,2 \text { a } 2 \times 10^{-6} \\
\text { SEM RECONCEN } \\
\text { TRAÇÃO }\end{array}$ & $\begin{array}{l}10^{-10} \\
\text { A. POR } \\
\text { ATIVI- } \\
\text { DADE }\end{array}$ & $\begin{array}{c}10^{-5} \\
\text { COLORI } \\
\text { METRIA }\end{array}$ & \multirow[b]{2}{*}{$12.10^{-6}$} & \multirow[b]{2}{*}{$0,5.10^{-6}$} & \multirow[b]{2}{*}{$10^{-6}$} \\
\hline & $\begin{array}{l}0,2 \text { a } 2 \times 10^{-7} \\
\text { COM RECONCEN } \\
\text { TRAÇÃO }\end{array}$ & $\begin{array}{l}10^{-9} \\
\text { A.CATA } \\
\text { LÎTICO }\end{array}$ & $\begin{array}{l}10^{-5} \text { a } 10^{-6} \\
\text { CONDUCTI } \\
\text { METRIA } \\
\text { A. " IN } \\
\text { SITU" } \\
\end{array}$ & & & \\
\hline $\begin{array}{l}\text { COMPORTAMENTO EM } \\
\text { ÄGUAS SUBTERR } \widehat{A}- \\
\text { NEAS }\end{array}$ & $\begin{array}{l}\text { INSATIS } \\
\text { FATÖRIO }\end{array}$ & $\begin{array}{l}\text { ACEITĀ } \\
\text { VEL EM } \\
\text { ÁGUAS } \\
\text { COM RE } \\
\text { DUZTDO } \\
\text { TEOR } \\
\text { EM I }\end{array}$ & $\begin{array}{l}\text { INSATIS } \\
\text { FATÖRIO }\end{array}$ & FATSORIOTIS & $\begin{array}{l}\text { INSATIS } \\
\text { FATÖRIO }\end{array}$ & $\begin{array}{l}\text { ACEI- } \\
\text { TẢVEL }\end{array}$ \\
\hline
\end{tabular}


1. deve se comportar exatamente cono o material mar cado, na fase do processo que se deseja investigar;

2. deve possuir uma propriedade particular que o distinga do material marcado, de maneira que possa ser facilmente detetado em presença de outras substânias.

A primeira condição pode requerer identidade física e química do traçador com o produto marcado ou somente uma delas, dependendo do parâmetro medido. Algumas propriedades, tais como o calor, indice de refração, densidade e conductivi dade de aditivos, têm sido empregadas satisfatoriamente em experjências de traçacores.

Sem düvida, os radioisötopos poden ser utilizados como traçadores, pois apresentam as seguintes vantagens:

1. a identidade entre o produto marcado e o traça dor pode chegar ao nível atômico (um átomo do traçador ou isó topo radioativo se comportarâ igual a um ätomo estävel do mes mo elemento);

2. a deteção do radiotraçador pode alcançar tambëm, niveis atômicos (os radioisótopos podem ser detetados em quan tidades tão pequenas como $10^{-1.6}$ ou $10^{-17}$ de gramas).

Como todos os materiais existentes na natureza, são formados por ätomos, e existem um ou mais isótopos radioati. vos para cada elemento, pode-se por meio de apropriados métodos quimicos de síntese, preparar radiotraçadores para qual quer produto, desde substâncias puras até nolëculas complexas como as do petróleo e seus derivados petroquímicos.

Präticamente os ünicos traçadores que competem com os radioativos, no aspecto relacionado ao requisito de identi dade, são os isótopos estáveis.

Em cada caso em particular deve-se usar un ou outro dependendo dos objetivos do trabalho, sensibilidade e facilidade de medição.

Alêm das vantagens já enumeradas, os radiojsötopos têm outras características que os condicionam a condição de traçadores ótimos: 
1. podem ser detetados seletivamente por discrimi ção do tipo e energia da radiação emitida;

2. as medições resultam fäceis e isentas de ambi guidades;

3. permitem predizer a precisão dos resultados, pe10 simples cálculo do êrro estatístico associa do com as medições de radioatividade.

Geralmente, uma experiência com raliotraçadores con siste em injetar em um ponto $p_{i}$ do sistema, entre $t_{i}$ e $t_{i}+\Delta t_{i}$, certa atividade $A_{i}$ incorporada a um volume $V_{i}$ de produto marcado, e observar a vaxiação da concentração da atividade $C_{0}(t)$, em função do tempo, em um ponto $P_{0}$. Esta situação esta representada no diagrama de bloco da figura a seguir

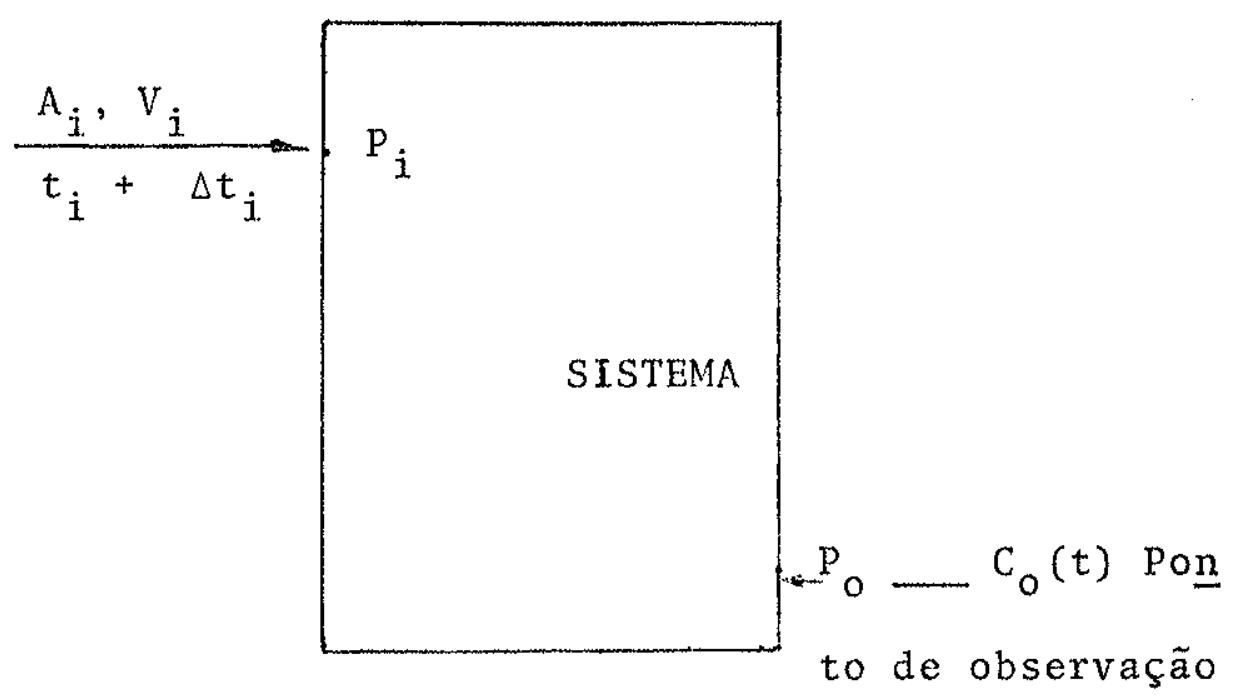

Esquema de uma experiência com radjotraçadores onde:

$$
\begin{aligned}
& A_{i}=\text { atividade inicial } \\
& v_{i}=\text { volume inicial } \\
& t_{i}=\text { inicio da injeção } \\
& p_{i}=\text { ponto de injeção do radiotxaçador } \\
& p_{0}=\text { ponto de medição }
\end{aligned}
$$


$\mathrm{C}_{\mathrm{o}}=$ concentração do radiotraçador em $\mathrm{p}_{\mathrm{o}}$

\section{5 APLICACAO DE RADIOTSO̊TOPOS}

Sem düvida, o primeiro requisito a qualquer aplicação de radiotraçadores, $\vec{e}$ o conhecimento pormenorizado das características do processo à investigar, para estabelecer se a tëcnica utilizada irá proporcionar resultados satisfatórios.

o segundo requisito importante ë planejar com mảx mo cuidado todas as etapas da experiencia, incluindo sele çäo e preparação do traçador mais conveniente, forma e dispositivo de injeção, instrumental de medição, metodologia de contagem e procedimento para interpretar os resultados. Deve -se prever também procedimentos alternativos, para qua1 quer eventualidade que poderia apresentar-se durante o curso da experiência. Com isto, muitas vezes erita-se malograrem por falta de previsão os objetivos do ensaio, os esfor ços e recursos empregados em sua realização.

Um fator essencial do ponto de vista prätico (que inclue considerações de custo, manipulação e de segurança ra diolögica) è a atjvidade total que deve ser incorporada ao sistema para marcä-1o. (Tabela IV).

\section{6 TECNICAS DE MEDIDA}

A deteção e medida das radiações baseiam-se em sua interação com a matëria, principalmente nos fenômenos de ioni zação e excitação. Quando um tipo de radiação incide sobre um detetor, este gera um sinal elêtrico, que é transformado em impulso de tensão. Uma vez amplificados e, em alguns casos, classificados de acôrdo com sua altura, esses impulsos são contados por um equipamento eletrônico provido de indicação analögica (integrador) ou digital (escala). Ao número de impulsos liberados por unidade de tempo dä-se o nome de 
TA B E I A IV

RADIOISŌTOPOS USADOS EM HIDROLOGIA

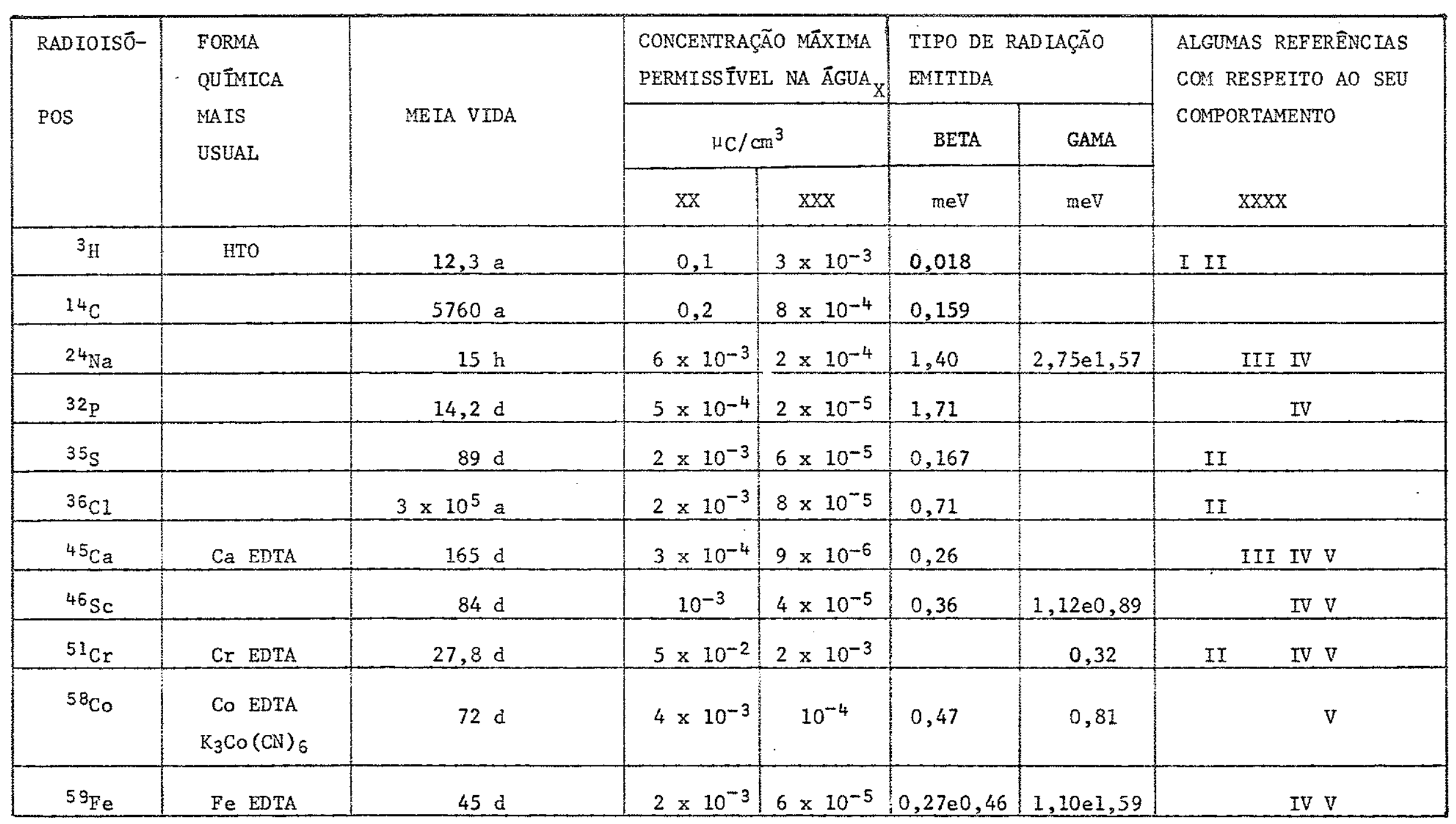


CONTIRUACAOO I A B E L A IV

\begin{tabular}{|c|c|c|c|c|c|c|c|c|}
\hline $60 \mathrm{Co}$ & $\begin{array}{l}\text { Co EDTA } \\
\mathrm{K}_{3} \mathrm{CO}(\mathrm{CN})_{6}\end{array}$ & $5,2 a$ & $10^{-3}$ & $5 \times 10^{-5}$ & 0,31 & $1,1721,33$ & II & IV V \\
\hline $65 \mathrm{Zn}$ & $\mathrm{Zn}$ EDTA & $245 d$ & $3 \times 10^{-3}$ & $10^{-4}$ & & 1,12 & & $\mathrm{IV} \mathrm{V}$ \\
\hline $82 \mathrm{Br}$ & $\mathrm{BrNh}_{4}: \mathrm{BrNa}$ & $36 h$ & $8 \times 10^{-3}$ & $3 \times 10^{-4}$ & 0,45 & $0,55 \mathrm{e} 1,47$ & $I I$ & \\
\hline $86 \mathrm{Rb}$ & & $19 \mathrm{~d}$ & $2 \times 10^{-3}$ & $7 \times 10^{-5}$ & $0,68 \mathrm{e} 1,76$ & 1,08 & & IV \\
\hline${ }^{89} \mathrm{Sr}$ & & $51 \mathrm{~d}$ & $3 \times 10^{-4}$ & $10^{-5}$ & 1,46 & & & IV \\
\hline${ }^{90} S r-90 v$ & & 89 a $64 \mathrm{~h}$ & & & $0,54-2,26$ & & & $I V$ \\
\hline $106_{\mathrm{RW}} 105_{\mathrm{Ph}}$ & & & & & & & II & IV V \\
\hline $110 \mathrm{Ag}$ & & $253 \mathrm{~d}$ & $9 \times 10^{-4}$ & $3 \times 10^{-5}$ & $0,88 \mathrm{e} 0,66$ & & & \\
\hline $114 \mathrm{In}$ & & & $5 \times 10^{-4}$ & $2 \times 10^{-5}$ & & & II & IV V \\
\hline $124 \mathrm{Sb}$ & & $60 \mathrm{~d}$ & $7 \times 10^{-4}$ & $2 \times 10^{-5}$ & $0,61 \in 0,22$ & $1,7000,72$ & & IV V \\
\hline $131 I$ & $\mathrm{NaI}$ & $8 d$ & $6 \times 10^{-5}$ & $2 \times 10^{-6}$ & 0,61 & $0,36 \mathrm{e} 0,64$ & II & \\
\hline $140 \mathrm{Ba}-140 \mathrm{La}$ & & $12,8 a-40 h$ & $8 \times 10^{-4}$ & $3 \times 10^{-5}$ & 1,38 etc. & 1,60 etc. & & $I V$ \\
\hline $143 \mathrm{Pr}$ & & & $20^{-3}$ & $5 \times 10^{-5}$ & & & & $\mathrm{IV}$ \\
\hline $147 \mathrm{Pm}$ & & $2,5 \quad a$ & $6 \times 10^{-3}$ & $2 \times 10^{-4}$ & 0,22 & & & IV \\
\hline $170 \mathrm{Tm}$ & & $127 \mathrm{~d}$ & $10^{-3}$ & $5 \times 10^{-5}$ & 0,97 & 0,084 & & IV \\
\hline
\end{tabular}


CONTINUAÇÃO T A B E L A IV

\begin{tabular}{|c|c|c|c|c|c|c|c|}
\hline $192 \mathrm{Ir}$ & Ir EDTA & $74 \mathrm{~d}$ & $10^{-3}$ & $4 \times 10^{-5}$ & $0,67 \mathrm{e} 0,54$ & $0,32 \mathrm{e} 0,46$ & \\
\hline $198_{\mathrm{Au}}$ & Coloidal & $65 \mathrm{~h}$ & $2 \times 10^{-3}$ & $5 \times 10^{-5}$ & 0,96 & 0,41 & IV \\
\hline
\end{tabular}

$X$ - DO "BASIC SAFETY STANDARS FOR RAD PROTECTION" IAEA, SAT. SERIE NO 9 (1962) (TNGERIDA POR ANO)

$X X-$ OPERADORES

XXX - RÜELICO E: GERAL

XXXX - I - EXCELENTE

II - EXISTEM NUEROSOS TRARALHOS CONEIPMANDO SEU BOM COMPORTAMETO EY ÁGUAS SUBTEPRAAIEAS E SUPERFICTAIS.

III - SE AS R̃GUS ESTÃO SATURADAS DESTES HLEWNTOS, PODEREMOS TE TESULTABOS ACEITAVEIS.

IV - COMO CATIONS SÃO GERALMENTE MAUS TRAÇADORES EM R̃GUAS SUETERRANEAS, MAS EU CERTOS TIPOS DE ESTRATOS PODEY SER ACEITAVEIS (CALCARIOS, AREIAS, ETC.)

V - Empogados GERALMENTE NA FOR:A DE COAPLEXO. 
taxa de contagem e, a partir da mesma, pode-se calcular a atividade da amostra medida, sua concentração ou sua atividade especifica.

Foram desenvolvidos muitos tipos de detetores, uns para usos gerais, outros para aplicações específicas e concretas. Limitaremos a descrever, de modo suscinto, o funciona mento de um cintilador, por ter sido este tipo de detetor uti lizado em nosso trabalho.

o detetor de cintilação e o sistema mais usado para as medições de raios gama, pois sua sensibilidade é superior a dos detetores Gej.ger - Muller.

$\mathrm{Na}$ figura 1 estâ representado de forma esquemâtica um detetor de cintilação. Consta de um crista1, normalmente de NaI ativado com Tâlio, ligado opticamente a um tubo foto multiplicador. Quando um raio gama incide sobre o crista1, que ë o elemento sensíve1, produz nele uma faisca luminosa, por excitação dos átomos de sua rêde cristalina. Esta faisca luminosa é "vista" pelo fotocatodo do tubo fotomultiplicador, que libera um determinado nümero de elëtrons(efei to similar ao da cêlula fotoelétrica), que por ação de um campo elëtrico presente, dirigem-se com velocidades elevadas até ao primeiro dinodo. Ao se chocarem contra o dinodo produ zem novo feixe de elétrons de maior intensidade que o inciden te. Este feixe dirige-se, em continuação, para o segundo dino do, produzindo um efeito similar ao anterior. o processo de mu1tiplicação do feixe de elëtrons repete-se nos diferentes dinodos, e assim, no anodo coletor chega um fluxo muito inten so destas partículas. Quando este fluxo de elëtrons, de intensidade $\dot{j}_{\text {, }}$ passa através da resistência $R$, origina um pulso de tensão de valor $\underline{i R}$, que dá origem a un impulso elê trico, registrado no equipamento eletrônico associado.

A duração de todo o processo ê da ordem de $1 \mathrm{~s}$ ou menos, e por isso estes detetores podem funcionar corretamen te, registrando taxas de contagem superiores a $10^{6}$ impulsos por minuto.

As técnicas de medida majs frequentemente utilizadas em hidrologia, com detetores de radiação, estão ilustra das na figura 2. No caso da técnica A, o detetor encontra-se 


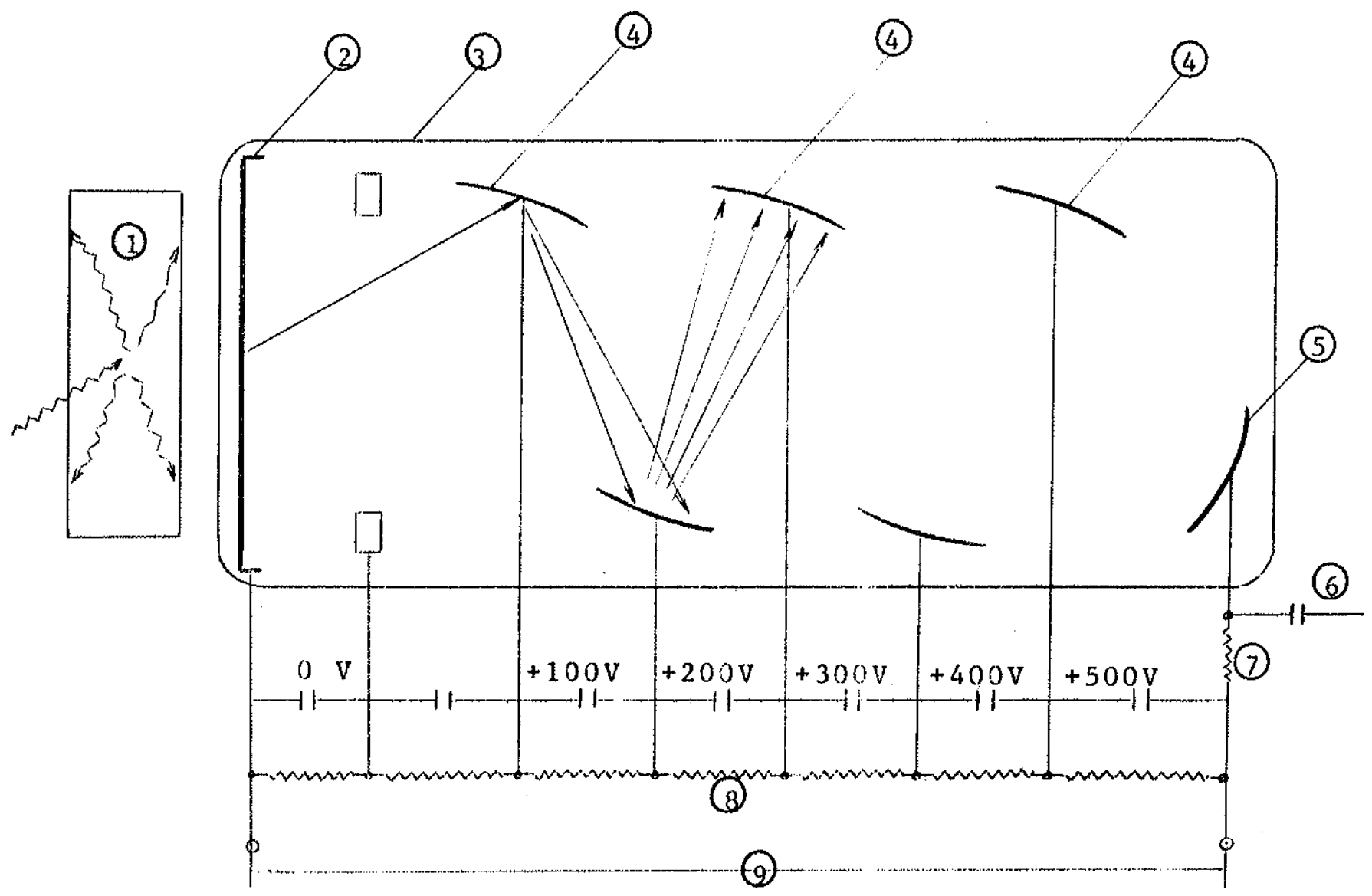

FIGURA 1 - Esquema de um cintilador.

(1)-cristal de NaI (II)

(2) - fotocatodo

(3) - tubo fotomultiplicador

(4) - dinodos

(5) - anodo

(6) - saida dos impulsos

(7) - resistência de carga R

(8) - divisor de tensão

(9) - voltagem aplicada 
FIGURA 2 - Disposição geométrica das formas de medida utilizadas com detetores de cintilação para a medida de emissores gana
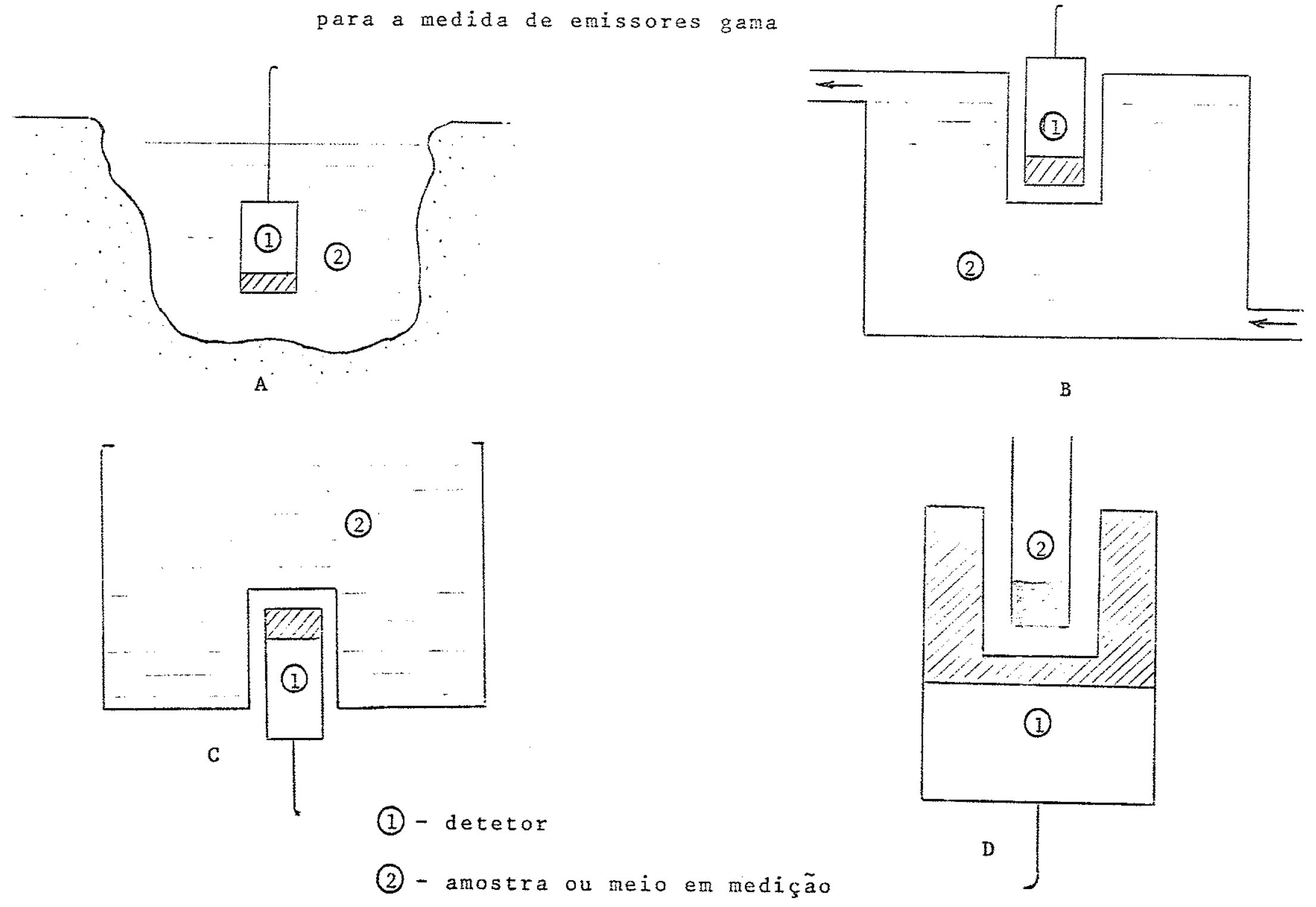
submerso na ägua. Se o volume de água que rodeia o detetor é suficientemente grande, e a concentração do traçador é unifor me, pode-se definir o chamado "volume infinito ou de saturação" como sendo o volume que contribui com 95\% da resposta do detetor e como é 10 gico, seu raio aumenta com a energia dos raios gama. Para o ${ }^{131_{1}} \vec{e}$ de aproximadamente $35 \mathrm{~cm}$ e para ${ }^{82} \mathrm{Br} \vec{e} \mathrm{da}$ ordem de $80 \mathrm{~cm}$. Com esta tëcnica de medida, o 1 imite inferior de concentração de ${ }^{131}$ I que pode ser medido,uti1 izando um detetor com cristal de NaI (TI) de $5 \mathrm{~cm}$ de diâme tro por $5 \mathrm{~cm}$ de altura, é da ordem de $5.10^{-4} \mathrm{Ci} / 1 i t r o$. Isto significa que, em tais condições, 1Ci deste isōtopo ë sufi ciente para marcar $2.10^{6} \mathrm{~m}^{3}$ de ägua. Para ${ }^{82} \mathrm{Br}$, estas cifras multiplicam-se por um fator, igual a 4 aproximadamente.

Nos casos $B \in C$, o detetor encontra-se rodeado por um volume fixo de ägua, determinado pelas dimensões do recipiente de medida. Em B, a ägua é impulsionada ao recipiente por meio de uma bomba, obtendo-se um contrôle contínuo ou periódico da concentração do traçador. A tëcnica mostrada em $\mathrm{C}$ é utilizada para medidas descontinuas de amostras. Em amm

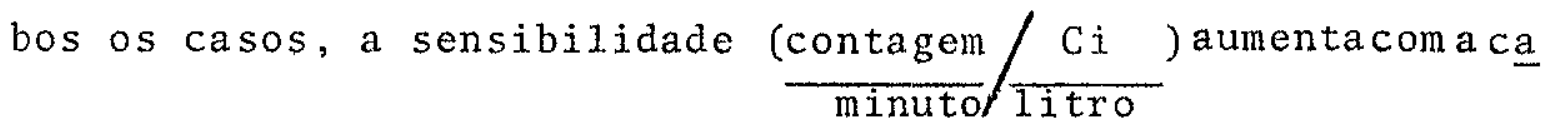
pacidade do recipiente, atẻ alcançar um valor mäximo corres pondente à técnica $A$.

Na tëcnica D utiliza-se un detetor mergulhado no po ço, isto ë, em um orificio cilindrico en cujo interior se introduz a amostra a medir. Esta disposição geomëtrica propor ciona uma eficiência de medida muito elevada, pois a maior parte dos raios gama emitidos pela amostra incidem sôbre a zo na efetiva do detetor. Mas, o volume da amostra pode ficar $1 \underline{i}$ mitado a 40 ou $50 \mathrm{~cm}^{3}$, segundo o tipo do detetor. Por isto, esta tëcnica é utilizada sōmente quando o traçador contido na ägua encontra-se em pequeno volume, por exemplo, mediante pre cipitação ou fixação em resinas de troca iônica. Ela ë fre quentemente empregada para medir o ${ }^{131} \mathrm{I}$, por precipitação des te em forma de AgI em amostras de ägua, de até 50 1itros. Uti lizando-se detetor de cintilação e este procedimento, pode se medir concentrações minimas de $5.10^{-5} \mu \mathrm{Ci} / \mathrm{L}$ tro, signifi - 
cando que $1 \mathrm{Ci}$ de ${ }^{131} \mathrm{I}$ é suficiente para marcar um volume de $2.000 \mathrm{~m}^{3}$ de ägua. Se levarmos em conta que o pêso em iodo des ta atividade é da orden de $10^{-6}$ gramas, e que o volume da solução que o contëm pode ser sōmente de värios mililitros, ficarä compreendido o enorme fator de diluição que este tipo de marcação proporciona.

I I. 7 VANTAGENS E INCONVENIENTES NO USO DE TRACADORES RADIOATTVOS

As vantagens dos traçadores radioativos frente aos inativos, podem ser resumidas nos seguintes pontos:

1. extraordinäria sensibilidade de deteção, permi tindo diluições da ordem de $2.000 \mathrm{~m}^{3}$ de ägua por $\mathrm{Ci}$. Uma marca ção similar com filuoresceina ou dicromato de potássio exige a proximadamente $500 \mathrm{Kg}$ destes produtos;

2. possibilidade de medida "in situ";

3. vida limitada do traçador, que pode ser escolh $\underline{i}$ do de acôrdo com a duração prevista para a experiência. Esta vantagem tem um valor decisivo quando se trata de águas de re novação lenta (äguas subterrâneas), que ficariam contaminadas durante longo tempo, se fôsse empregado traçador não radioati vo;

4. a medida seletiva, sem interferência de outros materiais contidos na ägua, radioativos ou não. Mediante es pectrometria de raios gama pode se identificar o traçador de forma inequívoca, detetando-se apenas sua energia caracteristica. Esta têcnica permite o emprego simultâneo de dois ou mais traçadores com garantia de identificação e medida de cada um deles;

5. um mesmo traçador pode ser empregado em diversas formas quimicas, sem que se modifique a sensibilidade da medi da. Isto é muito importante, pois pode se conseguir que o tra 
çador tenha um comportamento semelhante ao das molëculas de á gua.

Entre as desvantagens destes traçadores podemos citar:

1. No caso de isótopos de vida curta, eles tem que ser adquiridos e utilizados em datas fixas;

2. necessidade de autorização, para a aquisição e manipulação de materiais radioativos;

3. equipamento de medida mais custoso que o utiliza do para traçadores não radioativos.

II.8 RISCOS DERIVADOS DO USO DE RADIOISOTOPOS EM HIDROLOGIA

0 homem, no decorrer do seu processo evolutivo sôbre a Terra; sempre ficou exposto à radiação proveniente dos materiais radioativos naturais existentes na crosta terrestre, e à radiação cōsmica procedente do espaço exterior. Estas radiações não demonstraram ser um perigo sërio para a evolução e desenvolvimento da espëcie humana. Com o advento da era nuclear, os riscos foram incrementados, com a utilização em grande escala de diversos tipos de fontes, tornando se necessário estabelecer normas e regulamentos para que a radiação pudesse trazer reais beneficios à tecnologia.

A primeira manifestação das terríveis consequên cias que a energia nuclear poderia impôr para o futuro da hu manidade deu origem a um estado psicológico de prevenção e, inclusive, de temor contra este novo desenvolvimento da físi ca moderna, que afetou tambëm as aplicações pacíficas. porém este receio serviu de base para acelerar as investigações so bre a ação das radiações nos organismos vivos. As normas de proteção contra as radiações foram evoluindo, de acôrdo com os grandes avanços conseguidos no campo da Radiobiologia, fa zendo com que a tecnologia nuclear se desenvolvesse em condi ções de segurança superiores à maioria dos setores tecnológi 
cos restantes, como o demonstram as estatísticas de acidentes.

As normas e critêrio básicos de proteção contra as radiações encontram-se descritas nas recomendações da Comis são Internacional de Proteção Radiológica, organismo que cons titue a mäxima autoridade científica nesta matẻria. Estas re comendações refletem-se, assim mesmo, nas normas de proteção ditadas por outras organizações internacionais e nas regula mentações dos distintos países. A Agencia Internacional de Energia Atômica (IAEA), com sede em Viena, fixou normas conn cretas para o uso de radioisótopos em hidrologia. A descrição pormenorizada das normas de proteção radiológicas vigentes não condiz com o espirito deste trabalho, e por isto limitare mos ao resumo suscinto de alguns conceitos básicos e a descri ção geral dos riscos potenciais derivados de tais usos.

Os mecanismos dos efeitos biológicos das radiações têm sua origem nos fenômenos físicos de interação destas com a matêria. A energia das radiações é transferida aos eletrons do meio, provocando a ruptura dos enlaces químicos, alterando ou destruindo células. Os efeitos biológicos independem do tí po de radiação, mas sim, da quantidade total de energia absor vida pelos tecidos, da sua distribuição espacial e do tipo de orgão atingido. A periculosidade das distintas radiações depende apenas da dose absorvida pelo organismo e do seu poder de toxidade. Levando-se em conta o poder de penetração das ra diações, pode-se distinguir dois casos.

\section{8.1 IRRADIACCAO EXTERNA}

Neste caso, as radiações que agem sôbre o organismo procedem de uma fonte exterior e alheia ao mesmo. As partículas alfa e beta, em virtude do pequeno poder de penetração, não apresenta riscos importantes de irradiação externa, exceto em casos isolados. A ação destas partículas limita-se à pe le e às primeiras camadas do tecido subcutâneo, enquanto os 
raios $X$ e raios gama podem atingir os tecidos profundos do or ganismo.

Para medir a dose de radiação absorvida existem diferentes unidades, descritas a seguix:

1. Roentgen (R) è a medida da capacidade dos raios $X$ e dos raios gama de ionizar o ar. E uma unidade de exposição. Um roentgen traduz a quantida de de radiação (raio $X$ ou gama) capaz de produzir $2,58.10^{-4}$ coulombs de cargá elëtrica por quilograma de ar seco, à temperatura e pressão normais $\left(0^{\circ} \mathrm{C} \ddot{e}\right.$ uma atmosfera de pressão). Um submü1tip1o muito uti1izado ê o miliroentgen (mR), que equivale a uma milësima parte do roentgen;

2. Rad ê a unidade que representa a energia absorvida por grama de material, e equivale a 100 ergs por grama, de qualquer material. Logo $1 \mathrm{rad}=1.00 \mathrm{ergs} / \mathrm{grama}=0,01$ Joules/quilograma. Frequêntemente se utiliza o milirad (mrad), submủltiplo que é igual à milésima parte do rad $(1 \mathrm{mrad}=0,001 \mathrm{rad})$.

3. Rem - do ponto de vista biológico, algumas radiações são mais eficazes que outras. Isso quer dizer que a mesma dose de radiação em rads, produzida por diferentes tipos de radiação, não pro vocam necessariamente os mesmos efeitos biö1ogicos ou com a mesma intensidade. Por isso, na Radiobiologia, usa-se o Rem como unidade de dose equivalente. Com o objetivo de explicar o que se intende por Rem, é necessärio introduzir o con ceito de fator de qualidade de uma radiação. Este fator relaciona os efeitos das radiações com os dos raios gama provenientes do ${ }^{60} \mathrm{Co}$, como exem plo consideremos o caso de neutrons râpidos. Para produzirem os mesmos efeitos biológicos que 
os raios gama do ${ }^{60} \mathrm{Co}$, necessita-se apenas $1 / 10$ da dose fornecida pelos penetrantes raios gama. Diz-se então que o fator de qualidade dos neutrons räpidos $\vec{e} 10$. O fatôr de qualidade para os raios $X$, raios gama, raios beta e elëtrons $\vec{e}$ 1 ; para os neutrons lentos é 2,5; para os neutrons räpidos, prötons ate $10 \mathrm{MeV}$ e partỉcu las alfa é 10. O Rem é definido como a dose absorvida em rads multiplicada pelo fator de quali dade da radiação, assim, $R e m=\operatorname{rad} . F Q$, onde $F Q$ $\vec{e}$ o fator de qualidade.

As doses mäximas permissiveis aceitas internaciona 1 mente são diferentes segundo se trate de pessoas profissiona1 mente expostas a radiações e sujeitas por este motivo à contrôle médico períodico, ou de membros isolados da população ou ainda de grandes massas humanas.

Para o pessoal profissionalmente exposto, a dose mäxima permitida por ano, $\vec{e}$ calculada pela expressão $\mathrm{D}=5(\mathrm{~N} \cdot$ 18), sendo $\mathrm{N}$ a idade do indivíduo expressa em anos. Presume - se que nenhuma pessoa deva começar a trabalhar com radiações antes da idade de dezoito anos. A dose anual indicada equiva1e, aproximadamente, a 0,1 Rem por semana e a 0,5 milirem por hora. Sem dúvida, admite-se tambëm que uma pessoa possa rece ber até 3 Rem em somente treze semanas ou, tambëm, estes $\overline{3}$ Rem de uma sô vez, sempre que a dose total anual não supere - valor de 5 Rem. Estas doses se referem aos casos de jirra diação de todo o corpo ou das gônadas, orgãos hematopoiêticos e cristalino. Para outras zonas isoladas do corpo, as doses mäximas permissíveis são superiores. Assim, para as mãos, antebraços, pês e tornozelos, è de 20 Rem por ano.

Para pessoas não expostas profissionalmente, que podem permanecer em zonas submetidas a irradiação, a dose mäxima permissivel anual ë de 1,5 Rem para corpo inteiro, gônodas, orgãos hematopoiëticos e cristalino e de 7,5 Rem para as mãos e pës. Para membros da população, não submetidos a contrôle algum, estas doses se reduzem a 0,5 e 3 Rem, respectivamente. 
Por ultimo, para efeitos de repercuções genëticas, considera-se que a população em geral não deve receber uma do se superior a 5 Rem durante un período de 30 anos (dose genética).

II.8.2 IRRADIACAO INTERNA

Quando o material radioativo encontra-se no interior do organismo, o grau de periculosidade $\vec{e}$ inverso, isto $\vec{e}$, o risco é maior para particulas alfa e menor para os raios gama. Isto pelo fato das particulas alfa dissiparem toda sua energia em poucos milimetros de percurso, enquanto que os raios gama perdem energia em percursos maiores, escapando fre quentemente do interior do organjsmo. As particulas beta ocu pam uma posição intermediäria.

As regras de segurança em Radioproteção são bem dis tintas em ambos casos. Quando se trata de uma fonte externa, fäcil proteger-se contra as radiações emitidas utilizando - se blindagens adequadas, mantendo-se afastado das mesmas ou rem duzindo o tempo de exposição. Ao conträrio, quando o material radioativo $\vec{e}$ ingerido pelo organismo, nada se pode fazer para modificar a situação criada, senão esperar que a atividade do radioisôtopo diminua por desintegração e por eli minação biolögica.

Com relação à radiação interna, as normas de prote ção determinam para os diferentes radioisôtopos na ägua e ar, as concentrações máximas permissiveis que podem ser ingeridas pelas pessoas durante o período do ano. Estas grandezas, para os radioisótopos de uso mais frequênte em hidrologia são mostradas na tabela $V$. As atividades mảximas que podem ser ingeridas por ano foram obtidas a partir das concentrações mäximas permissiveis, tomando-se 8001 itros como sendo o volume de àgua ingerido anualmente, por pessoa. 
$\begin{array}{llllllll}T & A & B & E & L & A & V\end{array}$

CONCENTRAÇÕES MĀXIMAS PERMISSIVEIS PARA RADIOISŌTOPOS DE INTERESSE HIDROLÓGICO EM ĀGUA E AR E ATIVIDADE MÁXIMA QUE PODE SER INGERIDA OU INALADA DURANTE UM ANO.

\begin{tabular}{|c|c|c|c|c|c|c|}
\hline \multirow[t]{2}{*}{ ISŌTOPOS } & \multirow{2}{*}{\multicolumn{2}{|c|}{ ORGÃO CRITICO }} & \multicolumn{2}{|c|}{$\begin{array}{l}\text { CONCENTRAÇÃO MÃXIMA } \\
\text { PERMISSIVEL }\left(\mu \mathrm{Ci} / \mathrm{cm}^{3}\right)\end{array}$} & \multicolumn{2}{|c|}{$\begin{array}{c}\text { ATIVIDADE MĀXIMA } \\
\text { ASSIMILADA POR ANO }(\mu \mathrm{C} \dot{1})\end{array}$} \\
\hline & & & $\bar{\Lambda} G U A$ & $\mathrm{AR}$ & ĀGUA & $A R$ \\
\hline${ }^{3} \mathrm{H}$ & TODOS & SOL. & $\pm 3 \times 10^{-3}$ & $* 2 \times 10^{-7}$ & $2,6 \times 10^{3}$ & $1,2 \times 10^{3}$ \\
\hline${ }^{14} \mathrm{C}$ & TODOS & SOL. & $8 \times 10^{-4}$ & $10^{-7}$ & $6 \times 10^{2}$ & $6 \times 10^{2}$ \\
\hline \multirow{2}{*}{${ }^{24} \mathrm{Na}$} & INT. G. I. & INSOL. & $3 \times 10^{-5}$ & $5 \times 10^{-9}$ & $2,2 \times 10$ & $3,6 \times 10$ \\
\hline & INT. G. S, & SOL. & $2 \times 10^{-4}$ & $4 \times 70^{-8}$ & $1,5 \times 10^{2}$ & $3,1 \times 10^{2}$ \\
\hline \multirow[t]{2}{*}{$32 p$} & ossos & SOL. & $2 \times 10^{-5}$ & $2 \times 10^{-9}$ & $1,5 \times 10$ & $1,8 \times 10$ \\
\hline & $\begin{array}{l}\text { PULMAO } \\
\text { INT. G. I. }\end{array}$ & INSOL. & $2 \times 10^{-5}$ & $3 \times 10^{-9}$ & $1, \overline{8 \times 10}$ & $2,0 \times 10$ \\
\hline \multirow{2}{*}{${ }^{35} \mathrm{~S}$} & GÔNADAS & SOL. & $* 6 \times 10^{-5}$ & $* 9 \times 10^{-9}$ & $5,0 \times 10$ & $6,8 \times 10$ \\
\hline & $\begin{array}{l}\text { PULAO } \\
\text { INT. G. I. } \\
\end{array}$ & INSOL. & $3 \times 10^{-4}$ & $9 \times 10^{-9}$ & $2,2 \times 10^{-2}$ & $6,3 \times 10$ \\
\hline \multirow[b]{2}{*}{${ }^{46} \mathrm{Sc}$} & $\begin{array}{l}\text { INT. G. I. } \\
\text { EIGADO }\end{array}$ & SOL & $4 \times 10^{-5}$ & $8 \times 10^{-9}$ & $3,0 \times 10$ & $\begin{array}{l}6,1 \times 10 \\
6,0 \times 10 \\
\end{array}$ \\
\hline & $\begin{array}{l}\text { PULMAO } \\
\text { INT. G. I. }\end{array}$ & INSOL. & $4 \times 10^{-5}$ & $8 \times 10^{-10}$ & $3, \overline{0 \times 10}$ & $\begin{array}{r}6,0 \\
\end{array}$ \\
\hline \multirow{2}{*}{${ }^{51} \mathrm{Cr}$} & $\begin{array}{c}\text { INT. G. I. } \\
\text { TODOS }\end{array}$ & SOL. & $2 \times 10^{-3}$ & $* 4 \times 10^{-7}$ & $1,3 \times 10^{3}$ & $\begin{array}{l}2,6 \times 10^{3} \\
2,7 \times 10^{3} \\
\end{array}$ \\
\hline & $\begin{array}{l}\text { PULMAO } \\
\text { INT. G. I. }\end{array}$ & INSOL. & $2 \times 10^{-3}$ & $8 \times 10^{-8}$ & $1,2 \overline{10}$ & $5,6 \times 10^{2}$ \\
\hline \multirow[t]{2}{*}{${ }^{59} \mathrm{Fe}$} & TODOS, BACO, SANGUE & SOL. & $6 \times 10^{-5}$ & $5 \times 10^{-9}$ & $5,7 \times 10$ & $2,7 \times 10$ \\
\hline & PULUÃO, INT.G.I. & INSOL. & $5 \times 10^{-5}$ & $2 \times 10^{-9}$ & $5 \times 10$ & $1,1 \times 10$ \\
\hline
\end{tabular}


CONTINUAÇÄO TA B E

\begin{tabular}{|c|c|c|c|c|c|c|}
\hline${ }^{58} \mathrm{Co}$ & TODOS, INT.G.I. & SOL. & $10^{-4}$ & $* 3 \times 10^{-8}$ & $7,6 \times 10$ & $2 \times 10^{2}$ \\
\hline & PULAATO INT.G.I. & INSOL. & $9 \times 10^{-5}$ & $2 \times 10^{-9}$ & $10^{2}$ & $1,7 \times 10$ \\
\hline \multirow{2}{*}{${ }^{60} \mathrm{CO}$} & $\begin{array}{c}\text { INT. G.I. } \\
\text { TODOS }\end{array}$ & SOL. & $5 \times 10^{-5}$ & $* \quad 10^{-8}$ & $3,9 \times 10$ & $\begin{array}{l}8,0 \times 10 \\
8,7 \times 10 \\
\end{array}$ \\
\hline & $\begin{array}{l}\text { PULMAO } \\
\text { INT. G. I. }\end{array}$ & INSOL. & $3 \times 10^{-5}$ & $3 \times 10^{-10}$ & $2,8 \times 10$ & 2,2 \\
\hline \multirow{2}{*}{${ }^{65} \mathrm{Zn}$} & $\begin{array}{c}\text { TODOS } \\
\text { PRÓSTATA } \\
\text { EÍGADO } \\
\end{array}$ & SOL. & * $10^{-4}$ & $* 4 \times 10^{-9}$ & $\begin{array}{l}7,9 \times 10 \\
9,6 \times 10 \\
1,0 \times 10^{2} \\
\end{array}$ & $\begin{array}{c}2,6 \times 10 \\
3,2 \times 10 \\
- \\
\end{array}$ \\
\hline & $\begin{array}{l}\text { PULMÃO } \\
\text { INT. G. I. }\end{array}$ & INSOL. & $2 \times 10^{-4}$ & $2 \times 10^{-9}$ & $1,4 \times 10^{2}$ & $\begin{array}{c}1,5 \times 10 \\
- \\
\end{array}$ \\
\hline \multirow[t]{2}{*}{${ }^{82} \mathrm{Br}$} & $\begin{array}{l}\text { TODOS } \\
\text { INT. G. S. }\end{array}$ & SOL. & $3 \times 10^{-4}$ & $4 \times 10^{-8}$ & $\begin{array}{l}2,1 \times 10^{2} \\
2,2 \times 10^{2} \\
\end{array}$ & $2,8 \times 10^{2}$ \\
\hline & INT. G. I. & INSOL. & $4 \times 10^{-5}$ & $6 \times 10^{-9}$ & $3,0 \times 10$ & $4,7 \times 10$ \\
\hline \multirow{2}{*}{${ }^{86} R b$} & $\begin{array}{l}\text { TODOS } \\
\text { PÂNCREAS } \\
\text { FÍGADO } \\
\end{array}$ & SOE. & $* 7 \times 10^{-5}$ & $10^{-8}$ & $\begin{array}{c}5,4 \times 10 \\
5,4 \times 10 \\
\\
\end{array}$ & $\begin{array}{l}7,1 \times 10 \\
7,1 \times 10 \\
1,0 \times 10^{2} \\
\end{array}$ \\
\hline & $\begin{array}{l}\text { PULMÃO } \\
\text { INT. G. I. }\end{array}$ & INSOL. & $2 \times 10^{-5}$ & $2 \times 10^{-9}$ & $1,9 \times 10$ & $\begin{array}{c}1,7 \times 10 \\
\end{array}$ \\
\hline \multirow{2}{*}{${ }^{85} \mathrm{Sr}$} & TODOS & SOL. & $* \quad 10^{-4}$ & $8 \times 10^{-9}$ & $7,5 \times 10$ & $5,8 \times 10$ \\
\hline & $\begin{array}{l}\text { PULMÃO } \\
\text { INT. G.I. }\end{array}$ & INSOL. & $2 \times 10^{-4}$ & $4 \times 10^{-9}$ & $1,4 \times 10^{2}$ & $\begin{array}{c}2,6 \times 10 \\
\end{array}$ \\
\hline \multirow{2}{*}{${ }^{89} \mathrm{Sr}$} & Osso & SOL. & $10^{-5}$ & $10^{-9}$ & 7.6 & 8,5 \\
\hline & $\begin{array}{l}\text { PULMÃO } \\
\text { INT. G. I. }\end{array}$ & INSOL. & $3 \times 10^{-5}$ & $10^{-9}$ & $2,8 \times 10$ & 8,5 \\
\hline
\end{tabular}


\begin{tabular}{llllllll} 
CONTINUAÇÃO & T A & B & E & L & A & V \\
\hline
\end{tabular}

\begin{tabular}{|c|c|c|c|c|c|c|}
\hline \multirow{2}{*}{${ }^{90} \mathrm{Sr}$} & Osso & SOL. & $* \quad 10^{-7}$ & $10^{-12}$ & $3,2 \times 10^{-1}$ & $2,9 \times 10^{-1}$ \\
\hline & $\begin{array}{l}\text { PULMÃO } \\
\text { INT. G. I. }\end{array}$ & INSOL. & $4 \times 10^{-5}$ & $2 \times 10^{-10}$ & $2,8 \times 10$ & $\begin{array}{r}1,4 \\
\end{array}$ \\
\hline \multirow{2}{*}{${ }^{95} \mathrm{Zr}$} & TODOS & SOL. & $6 \times 10^{-5}$ & $\div 4 \times 10^{-9}$ & $5,7 \times 10$ & $3,4 \times 10$ \\
\hline & $\begin{array}{l}\text { PULMÃO } \\
\text { INT. G. I. }\end{array}$ & INSOL. & $6 \times 10^{-5}$ & $10^{-9}$ & $5,7 \times 10$ & 8,5 \\
\hline \multirow{2}{*}{${ }^{103} \mathrm{Ru}$} & RIM & SOL. & $8 \times 10^{-5}$ & $2 \times 10^{-8}$ & $6 \times 10$ & $1,3 \times 10^{2}$ \\
\hline & $\begin{array}{l}\text { PULMÃO } \\
\text { INT. G. I. }\end{array}$ & INSOL. & $8 \times 10^{-5}$ & $3 \times 10^{-9}$ & $6 \times 10$ & $2,5 \times 10$ \\
\hline \multirow[b]{2}{*}{${ }^{109} \mathrm{Cd}$} & FÍGADO & SOL. & $2 \times 10^{-4}$ & $2 \times 10^{-9}$ & $1,5 \times 10^{2}$ & $1,7 \times 10$ \\
\hline & $\begin{array}{l}\text { PULMÃO } \\
\text { INT. G. I. }\end{array}$ & INSOL. & $2 \times 10^{-4}$ & $3 \times 10^{-9}$ & $1,5 \times 10^{2}$ & $2,5 \times 10$ \\
\hline \multirow{2}{*}{${ }^{110} \mathrm{Ag}$} & RIM & SOL. & $3 \times 10^{-5}$ & $7 \times 10^{-9}$ & $2,8 \times 10$ & $6 \times 10$ \\
\hline & $\begin{array}{l}\text { PULWÃO } \\
\text { INT. G. I. }\end{array}$ & INSOL. & $3 \times 10^{-5}$ & $3 \times 10^{-10}$ & $2,8 \times 10$ & 2,5 \\
\hline \multirow{2}{*}{$124 \mathrm{Sb}$} & osso & SOL & $2 \times 10^{-5}$ & $5 \times 10^{-9}$ & $1,7 \times 10$ & $2,7 \times 10$ \\
\hline & INT. G. I. & INSOL. & $2 \times 10^{-5}$ & $7 \times 10^{-10}$ & $1,7 \times 10$ & 5,5 \\
\hline \multirow{2}{*}{${ }^{131} I$} & TIRÓIDES & SOL. & $2 \times 10^{-6}$ & $3 \times 10^{-10}$ & 1,6 & 2,1 \\
\hline & $\begin{array}{l}\text { INT. G. I. } \\
\text { PULMÃO }\end{array}$ & INSOL. & $6 \times 10^{-5}$ & $10^{-8}$ & $\begin{array}{c}5,1 \times 10 \\
- \\
\end{array}$ & $\begin{array}{l}8,0 \times 10 \\
8,0 \times 10 \\
\end{array}$ \\
\hline
\end{tabular}


\begin{tabular}{llllllll} 
CONTINUAÇÃO & T A & B & E & L & A & V \\
\hline
\end{tabular}

\begin{tabular}{|c|c|c|c|c|c|c|}
\hline \multirow[t]{2}{*}{${ }^{137} \mathrm{Cs}$} & $\begin{array}{l}\text { TODOS } \\
\text { FÍGADO } \\
\text { BAÇO } \\
\text { MÜSCULO }\end{array}$ & SOL. & $* 2 \times 10^{-5}$ & $2 \times 10^{-9}$ & $\begin{array}{l}1,2 \times 10 \\
1,4 \times 10 \\
1,8 \times 10 \\
1,9 \times 10\end{array}$ & $\begin{array}{c}1,6 \times 10 \\
- \\
- \\
-\end{array}$ \\
\hline & $\begin{array}{l}\text { PULMÃO } \\
\text { INT. G. I. }\end{array}$ & INSOL. & $4 \times 10^{-5}$ & $5 \times 10^{-10}$ & $3,5 \times 10$ & 3,6 \\
\hline \multirow{2}{*}{$140 \mathrm{Ba}$} & Osso & SOL. & $3 \times 10^{-5}$ & $4 \times 10^{-9}$ & $2,8 \times 10$ & $3,4 \times 10$ \\
\hline & INT. G. I. & INSOL. & $2 \times 10^{-5}$ & $10^{-9}$ & $1,7 \times 10$ & 8,5 \\
\hline \multirow[t]{2}{*}{${ }^{192} \mathrm{Ir}$} & $\begin{array}{l}\text { INT. G. I. } \\
\text { RIM } \\
\text { BAÇO }\end{array}$ & SOL. & $4 \times 10^{-5}$ & $4 \times 10^{-9}$ & $3,4 \times 10$ & $3,4 \times 10$ \\
\hline & $\begin{array}{l}\text { PULMÃO } \\
\text { INT. G. I. }\end{array}$ & INSOL. & $4 \times 10^{-5}$ & $9 \times 10^{-10}$ & $3,4 \times 10$ & 7,8 \\
\hline \multirow{2}{*}{$198 \mathrm{Au}$} & INT. G.I. & SOL. & $5 \times 10^{-5}$ & $10^{-8}$ & $4,1 \times 10$ & $8,0 \times 10$ \\
\hline & INT. G.I. & INSOL. & $5 \times 10^{-5}$ & $8 \times 10^{-9}$ & $3,7 \times 10$ & $5,9 \times 10$ \\
\hline${ }^{222} \mathrm{Rn}$ & PULMÃO & - & - & $10^{-8}$ & - & $6,5 \times 10$ \\
\hline \multirow{2}{*}{$22 \varepsilon_{\mathrm{Ra}}$} & OSSO & SOL. & $10^{-8}$ & $10^{-12}$ & $7,6 \times 10^{-3}$ & $8,5 \times 10^{-3}$ \\
\hline & $\begin{array}{l}\text { PULMÃO } \\
\text { INT. G. I. }\end{array}$ & INSOL. & $3 \times 10^{-5}$ & $6 \times 10^{-9}$ & $2,8 \times 10$ & $5 \times 10$ \\
\hline \multirow{2}{*}{$232 \mathrm{Th}$} & OSSO & SOL. & $2 \times 10^{-6}$ & $7 \times 10^{-14}$ & 1,5 & $5,5 \times 10^{-4}$ \\
\hline & $\begin{array}{l}\text { PULMÃO } \\
\text { INT. G. I. }\end{array}$ & INSOL. & $4 \times 10^{-5}$ & $4 \times 10^{-13}$ & $3,4 \times 10$ & $3,4 \times 10^{-3}$ \\
\hline
\end{tabular}


CONTINUAÇÄO TA

\begin{tabular}{|c|c|c|c|c|c|c|}
\hline \multirow{2}{*}{$2{ }^{38} \mathrm{U}$} & Osso & SOL. & $4 \times 10^{-5}$ & $3 \times 10^{-12}$ & $3,4 \times 10$ & $2,5 \times 10^{-2}$ \\
\hline & $\begin{array}{l}\text { PULMÃO } \\
\text { INT. G. I. }\end{array}$ & INSOL. & $4 \times 10^{-5}$ & $5 \times 10^{-12}$ & $3,4 \times 10$ & $3 \times 10^{-2}$ \\
\hline \multirow{2}{*}{$239 \mathrm{Pu}$} & Osso & SOL. & $5 \times 10^{-6}$ & $6 \times 10^{-14}$ & 5 & $5 \times 10^{-14}$ \\
\hline & $\begin{array}{l}\text { PULMÃO } \\
\text { INT. G. I. }\end{array}$ & INSOL. & $3 \times 10^{-5}$ & $10^{-12}$ & $\begin{array}{c}2,8 \times 10 \\
3,0 \\
\end{array}$ & $8,5 \times 10^{-3}$ \\
\hline \multirow{2}{*}{$241 \mathrm{Am}$} & $\begin{array}{l}\text { RIM } \\
\text { osso }\end{array}$ & SOL. & $4 \times 10^{-5}$ & $2 \times 10^{-13}$ & - & $1,5 \times 10^{-3}$ \\
\hline & $\begin{array}{l}\text { PULMĀO } \\
\text { INT. G. I. }\end{array}$ & INSOL. & $3 \times 10^{-5}$ & $4 \times 10^{-12}$ & $2,2 \times 10$ & $2,6 \times 10^{-2}$ \\
\hline \multirow{2}{*}{${ }^{252} \mathrm{Cf}$} & osso & SOL. & $7 \times 10^{-6}$ & $2 \times 10^{-13}$ & 6 & $1,7 \times 10^{-3}$ \\
\hline & $\begin{array}{l}\text { PULIÃO } \\
\text { INT. G. I. }\end{array}$ & INSOL. & $7 \times 10^{-6}$ & $10^{-12}$ & 6 & $8,5 \times 10^{-3}$ \\
\hline
\end{tabular}

OBSERVACÃO:- OS VALÔRES PRECEDIDOS DE ASTERISCO SÃO DADOS PARA TODO O CORPO E GÔNODAS.

ABREVIACẼES:- SOL. = RADIOISŌTOPOS DISSOLVIDOS LU ĀGUA.

INSOL. = RADIOISÓTOPOS EM FORMA NÃO SOLŨVEL FIXADO,POR EXEMPLO, NOS MATERIAIS SŌLIDOS TRANSPORTADOS PELA ĀGUA.

TODOS $=$ TODO O CORPO.

INT.G.I. $=$ INTISTINO GROSSO INFERIOR.

INT.G.S. = INTESTINO GROSSO SUPERIOR. 


\section{IT.8.3 RISCOS POTENCIAIS DAS TECNICAS ISOTOPICAS UTILIZADAS}

Para uma orientação sobre os riscos potenciais das tëcnicas isotópicas utilizadas em hidrologia, vamos considerar três grupos:

1. Têcnicas baseadas nos isötopos naturais do meio. o risco para estas tẻcnicas é nulo, pois não se adiciona radioatividade alguma ao meio em estudo e porque os niveis de radioatividade existen tes são extremamente baixos.

2. Técnicas baseadas no emprêgo de equipamentos por tadores de fontes radioativas seladas.

por tratar-se de fontes seladas, o risco que estes equipamentos podem apresentar é somente de irradiação externa, pois a possibilidade de ingestão por membros da população é praticamente nula. Sendo maior o risco de contaminação externa para as pessoas que fazem uso dos equipamen tos, elas podem tomar precauções oportunas em cada caso.Como os equipamentos são comercia1 mente acessíveis, os fabricantes devem dotalos de meios de proteção exigidos pelas normas vigen tes.

3. Técnicas baseadas no emprego de traçadores adicionados ao meio.

Este tipo de técnica pode oferecer riscos, não somente para as pessoas que realizam o trabalho, mas tambëm para a população em gera1. Levando - se em conta o risco de irradiação externa da população em geral, ele será ntılo, pois a atividade adicionada ao meio se distribui em um volu me mito grande e as radiações emitidas, em sua maioria, ficam autoabsorvidas. Os profissionais que manuseiam os radioisỏtopos conhecem muito 
bem as normas e por isto se protegem com o uso de recipientes de chumbo, manipulação à distân cia, contrôle do tempo de exposição, etc.

Vamos considerar as possibilidades de irradiação in terna. Nos casos onde existem probabilidades do material ra dioativo injetado em determinado local, ser ingerido por mem bros da população, torna-se necessārio que as concentrações dos radioisótopos adicionados ao mejo não sejam superiores às mäximas permissiveis. Deve-se tambëm levar em conta que:

1. na maioria dos casos, utilizam-se traçadores radioativos de meia vida curta, e por isto o meio estudado fica isento de contaminação após um período relativamente pequeno. A meia vida do isötopo escolhido deve sempre ser compatível com a duração dos trabalhos. Assim, terminadas as me dições, a concentração do traçador radioativo na ảgua serả tão pequena, que sua contaminação é considerada desprezível;

2. a elevada sensibilidade dos detetores de radiação disponíveis permite medir concentrações muito inferiores à concentração mâxima permissível;

3. normalmente o traçador é incorporado em gran des volumes de ägua ou em sedimentos transportados pela mesma, com diluição e difusão turbulenta, que ocasionam redução progressiva da sua concentração. Na maioria dos casos, em tempo relativamente curto, a concentração do traça dor injetado no meio alcança níveis bem inferiores aos mâximos permissiveis;

4. as experiências realizadas com traçadores incorporados ao meio podem ser de tipo local, signifi cando que o alcance da contaminação é limitado e facilmente controlável. 
Como conclusão, devemos dizer que as normas de proteção contra as radiações regulam qualquer tipo de aplicação de materiais radioativos com finalidades hidrológicas. Trabalhando-se dentro destas normas, os riscos de perigo para a saủde do pessoal tẻcnico e população em geral serão nulos. 


\section{CAPITULO III}

\section{MEDIDAS DE VAZĀO}

\section{1 METODOS CONVENCIONAIS}

As medições de vazão de fluidos, em engenharia e hi drologia, são realizadas com tẻcnicas e instrumental de efi ciência limitadas pelas caracteristicas físicas e químicas dos fluidos, do tipo de conduto, canalização, leito e interva 10 ou escala de medição.

Muitos projetos de investigação e processos indus triais dependem das medidas de vazão, para a anālise de dados. As vezes torna-se necessārio boa precisão nas medidas, enquan to que em alguns casos tolera-se medidas menos precisas. A se leçäo dos instrumentos próprios para uma aplicação em particu lar, depende de vários fatôres, entre eles o preço.

Dentre as diversas técnicas convencionais de medi. das de vazão (volume do fluido que escoa por unidade de tempo), podemos citar:

1. medida direta

Consiste em verificar qual o tempo necessário pa ra acumular determinado volume em um reservató rio natural ou artificial, sem descarga de saida. A razão entre este volume e o tempo necessärio para atingi-1o, determina a vazão de enchimento.

2. medida a partir do nível de àgua

Para se partir, simplesmente, do conhecimento do nivel da àgua, usa-se um dos tipos de dispositivos seguintes:

- calhas medidoras - qualquer dispositivo que provoque a passagem do escoamento do fluido de um regime fluvial a um torrencial serve para 
esse tipo de medida. A mudança de regime obriga a existência de profundidade critica dentro da instalação. A vazão serā função dessa pro fundidade e das caracteristicas do medidor. Há a formação de um ressalto a jusante se o escoa mento fôr fluvial em condições naturais. Como exemplo de instalações pradonizadas deste tipo, podemse citar a calha parshall.

- vertedores - conhecendo-se a espessura da 1âmi na de água sôbre um vertedor, pode-se determinar a descarga atravês de tabelas e gräficos, desde que se proceda, prèviamente, à calibra ção da instalação. Existem tambẻm vertedores padronizados que dispensam a calibração como o tipo Thompson e Scimeni.

As duas instalações causam um represamento a montan te que corresponde ao consumo de uma vazão por acumulação e que não estā sendo medida. Isto só deve ser levado em conside ração quando representar uma quantidade apreciävel frente às grandezas em jôgo. Um vertedor tem a desvantagem de elevar mais o nivel da ägua que a calha, sendo que esta permite mais fàcilmente, a passagem dos materiais arrastados pelo rio.

3. medidores de velocidade

Temos o tipo turbina ou molinete como por exem plo o Price, Woitman, etc. O nümero de rotações é proporcional à velocidade da corrente, ficando os resultados dependentes do estado mecânico dos mesmos. Os molinetes são aparelhos que permitem, desde que bem aferidos, o cälculo da velocidade, mediante a medida do tempo necessärio para uma hêlice ou concha girar certo nümero de rotações. por meio de um sistema elëtrico, o molinete envia um sinal luminoso ou sonoro ao operador em cada numero de voltas realizadas $(5,10,20$ ou mais). Marca-se o tempo decorrido entre alguns toques para se obter o número de rotações por se 
gundo $(n)$. Cada molinete, quando aferido, recebe sua curva $V=a n+b$, onde $n$ tem o significado visto acima e a e $\underline{b}$ são constantes do aparelho, permitindo o cálculo da velocidade $V(\mathrm{~m} / \mathrm{s})$ em cada ponto considerado. A precisão da medição depende do número de molinetes e da posição dos mesmos na seção de medição. Estes equipamentos também são afetados por redemoinhos, trocas de direção de corrente, etc. A velocidade do molinete ê fun ção de sua posição na seção, pois como se sabe, existe um gradiente vertical e outro horizontal de velocidades. A velocidade média está compreen

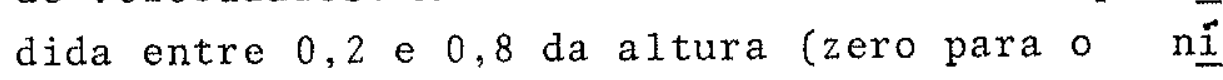
vel superior e um para o fundo). Não obstante os inconvenientes mencionados, estes dois tipos de medidores são insubstítuiveis, quando se deseja medições em forma contínua. Os medidores tipo Venturi, Pitot, etc., têm como base manômetros diferenciais que controlam a perda de carga ou pressão estätica e dinâmica entre a entrada e a saída do cone redutor. São usados geralmente em tubulações.

4. medidores do níve1 da ägua

São os linimetros ou escalas verticais graduadas, dispostas de tal forma que uma parte da mesma es ta permanentemente imersa na água. Estes equipamentos, colocados geralmente nas estações de medição de vazão, podem estar equipados com registradores gräficos ligados a flutuadores. Neste caso a vazão depende da seção transversal, e das caracteristicas topogräficas do talvegue, a montante e a jusante das estações de medição. Nestas condições a vazão ê função de:

$$
Q=f(h, t, S), \quad \text { onde }
$$


$Q$ é a vazão

h é a altura medida sôbre o linimetro

$t$ é um fator de correção (função do talvegue a montante e jusante da estação de medição)

$S$ è a seção do rio ou estação de medição

5. medidas com traçadores químicos

De modo geral a técnica consiste em injetar certa quantidade de traçador em um ponto da corrente e medir sua concentração em estações à jusante. Entre esse traçadores temos os considerados químicos incolores (cloreto de sôdio, fenóis, ácido börico, detergentes, etc.) e os colorantes (flouresceina, dicromato de potässio, rodamina $B$, eosina, roxo do Congo, azul de metileno, anilina, etc.). Todos eles tem inconvenientes quando usados para medir grandes vazões, ou ...meios contaminados com substâncias poluentes. Por exem plo, para medições da ordem de $1 \mathrm{~m}^{3} / \mathrm{s}$ com dicroma to, deve-se injetar quantidade não inferior a

$1 \mathrm{Kg}$ deste material.Para vazões superiores a $50 \mathrm{~m}^{3} / \mathrm{s}$, torna-se necessärio injetar grandes quan tidades de dicromato, o que é desvantajoso. 0 mesmo ocorre com os traçadores convencionais não colorimëtricos.

\section{III.2 DISTÂNCIA MINIMA DE HOMOGENEIZACÃO}

As particulas marcadas com um taçador ideal obede cem às mesmas leis de movimento que as particulas não marca das. A este enfoque do problema deve se acrescentar o fato de não haver perdas por absorção físico-química, troca iônica, etc.

Desde o instante em que o traçador $\vec{e}$ injetado no meio estudado, ele deve participar da dinâmica do sistema. Fe nômenos de difusão molecular e turbulenta contribuem para dí 
persá-1o quando, em forma de solução, é injetado em meio aquoso. Nestas condições durante um periodo relativamente curto, estabelece-se um regime transitório, responsāvel por gran des variações de concentração. Depois de homogeneizado com 0 meio aquoso, a concentração do traçador deve ser constante em cada ponto ao longo do tempo. Começa então um regime permanen te, em que a concentração $\vec{e}$ independente das condições em que o traçador foi injetado. (Figura 3)

0 traçador homogeniza-se mais facilmente com o flui do no sentido longitudinal do escoamento e em profundidade, do que no sentido lateral. Este fato é que präticamente determina, na maioria dos casos, a distância minima de homogeneiza ção do traçador com o meio aquoso.

Estas condições são válidas, se durante o periodo que compreende o tempo transcorrido entre a injeção do traçador e sua passagem pelo ponto de medição, o regime de fluxo for constante ou estacionärio. Quando a velocidade for função apenas do ponto, o regime $\vec{e}$ permanente, e se no mesmo ponto variar com o tempo o movimento deixa de ser permanente.

A distância de homogeneização depende de vários fatôres, entre eles:

1. da velocidade do fluido e por consequinte do tipo de movimento, laminar ou turbulento. 0 movi mento turbulento facilita a homogeneização. (figura 4). Passa-se do regime laminar ao regime turbulento quando o movimento do meio estudado ultrapassar a velocidade critica superior. Ao contrârio, passa-se do regime turbulento ao lami nar, quando se atinge a velocidade crítica infefior. O regime entre estas duas velocidades limi tes ê laminar instável ou turbulento instâve1.

- em canais ou tubulações - Considerando-se o nú ro de Reynolds (Re) definido pela equação

$$
\operatorname{Re}=V_{m} d \rho / \mu \text {, onde }
$$




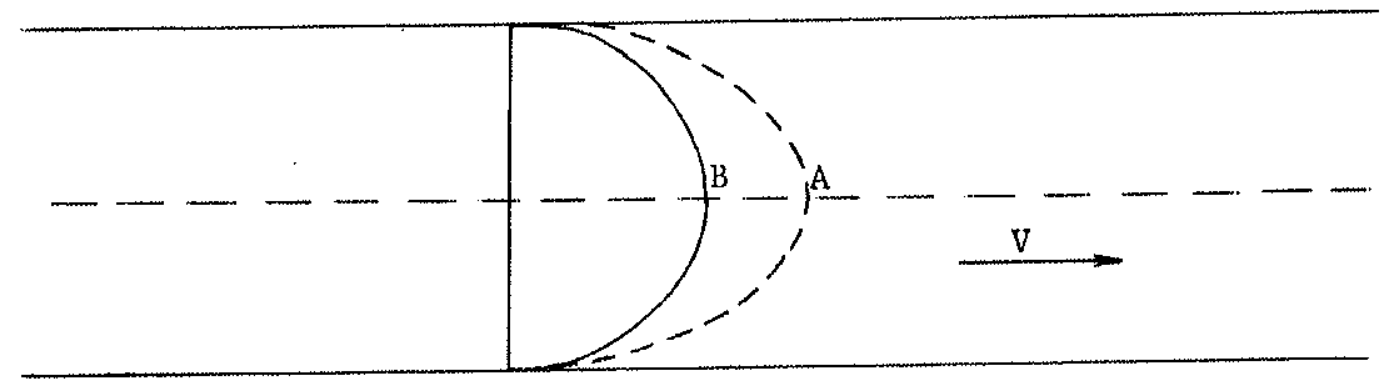

FIGURA 3 - Diagrama de velocidades com vazão constante em regime laminar (A) e turbulento (B).

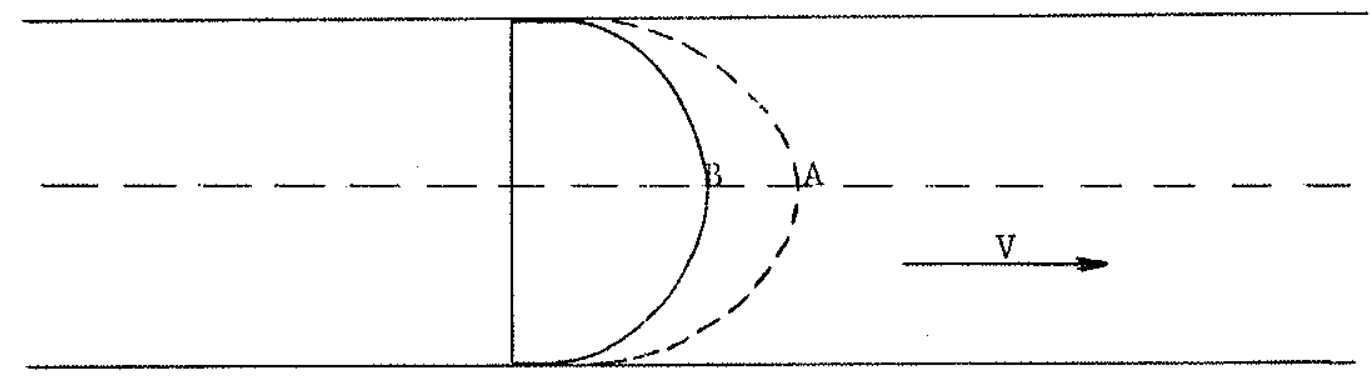

FIGURA 4- Diagrama de velocidades com vazão constante em superfície lisa (A) e rugosa (B). 
Vm è a velocidade mêdia

$\mu \quad \vec{e}$ a viscocidade dinâmica (g/cm.s)

$\rho$ è a densidade $\left(\mathrm{g} / \mathrm{cm}^{3}\right)$

d è o diâmetro da tubulação $(\mathrm{cm})$,

temos que para $\operatorname{Re}<1000$ o movimento è laminar estâve1, para $\operatorname{Re}>1000$ o movimento é turbulen to instäve1. Como limite frequente sintetiza se $\operatorname{Re}=2000$.

- em rios - Pode-se escolher um critério similar.

- em äguas subterrâneas - o limite superior de validez das expressões que definem as velocida des do fluido em meios porosos está definido, para $1<\operatorname{Re}<10$, ainda que se tenha encontrado, tambëm, movimento laminar para $1<\mathrm{Re}<700$, ut $\underline{\mathbf{i}}$ 1izando-se

$$
\operatorname{Re}=V_{m} \rho d / \mu \text {, onde }
$$

d $\vec{e}$ o diâmetro das partículas.

2. da rugosidade das paredes, superfície do leito no caso de rios, granulometria ou natureza do me io em äguas subterrâneas, etc. Na prâtica utilizam-se as seguintes expressões para fixar as dis tâncias mínimas de homogeneização:

- em tubulações ou condutos sob pressão (com injeção no centro do conduto)

$$
\mathrm{L}_{\min }>75 \mathrm{~d}
$$

Quando as instalações permitirem é conveniente acrescentar um fator de segurança, particularmente nos casos em que a velocidade mëdia é pe quena, tendendo para o movimento laminar.

- em canais ou rios - Existem värias förmulas em 
píricas e entre elas podemos citar:

Förmula de CREC

$\mathrm{L}_{\min }>9,5 \mathrm{nh}=9,5 \cdot 0,32 \cdot \mathrm{K} \cdot \mathrm{R}^{1 / 6} \cdot \mathrm{h}=3 \cdot \mathrm{h} \cdot \mathrm{K} \cdot \mathrm{R} \cdot \cdot^{1 / 6}$

Förmula de RINNAR

$L_{\text {min }}>0,13 \cdot N \cdot b^{2} / h$, sendo $N=C \cdot(0,7 C+6) / g$

Fórmula de HULL

$L_{\text {min }}=a \cdot Q^{1 / 3}$

onde:

$L_{\text {min }}$ é a distância mínima de homogeneiza ção

d e o diâmetro da tubulação (m)

$\mathrm{h}$ è a altura de água (m)

$K$ é o coeficiente de rugosidade de Strickler

$R$ è o raio hidräulico

$n$ é a relação entre a velocidade mëdia e a velocidade de flotação

b è a largura média da seção de medição (m)

c ê o coeficiente de Chézy (15 ou 20)

$\mathrm{g}$ é a aceleração da gravidade $\left(\mathrm{m} / \mathrm{s}^{2}\right)$

$Q$ è a vazão estimada $\left(\mathrm{m}^{3} / \mathrm{s}\right)$

a é um coeficiente igual a $50 \mathrm{com}$ injeção central e igual a 200 com injeção lateral do traçador.

III.3 VERIFICACAO DA HOMOGENEIZACAO (LATERAL)

As expressões anteriores foram calculadas ou verifi cadas para um grau de homogeneização inferior a $1 \%$. Significa que se tomarmos simultâneamente três amostras, sendo duas la- 
terais (margem esquerda e margem direita) e uma central, o grau de homogeneização $G\left(\frac{\circ}{0}\right)$ será definido por:

$$
G\left(\frac{0}{0}\right)=\frac{1-\left(N_{e}-N_{m}\right)+\left(N_{c}-N_{m}\right)+\left(N_{d}-N_{m}\right)}{3 N_{m}} \text {, onde }
$$

$N_{e} \vec{e}$ a contagem total da amostra, tomada na margem esquerda $\mathrm{N}_{\mathrm{d}}$ e a contagem total da amostra, tomada na margem direita $\mathrm{N}_{\mathrm{c}}$ ë a contagem total da amostra, tomada no centro do caudal $\mathrm{N}_{\mathrm{m}}$ é a contagem média, ou seja $\mathrm{N}_{m}=\underline{\mathrm{N}_{e}+\mathrm{N}_{d}+\mathrm{N}_{c}}$

O valor de $G$ deve ser inferior a $1 \%$ para se alcan çar a homogeneização acima referida.

\section{III.4 TEMPO DE PASSAGEM DA "ONDA RADIOATIVA"}

Quando se realiza injeção instantânea (figura 5) em um conduto ou canal, deve transcorrer um tempo $T$ para que $99,9 \%$ da atividade injetada passe por uma seção distante $X$ me tros do ponto de lançamento. O valor de $T$ pode ser calculado pela equação

$$
\mathrm{T}(\mathrm{s})=9,3 \sqrt{\mathrm{mhx} / \mathrm{nV}_{\mathrm{m}}^{2}}, \text { onde }
$$

$m$ é o coeficiente adimensional de dispersão longitudinal $(7,3$ para canais e 10,1 para condutos sob pressão)

$V_{m}$ è a velocidade mëdia (m/s)

Em rios è difícil predizer este tempo, pois necessi ta-se conhecer os coeficientes mêdios de dispersão turbulen ta longitudina1. E prudente começar as medições imediatamen te após o lançamento do traçador e terminar a operação quando a atividade natural de fundo for restabelecida, isto $\vec{e}$, nas 


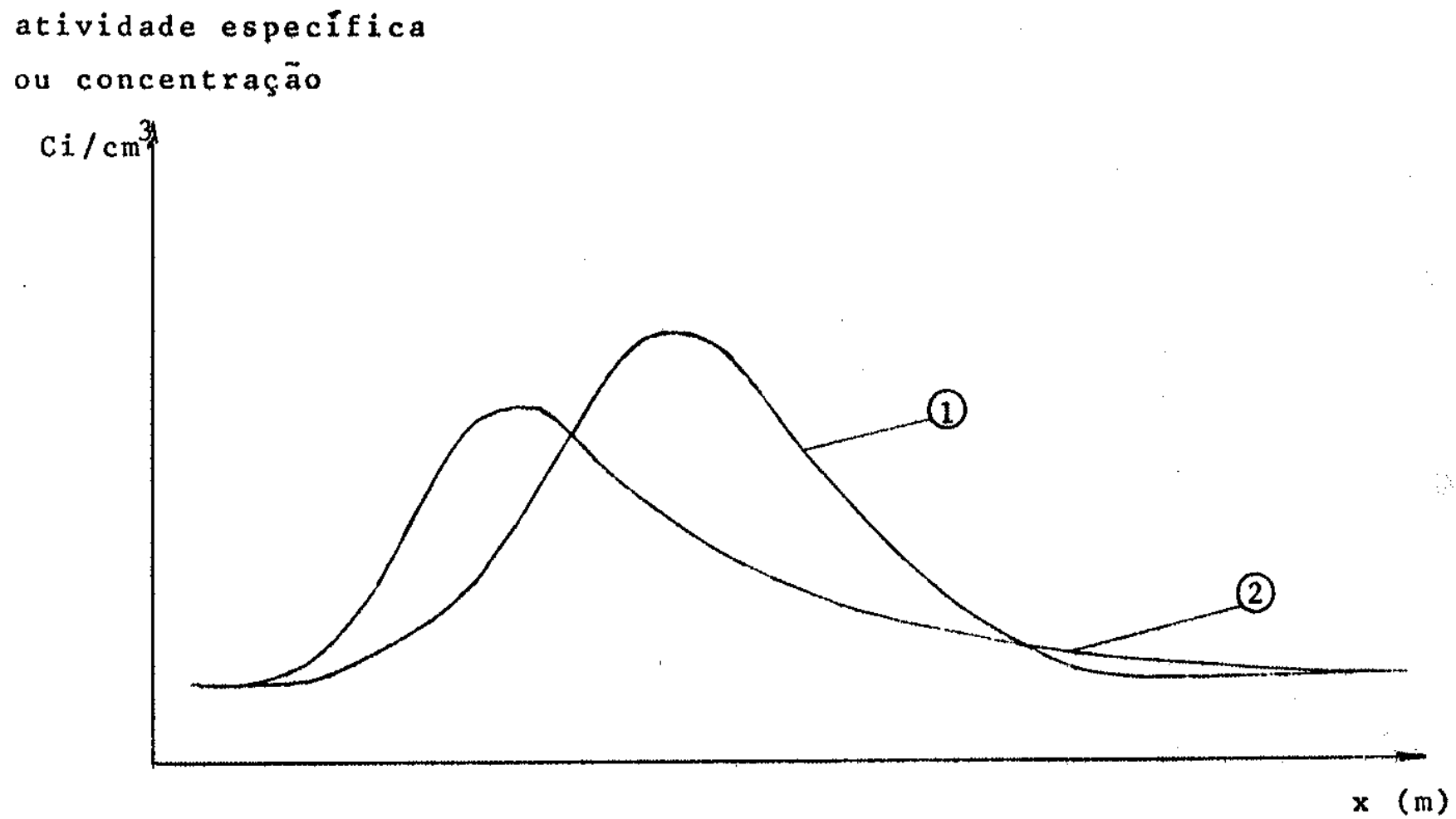

FIGURA 5 - Concentração do traçador em uma seção qualquer, à jusante do ponto de injeção, com injeção instantânea.

(1) - movimento turbulento

(2) - movimento laminar 
mesmas condições que existiam antes da injeção (figura 6).

\section{III.5 METODOS RADIOTSOTÓPICOS}

\section{III.5.1 METODO DOS DOIS PICOS}

Este método, só ê aplicảvel em condutos de seção ou perimetro molhado conhecido. Consiste em injetar o traçador, em forma instantânea e puntiforme, em uma seção do conduto, e medir sua passagem a jusante, com dois detetores, que podem estar submersos ou nas imediações da tubulação ou leito (figu ra 7$)$.

Para reduzir o êrro, é conveniente que a distân cia entre o ponto de injeção e o primeiro detetor seja superior à distância mínima de homogeneização. A distância entre os detetores deve ser superior à distância de interfe rência dos dois picos, que ê função da dispersão longitudinal do traçador (figura 8 ).

A vazão $Q\left(\mathrm{~m}^{3} / \mathrm{s}\right)$ de acordo com a definição $\bar{e}$ dada por:

$$
Q=\iint_{S} V_{d} S=V_{m} S, \quad \text { onde }
$$

$V$ é a velocidade instantánea

$S$ é a seção de medição

Quando a distância entre detetores $(\Delta I)$ for cons tante, a velocidade média $V_{m}$ é calculada por

$$
V_{m}=\frac{\Delta 1}{n} \Sigma_{i}\left(\frac{1}{\Delta t}\right)_{i}=\Delta 1\left(\frac{1}{\Delta t}\right)_{m} \text {, onde }
$$

n ê o nümero de partículas em movimento. 


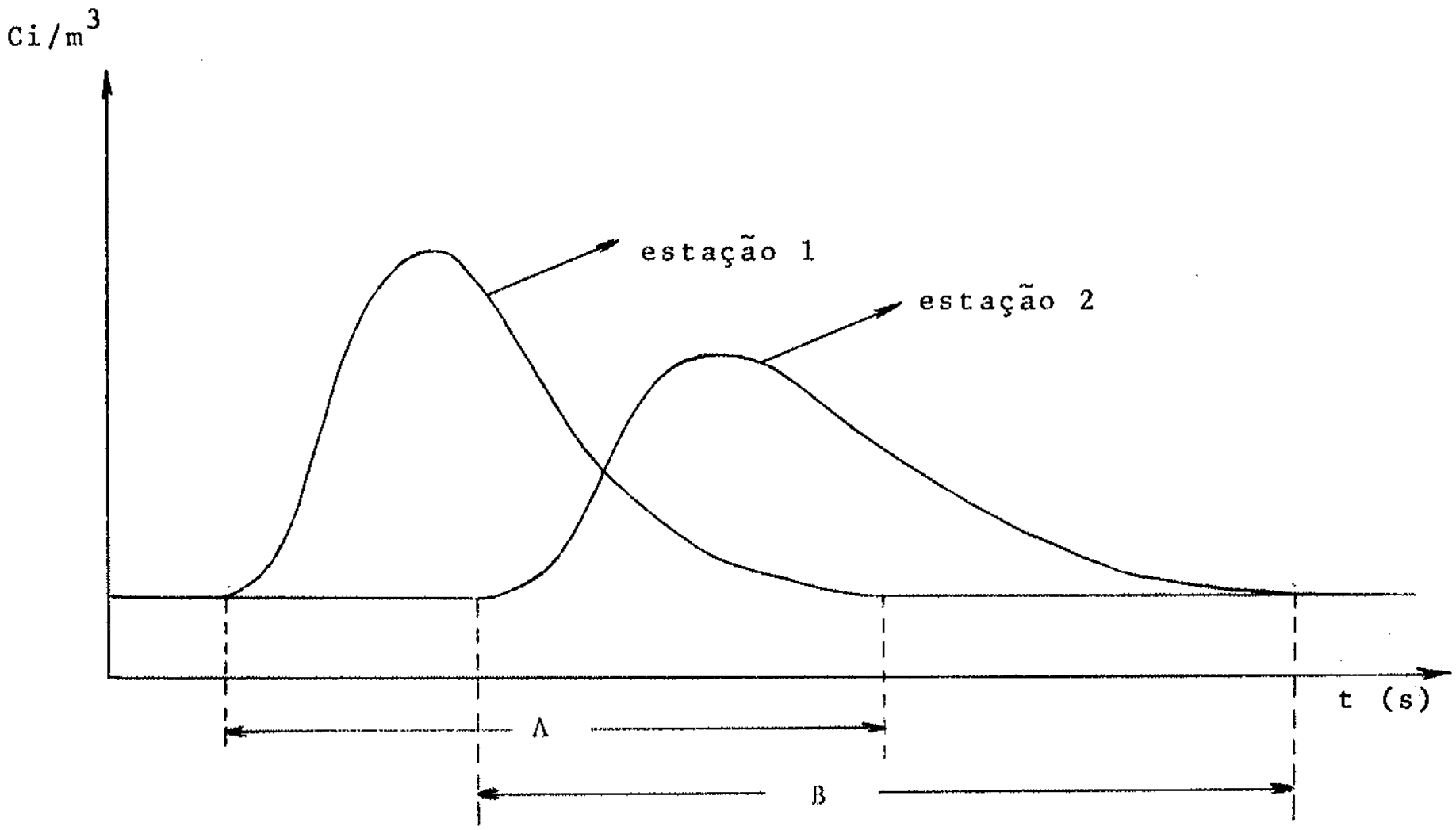

FIGURA 6 - Intervalo de tempo necessärio para a medição de toda a onda radioativa, sendo $\Lambda$ o intervalo necessärio pa ra a medição na estação 1 (mais próxima ao ponto de injeção da solução traçadora) e $B$ o intervalo necessário para a estação 2 , situada à jusante da anterior 
Observa-se pela figura 9 que a velocidade do centro de gravidade da nuvem radioativa $\left(V_{g}\right)$, é representada pe la relação entre a vazão medida ( $Q$ medida) e a seção (S):

$$
Q \text { medido }=V_{g} S=\Delta 1\left(\frac{1}{\Delta t m}\right) S
$$

Por outro lado, a vazão medida será igual à vazão real quando

$$
\mathrm{v}_{\mathrm{g}}=\mathrm{v}_{\mathrm{m}} \therefore \frac{1}{\Delta \mathrm{tm}}=\frac{1}{\Delta \mathrm{t}}
$$

Quando o movimento for turbulento pode-se dizer que, a velocidade do centro de gravidade da "nuvem radioativa" é praticamente igual à velocidade mëdia das particulas:

$$
\mathrm{V}_{\mathrm{g}}=\mathrm{V}_{\mathrm{m}} ; 1<\mathrm{V}_{\mathrm{g}} / \mathrm{V}_{\mathrm{m}}<1,05
$$

A medida que o movimento se aproxima do regime lami nar, ou que a dispersão longitudinal aumenta, a relação ante rior também aumenta.

0 mëtodo deve ser aplicado nas seguintes condições:

- a vazão não deve variar durante o período de medi da, isto é, entre a injeção e a passagem do traça dor pelo segundo detetor;

- a seção deve ser constante entre os dois pontos de deteção da radiação;

- a radiação natural de fundo (background) não deve variar durante o período de medição;

- não houver ganho ou perda de vazão entre as seções de medição. 

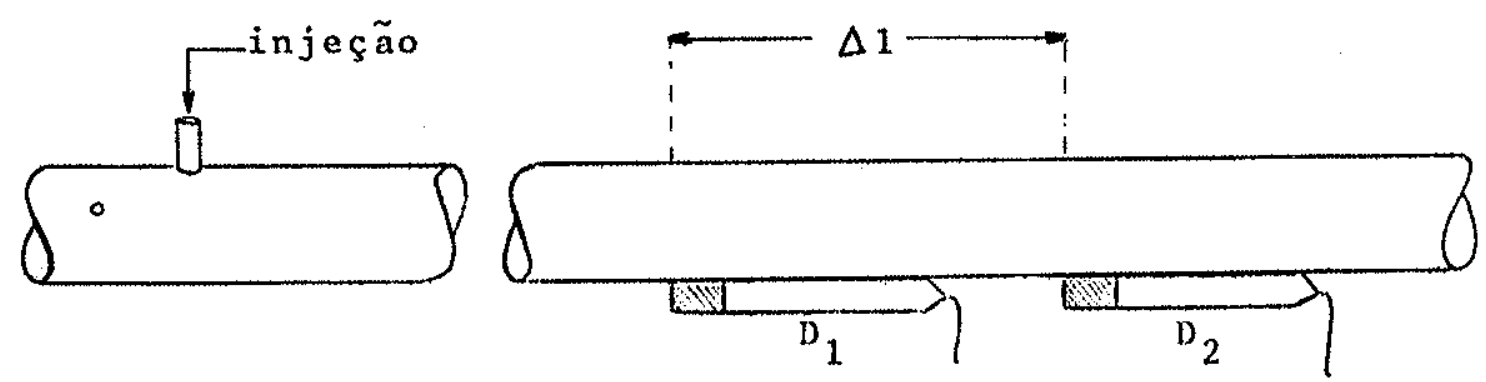

FIGURA 7 - Disposição dos detetores $\left(\mathrm{D}_{1}\right.$ e $\left.\mathrm{D}_{2}\right)$ no local de medição para cálculo da vazão pelo método dos Dois Picos.

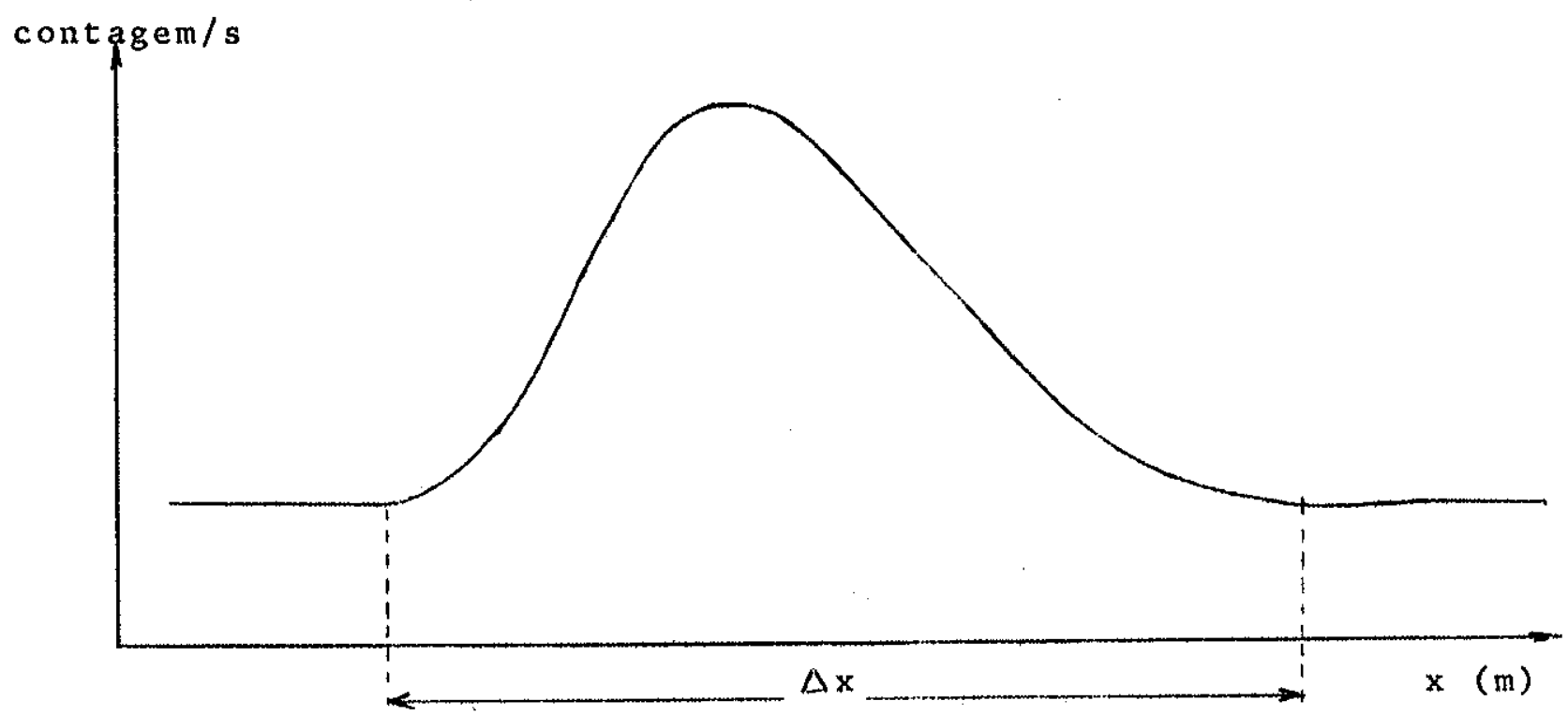

FIGURA 8 - Dispersäo longitudinal a nuvern radioativa $(\Delta x)$.

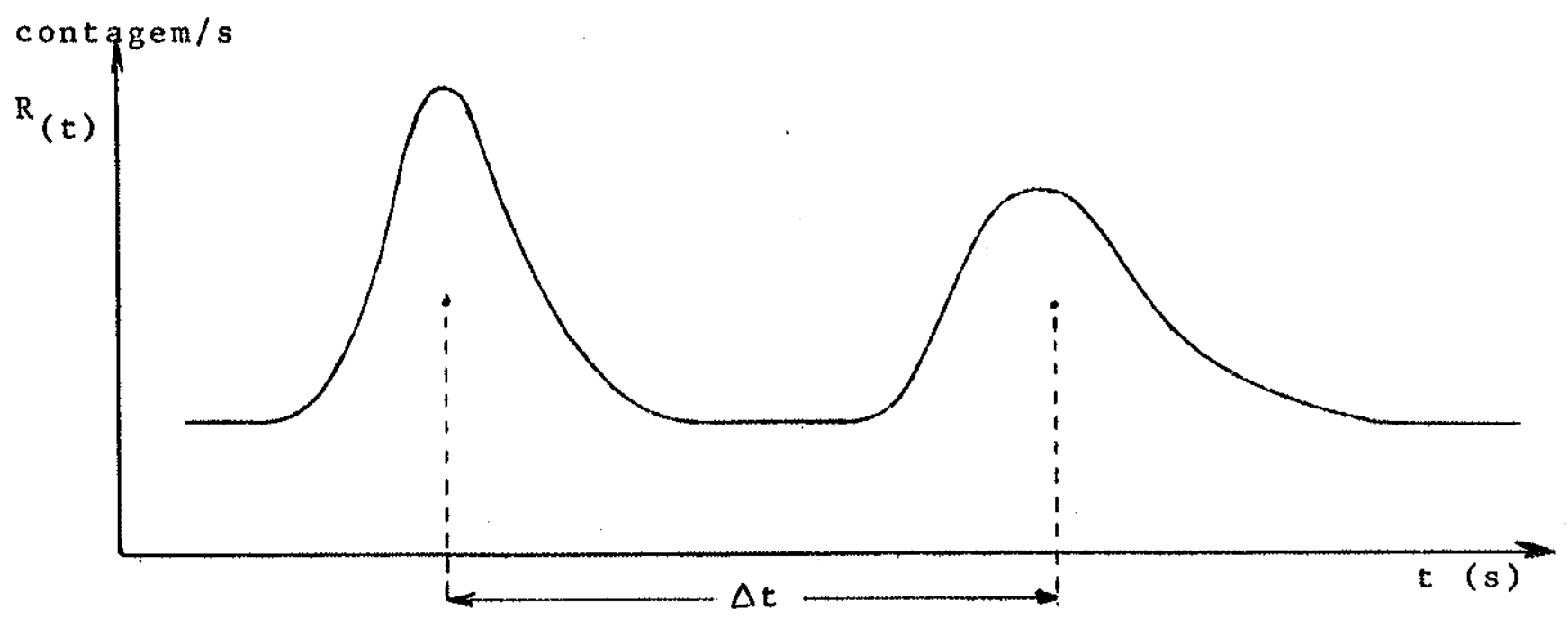

FIGURA 9 - Tempo decorrido entre os baricentros das curvas para cälculo da vazão utilizando o método dos Dois Picos. 
o melhor instrumental para medir vazões com este mé todo consta de dois detetores, fontes de tensão, integrador e registrador gräfico.

Em virtude do cãlculo do tempo de medição entre os baricentros das duas curvas registradas graficamente, com base na distância existente entre eles, ê aconselhâvel verifi car se a velocidade nominal do registrador corresponde à real.

$$
Q_{\text {medido }}=V_{g} S=\Delta 1\left(\frac{1}{\Delta t g} S\right.
$$

A velocidade do papel do registrador é dada por

$$
\mathrm{V}_{\text {papel }}=\Delta \mathrm{tg} / \Delta 1 \mathrm{~g} \therefore \Delta \mathrm{tg}=\Delta 1 \mathrm{~g} / \mathrm{V}_{\text {papel }}
$$

substituindo (19) em (18), temos:

$$
\mathrm{Q}_{\text {medido }}\left(\mathrm{m}^{3} / \mathrm{s}\right)=\frac{\Delta 1}{\Delta 1 \mathrm{~g} / \mathrm{V}_{\text {pape }}} \mathrm{s} \text {, onde }
$$

$\Delta 1$ è a distância entre os detetores (m)

$\Delta \lg$ é a distância entre os baricentros das cur vas no papel registrador gräfico $(\mathrm{cm})$.

$V_{\text {papel }}$ é a velocidade do papel registrador gräfico $(\mathrm{cm} / \mathrm{s})$.

$S$ è a seção da tubulação entre os pontos de medi ção $\left(m^{2}\right)$.

Entre as têcnicas radioisotópicas este mêtodo è con siderado pouco preciso porque, o que realmente medimos é a ve locidade e não vazão. 
IIT.5.2 METODO DA CONTAGEM TOTAL

Este mêtodo foi desenvolvido por D. E. Hull (1957), e seu uso jâ foi adaptado para medições de vazão de gases ou 1 iquidos em tubulações, canalizações e rios. Ele ë particu larmente ütil na medição de vazão de rios turbulentos ou com grandes caudais, já que a atividade injetada em cada medi ção é relativamente pequena.

A tëcnica consiste em um lançamento instantâneo e puntiforme de traçador radioativo com atividade conhecida. Em uma seção, à jusante da de lançamento mede-se a variação da concentração do traçador, durante sua passagem pela seção de deteção (figura 10).

Sendo a vazão $Q$ constante (regime permanente), a concentração na seção de medição varia somente em função do tempo de passagem da nuvem radioativa.

As vantagens deste mëtodo em relação ao método dos "Dois Picos" são:

1. não se necessita conhecer a seção do escoamento a medir;

2. a aparelhagem de medição ê mais simples;

3. mede-se realmente a vazão e não velocidade.

Admitindo-se que as respostas do detetor $\mathrm{R}_{t}$ (contagem/s), ê linear com respeito à concentração $C_{t}\left(\mu \mathrm{Ci} / \mathrm{m}^{3}\right)$, tem-se:

$$
\mathrm{R}_{t}(\text { contagem } / \mathrm{s})=\mathrm{F}\left(\frac{\text { contagem } / \mathrm{s}}{\mu \mathrm{Ci} / \mathrm{m}^{3}}\right) \mathrm{C}_{t}\left(\mu \mathrm{Ci} / \mathrm{m}^{3}\right)
$$


A contagem total na seção de medição durante a passagem da nuvem radioativa será (figura 10 )

$$
N=\int_{t_{(a)}}^{t}(b) R_{t} d t \therefore N=F \delta_{t_{(a)}}^{t}(b) C_{t} d t
$$

onde $N$ e a contagem total da radioatividade entre os instantes ${ }^{t}(a)$ e ${ }^{t}(b)$.

$$
0 \text { valor } F \frac{(\text { contagem } / \mathrm{s})}{\mathrm{Ci} / \mathrm{m}^{3}} \ddot{e} \text { denominado constante }
$$

de calibração e, como será visto, depende das características do detetor, geometria de deteção e radioisótopo utilizado. Por definição a vazão $Q\left(\mathrm{~m}^{3} / \mathrm{s}\right)$ constante durante a experiência, è definida por:

$$
Q=d v / d t \therefore d t=d v / Q
$$

Substituindo (23) em (22)

$$
N=F / Q \cdot \int_{t_{(a)}}^{t}(b) C(t) d V
$$

A integral da expressão (24) e a atividade $\mathrm{A}(\mu \mathrm{C} i)$, injetada no escoamento

$$
\int_{t(a)}^{t} C_{(t)} d V=A
$$

onde dV è o volume elementar do meio homogêneo e isotrôpico marcado, que $\vec{e}$ exposto ao detetor.

A contagem total registrada entre $t_{(a)} e^{t}{ }_{(b)}$ 
representada por:

$$
N=F \cdot A / Q \quad \therefore Q=F A / N
$$

Este desenvolvimento sỏ $\vec{e}$ vảilido se:

1. a atividade A injetada chegar ao ponto de medição sem perdas no caminho, por absorsão, troca iônica, etc.;

2. a concentração $C_{(t)}$ (atividade por unidade de volume) em um instante dado, for a mesma em qualquer ponto da seção de medição. Se a distância entre o ponto de injeção e o de medição supe rar a distância mínima de homogeneização, a condição

$$
\int_{(a)}^{t(b)} C_{(t)} d t=\text { constante }
$$

serä cumprida;

3. a constante $F$ for determinada nas mesmas condições das medições "in situ";

4. a constante $F$ e a medição de vazão são determina das em um intervalo onde $\vec{e}$ inear a resposta do detetor $R_{(t)}$, com respeito a concentração $C_{(t)}$;

5. a radiação natural de fundo (background) no pon to de deteção não variar durante o período de me dição; 
6. a meia vida do radioisôtopo for compativel com o tempo gasto na experiência. Quando ê usado isóto po de meia vida curta, a contagem obtida deve ser corrigida para o mesmo instante em que se medir o fator de calibração;

7. o tempo ou intervalo de contagem $\left(t_{(a)}{ }^{-t}(b)\right)$ for superior ao tempo de passagem da nuvem ra dioativa.

O valor de $N$, na equação (26), refere-se à contagem líquida, ou seja, só considera a radioatividade prove niente da nuvem radicativa. Significa que da contagem total deve se subtrair a contagem proveniente da radiação natural de fundo $\mathrm{N}_{\mathrm{F}}$, acumulada durante o tempo de medição.

0 método também é valido para qualquer tipo de ind cador, bastando para isto substituirmos na equação (25) a atividade A pela massa $M$ do novo traçador e a concentração $C_{(t)}$ referir-se a esta massa. Portanto

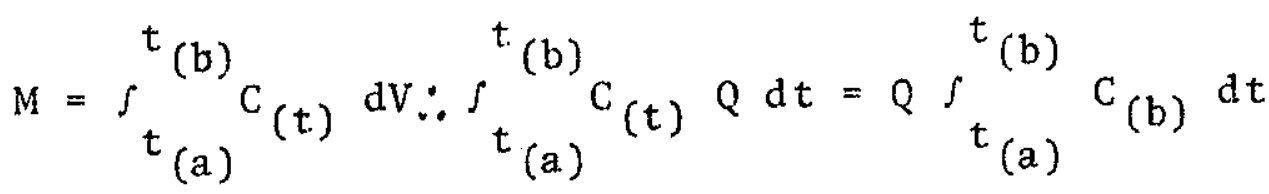

$$
\begin{aligned}
& Q=M / \int_{t}^{t}(b) \quad C(t) d t
\end{aligned}
$$


III. 5.2.1 VARIANTES DO METODO

0 método da Contagem Total é indicado para medir per das de diversos fluidos e sölidos. A deteção da atividade pode ser continua (sonda submersa, semisubmersa ou encostada nas tubulaçōes) ou descontínua, por extração de amostras periodica mente.

Quando a altura d'ägua na seção de medição é inferior a $7 X^{\prime} 1 / 2{ }^{\prime}$, nos casos em que o rio arrasta pedras ou seixos ou ainda se o regime for de altissima turbulencia $\vec{e}$ aconselhävel não introduzir o detetor no escoamento. Nes tas condiçōes extrai-se durante o periodo de medição, uma vazão $Q$ ' constante, fazendo-a passar por um recipiente "ad-hoc", no centro do qual se coloca o detetor. Neste caso, a cons tante de calibração deve ser determinada no mesmo recipiente, para que a geometria seja idêntica.

Quando a medição se realiza com extração periódica de amostras, deve-se levar em conta que

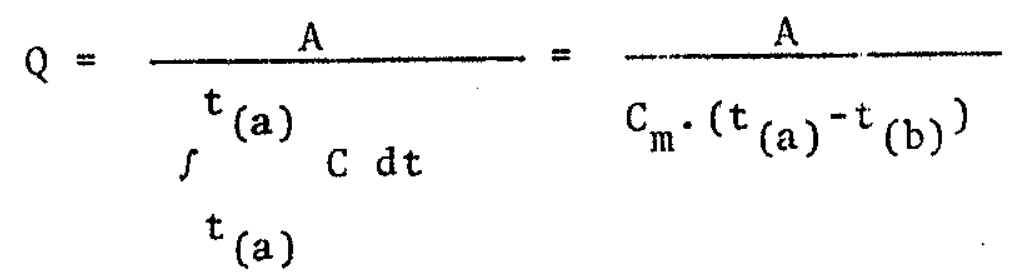

Este método permite calcular a concentração durante. um periodo maior ou igual a $\left(t_{(a)}-t_{(b)}\right)$, e assim me1horar a estatistica de contagem.

Guizerix e outros (1962) preconizaram o uso de uma variante deste método de amostragem, que consiste em recolher da corrente principal uma vazão constante $Q^{\prime}$, e armazenā-1a em um recipiente para depois medir a concentração mëdia.

$$
Q / Q^{\prime}=A / a \quad \text { e } \quad a / A_{c}=N / n_{c} \cdot t
$$

onde 
Q' è a vazão constante desviada para o recipiente de medição $\left(\mathrm{m}^{3} / \mathrm{s}\right)$

a $\vec{e}$ a atividade desviada da corrente principal ( $\mu \mathrm{C} i$ )

e armazenada no recipiente.

$A_{c} \vec{e}$ a atividade usada na calibração ( $\mu$ Ci $)$

$n_{c}$ é a atividade medida na calibração (contagem/s)

t $\vec{e}$ o tempo de contagem da atividade recolhida no rio (s)

A vazão é calculada a partir da equação

$$
Q=Q^{\prime} A / \mathrm{Q}
$$

ou substituindo (29) em (30), temos

$$
Q=\frac{A \cdot n_{C} \cdot Q^{\prime} t}{A_{C} \cdot N}
$$

A atividade A a ser injetada é calculada pela equação $(30)$.

Fixa-se, a priori, o valor $Q^{\prime}$ em função do tempo esti mado de passagem da onda radioativa, ou por cálculo de acordo com a equação (31).

Fixando-se o volume do recipiente em 18 litros,tem-se:

$$
Q^{\prime}=18 / t_{(a)}-t_{(b)} \quad(1 j \operatorname{tros} / s)
$$

Escolhe-se este volume de 18 litros levando-se em conta transporte, portabilidade aos lugares de medição, etc. Sem dúvida, um volume ótimo para emissores gama de alta ener gia deve ser consideravelmente maior se quisermos medir. 
com volume "infinito".

Estes mêtodos de amostragem continuos ou descontinuos tem a vantagem de permitir uma contagem total $\mathrm{N}$, tal que o êrro estatístico fique reduzido a uma expressão mínima. Por outro 1ado, pode-se tomar amostras em uma margem ou no cen tro da corrente principal permitindo reduzir o êro ou compro var a homogeneização do traçador com o meio estudado.

Este mëtodo é recomendāvel para medição de vazão utilizando o tritio como traçador.

\section{III.5.2.2 SISTEMAS DE INJECAO}

Pode se utilizar qualquer dispositivo que permita injetar a solução traçadora preferencialmente no centro da canalização, rio ou tubulação em tempo relativamente curto.

\section{III.5.2.3 CORRENTES DIVERGENTES}

A medição de vazão $Q$ de uma canalização, rio ou tubulação pode ser feita em efluente ou subsidiảrio, sempre que a distância entre o ponto de injeção e o ponto de divergência seja superior ’a distância mínima de homogeneização (figura 11).

Se o subsidiário leva a fração xQ do caudal principal $Q$, tambēm levarä uma fração $x A$ da atividade injetada, e por isso tem-se

$$
N=X A \cdot F / X Q=A \cdot F / Q
$$

Significa que se pode medir a vazão no efluente do principa1, desde que seja cumprida a condição de homogeneidade antes da divergência.

Esta vantagem do método pode ser ütil nos casos de canalizações principais inacessíveis ou rios com margens de dificil acesso. 
contagem/s

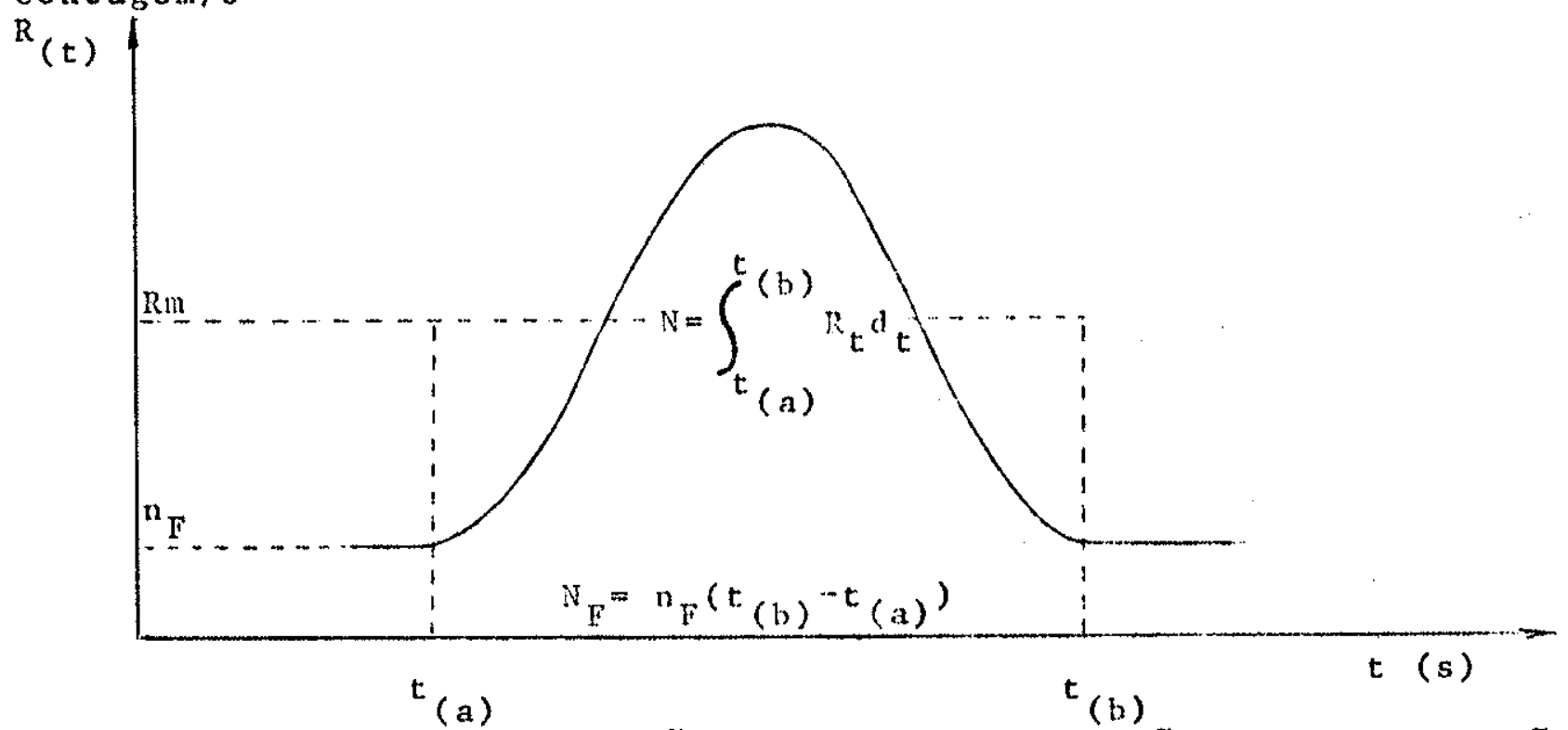

FIGURA 10 - Representação da curva de variação da ooncentração do traçador radioativo, em função do tempo no méto do da Contagem Total.
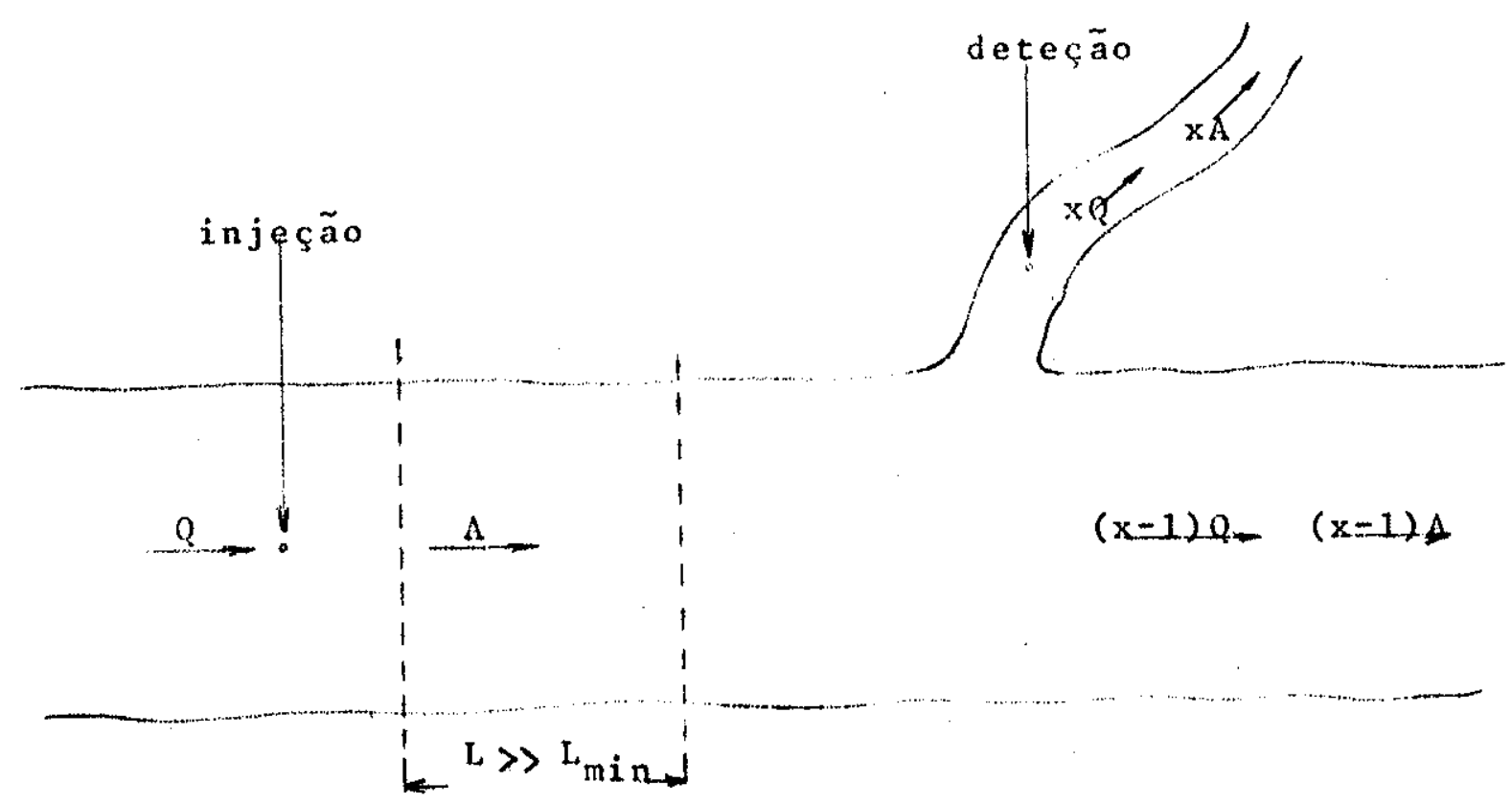

FIGURA 11 - Possibilidades de medição com correntes divergentes pelo método da contagem Total. 
III.5.2.4 CONSTANTE DE PROPORCIONALTDADE OU DE CALIBRACÃO

E a resposta $\mathrm{N}_{\mathrm{c}}$ (contagem/s), do detetor e instrumental associado, na presença de determinada concentração de traçador radioativo

$$
C=A_{c} / V_{c}\left(\mu C i / m^{3}\right) \therefore F=\frac{N_{c}}{A_{c} / V_{c}}\left(\frac{\text { contagem } / s}{\mu C i / m^{3}}\right)
$$

onde

$N_{c}$ é a resposta do detetor (contagom/s)

$A_{c} \vec{e}$ a atividade usada na calibraçño ( $\left.\mu \mathrm{C} i\right)$

$\mathrm{V}_{\mathrm{c}}$ è o volume do recipiente de calibração $\left(\mathrm{m}^{3}\right)$

Ela também é dependente do instrumental de medição, do radioisótopo utilizado e da geometria de deteção; daí a necessidade de determinä-la en condições similares às de me dição "in situ".

Quando o detetor estiver submerso no rio e o volume de água que o rodeia for superior ao volume sensivel de dete ção, a calibração deverâ ser realizada em um recipiente com dimensões maiores ou iguais a de uma esfera com raio superior a sete vezes o valor de $x_{1 / 2}^{\prime}$, onde

$$
X_{1 / 2}^{\prime}=1 / \mu 0_{1} ; \quad X_{\infty}^{\prime}>7 X_{1 / 2}^{\prime}
$$

sendo $\mu o_{1}$ o coeficiente de atenuação linear em ägua $\left(\mathrm{cm}^{-1}\right)$. Para a maioria dos radioisótopos usados em hidrologia determinaram-se valores de $X_{1 / 2}^{\prime}$, os quais estão na tabe Ia I.

Quando se trata de medir vazões em tubulações com detetor enconstado à sua superfície, determina-se a constan te de calibração utilizando-se um pedaço da tubulação convenientemente escolhido, de maneira que o "volume visto" pe1o detetor seja similar ao real. 
Neste tipo de calibração estātica é importante co nhecer a atividade e o volume marcado com boa precisão, jä que o êrro se propagarâ nas medições de vazão. E aconselhavel utilizar na calibração uma aliquota da atividade injetada no escoamento, para compensar os possíveis êrros de determinação da atividade absoluta. No caso de se usar uma aliquota ( $f$ ) da atividade injetada teremos pela expressão (34).

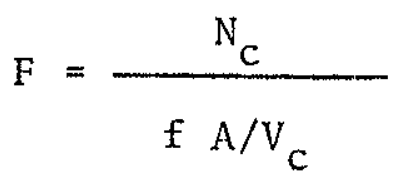

$$
\left(-\frac{\text { contagem } / \mathrm{s}}{\mu \mathrm{Ci} / \mathrm{m}^{3}}\right)
$$

substituindo (34) em (26)

$$
Q=N_{c} / f \cdot A \cdot A / N \cdot V_{c}=N_{c} \cdot V_{c} / f \cdot N
$$

Assim se reduzem os êrros, jă que as atividades A e $A_{C}$ provêm de dois fracionamentos distintos, nos quais $\vec{e}$ possivel esperar, em alguns casos, êrros de $\pm 5 \%$. A propagação desses êrros na expressão (36) afetaria consideravelmen te a precisão com que é medida a vazão $Q$. Ao conträrio, sé usarmos uma alíquota, a calibração de atividade não infiui e somente os êrros de medição de volumes e massas devem ser considerados.

E preciso notar que a ordem de magnitude de $A$ com respeito a $A_{C}$ difere de um fator quatro a cinco vezes, para uma vazão da ordem de $20 \mathrm{~m}^{3} / \mathrm{s}$.

A calibração estätica poderā ser substituida por uma calibração dinâmica nos casos em que se conhece a vazão com suficiente precisão, utilizando-se a expressão (26)

$$
Q=F \cdot A \cdot / N \quad \therefore \quad F=Q \cdot N / A
$$


A constante de proporcionalidade $F$, assim determina da, pode ser usada na medição de outros caudais, sempre que o detetor, instrumental associado, radioisótopo e geometria de medição sejam as mesmas.

ITI. 5.2.5. CALCULO DA ATIVIDADE A INJETAR

Esta variâvel ë determinada geralmente em bases semiempiricas, levando-se em conta os seguintes fatôres:

1. precisão requerida na medição do parâmetro inve tigado;

2. diluição estimada do traçador no ponto de observação;

3. eficiência de deteção;

4. tempo disponivel para as medições.

E sabido que tôdas as medições de radioatividade são inevitavelmente acompanhadas de uma imprecisão devida a natureza estatística do processo radioativo.

A contagem líquida total registrada $(N)$, depende da atividade injetada, da vazão e da constante de calibração, de acôrdo com a equação

$$
N=F \cdot A / Q
$$

o desvio padrão relativo $\delta_{N} / N$ e representado por

$$
\delta_{N} / N=1 / N \cdot \sqrt{\left(N+N_{f}\right)+N_{f}}=1 / N \cdot \sqrt{N+2 N_{f}}
$$




$$
100 \delta_{N} / N=\sqrt{N / N^{2}+2 N_{f} / N^{2}}=P\left(\frac{0}{b}\right)
$$

sendo $P$ a precisão porcentual que se obtem na medição da vazão. Substituindo (38) em (39) tem-se:

$$
\begin{gathered}
\delta_{N} / N=\sqrt{Q / F A+2 N_{f} \cdot t \cdot Q^{2} / F^{2} A^{2}}=P / 100 \\
P^{2} / 100^{2}=Q / F A+2 N_{f} \cdot t \cdot Q^{2} / F^{2} A^{2}
\end{gathered}
$$

multiplicando-se a expressão (40) por $A^{2}$ e igualando a zero, vem

$$
\mathrm{p}^{2} \mathrm{~A}^{2} / 100^{2}-\mathrm{QA} / \mathrm{F}-2 \mathrm{~N}_{\mathrm{f}} \cdot \mathrm{t} \cdot \mathrm{Q}^{2} / \mathrm{F}^{2}=0
$$

A solução desta equação de segundo grau em A é:

$$
\begin{aligned}
& \frac{Q / F \pm \sqrt{Q^{2} / F^{2}+8 P^{2} / 100^{2} \cdot N_{f} \cdot t \cdot Q^{2} / F^{2}}}{2 P^{2} / 100^{2}}=\frac{Q / F+Q / F \sqrt{1+8 P^{2} / 100^{2} \cdot N_{f} \cdot t}}{2 P^{2} / 100^{2}} \\
& A=Q / F\left(\frac{100^{2 \pm} \pm 100^{2}}{2 \mathrm{p}^{2} \frac{100^{2}}{\sqrt{100^{2}+8 \mathrm{p}^{2} \mathrm{~N}_{f t}}}}\right)=\left(\frac{100^{2} \pm 100 \sqrt{100^{2}+8 \mathrm{PN}_{f} t}}{2 \mathrm{p}^{2}}\right) \cdot \mathrm{Q} / \mathrm{F}
\end{aligned}
$$


onde
$A$ è a atividade a injetar ( $\mu \mathrm{C} j)$
$Q$ é a vazão estimada $\left(\mathrm{m}^{3} / \mathrm{s}\right)$
F è a constante de calibraçäo
$N_{f} \vec{e}$ a contagem de fundo (contagen/s)
p é a precisão desejada, tendo em conta o êrro esta tistico
$t \vec{e}$ o tempo de contagem, maior ou igual ao tempo de passagem da nuvem radioativa (s).

Por ûltimo temos que a atividade a injetar em uma medição de vazão pelo mëtodo da contagem total deve ser igual ou maior que $A_{m i n}(\mu \mathrm{Ci})$, para obtermos um êrro estatístico relativamente menor que $p\left(\begin{array}{l}o \\ b\end{array}\right)$ :

$$
A_{\min }(\mu \mathrm{C} i) \geqslant Q / F\left(\frac{100^{2}+100 \sqrt{100^{2}+8 \mathrm{P}^{2} \mathrm{~N}_{\mathrm{f}} \cdot t}}{2 \mathrm{p}^{2}}\right)
$$

III.5.3 METODO DA INJECAO CONT INUA OU DA DILUICAOO

Este mêtodo ê mais uma variação da forma de aplicação dos conceitos do mëtodo anterior.

Ao se comparar a concentração $C_{1}$ do traçador injeta do com vazão $Q^{\prime}$ constante em um escoamento de vazão $Q$, com a concentração $C_{2}$ que se mede à jusante, (figura 12), temos:

$$
Q C_{0}+Q^{\prime} C_{1}=\left(Q+Q^{\prime}\right) C_{2}
$$

onde 
Q é a vazão que se deseja medir $\left(\mathrm{m}^{3} / \mathrm{s}\right)$

$C_{0}$ è a concentração residual do traçador que pode ria estar incorporada ao escoamento antes da injeção $\left(\mu \mathrm{Ci} / \mathrm{cm}^{3}\right)$

Q' è a vazão constante injetada $\left(\mathrm{m}^{3} / \mathrm{s}\right)$

$\mathrm{C}_{1}$ é a concentração do traçador injetado $\left(\mu \mathrm{Ci} / \mathrm{cm}^{3}\right)$

$\mathrm{C}_{2}$ e a concentração do traçador medido à jusante $\left(\mu \mathrm{Ci} / \mathrm{cm}^{3}\right)$

geralmente temos

$$
\begin{aligned}
& C_{0}=0 ; \quad C_{1} \gg C_{2} \quad \text { e } Q^{\prime} \ll Q \\
& Q^{\prime} C_{1}=Q C_{2} \therefore Q=Q^{\prime} C_{1} / C_{2} .
\end{aligned}
$$

Analogamente, se as concentrações foram medidas com o mesmo instrumental de deteção, radioisótopo, geometria e se a resposta do detetor, no intervalo de concentraçós assinalado, for linear, tem-se

$$
Q=Q^{\prime} R_{1} / R_{2}
$$

onde $R_{1}$ e $R_{2}$ são a resposta do instrumental de medição para $\mathrm{C}_{1}$ e $\mathrm{C}_{2}$ (contagem/s) (figura 13).

Este método tambêm é independente da velocidade e por conseguinte aplicảvel nos casos de seções desconhecidas.

Esta têcnica é vảlida quando os seguintes fatôres forem cumpridos:

1. não existir perdas de traçador por absorção,precipitação, etc., entre o ponto de injeção e o de medição;

2. a concentração $C_{2}$ na seção de medição for 


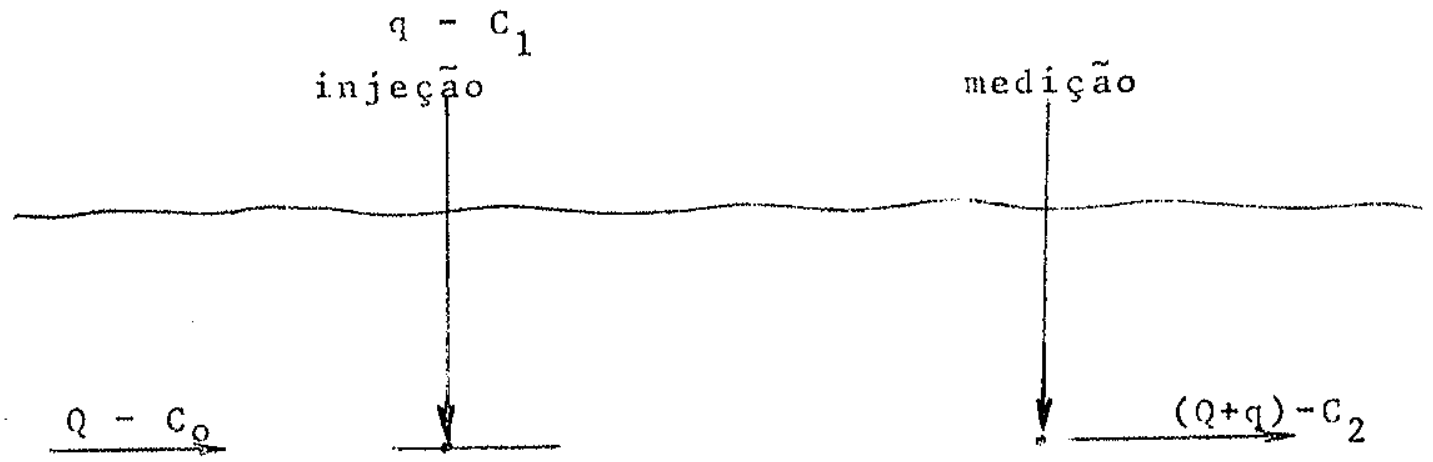

FIgURA 12 - Representação esquemätica do método da Diluição ou da Injeção contínar.

contagem/s

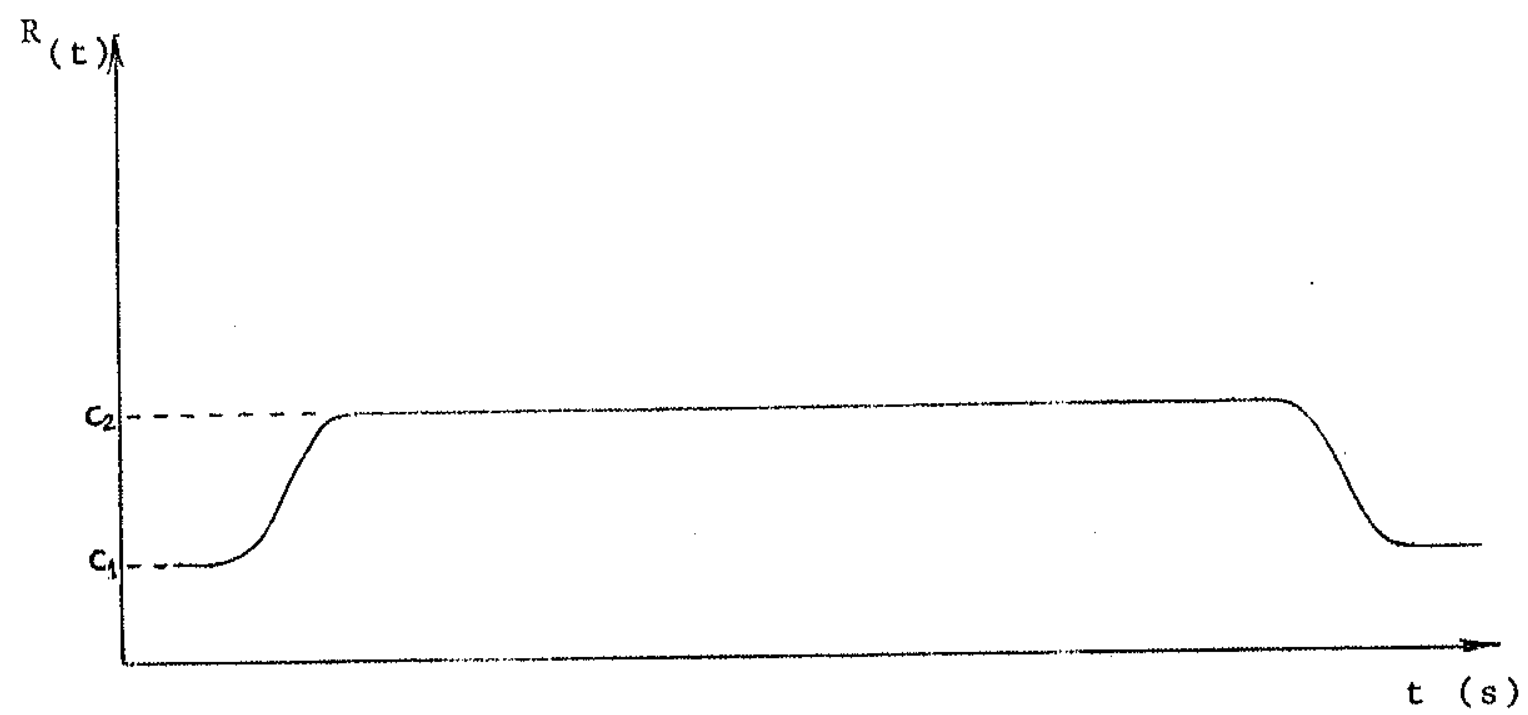

FIGURA 13 - Variação da concentração da solução radioativa em funçäo do tempo de contagem no mëtodo da Injeção Contínua ou da Diluição. 
constante. Isto quer dizer que foi alcançada a linearidade na curva $C=f(t)$ (figura 13);

3. a radiação natural de fundo (background) não variar durante a experiência;

4. regime permanente.

\section{III.5.3.1 CALCULO DA ATIVIDADE A INJETAR}

Analogamente, a atividade mínima a injetar é calculada de forma similar ao método da Contagem Tota 1

$A_{\min } \gg Q^{\prime} C_{1}(\mu \mathrm{Ci} / \mathrm{s})=Q / F\left(\frac{100^{2}+100 \sqrt{100^{2}+8 \mathrm{P}^{2} \mathrm{~N}_{f} t}}{2 \mathrm{p}^{2}}\right)$

onde

$Q^{\prime} \vec{e}$ a vazäo constante injetada $\left(\mathrm{m}^{3} / \mathrm{s}\right)$

$C_{1}$ é a concentração injetada $\left(\mu \mathrm{Ci} / \mathrm{m}^{3}\right)$

$t e ́$ o tempo de contagem (com integrador $t=2 R C$ )

$N_{f}$ é a atividade natural de fundo (contagem/s)

P ê a precisão desejada

\section{6 COMPARACAO ENTRE OS METODOS DESCRITOS}

0 mëtodo denominado de "dois picos" requer o uso de duas sondas detetoras e o conhecimento da seção por onde escoa o fluido. No método da Contagem Total e da Diluição necessita-se um só detetor e não é preciso conbecer-se a seção 
de medição. Sem dûvida, estes dois ultimos necessitam de cali brações prêvias para as medições, em virtude das comparações entre as concentrações injetadas e detetadas no ponto de medição (figura 14).

As sondas detetoras usadas em campanhas de medição de vazões pelo método de Diluição ou da Contagem Total são simples, pois constam de escalimetro, uma fonte de tensão e um registrador gráfico. O mesmo pode-se dizer do sistema de injeção do traçador, ainda que para injetar uma solução com vazão constante durante certo tempo (método de Diluição) o sistema mecânico seja mais complexo e dificil de operar com condições geogräficas e metereolögicas desfavoräveis.

No método da Diluição, caso $Q^{\prime}$ e $Q$ sejam constan tes, o êrro relativo é dado por

$$
\Delta Q / Q=\sqrt{\left(\Delta C_{1} / C_{1}\right)^{2}+\left(\Delta C_{2} / C_{2}\right)^{2}}
$$

No mëtodo da Contagem Total utilizando-se dete tor submerso no escoamento, o desvio padrão será calculado como segue:

$$
\delta_{1}=\left(\delta_{t(a)}^{t(b)} R_{(t)} d t\right)^{1 / 2}
$$

Ao conträrio, tomando amostras contínuas ou periódi cas que depois são armazenadas, homogeneizadas e contadas, o desvio padrão será calculado pela equação

$$
\delta_{2}=\left[R_{m}\left(t(b)-t_{(a)}\right)\right]^{1 / 2}
$$


contagem/s

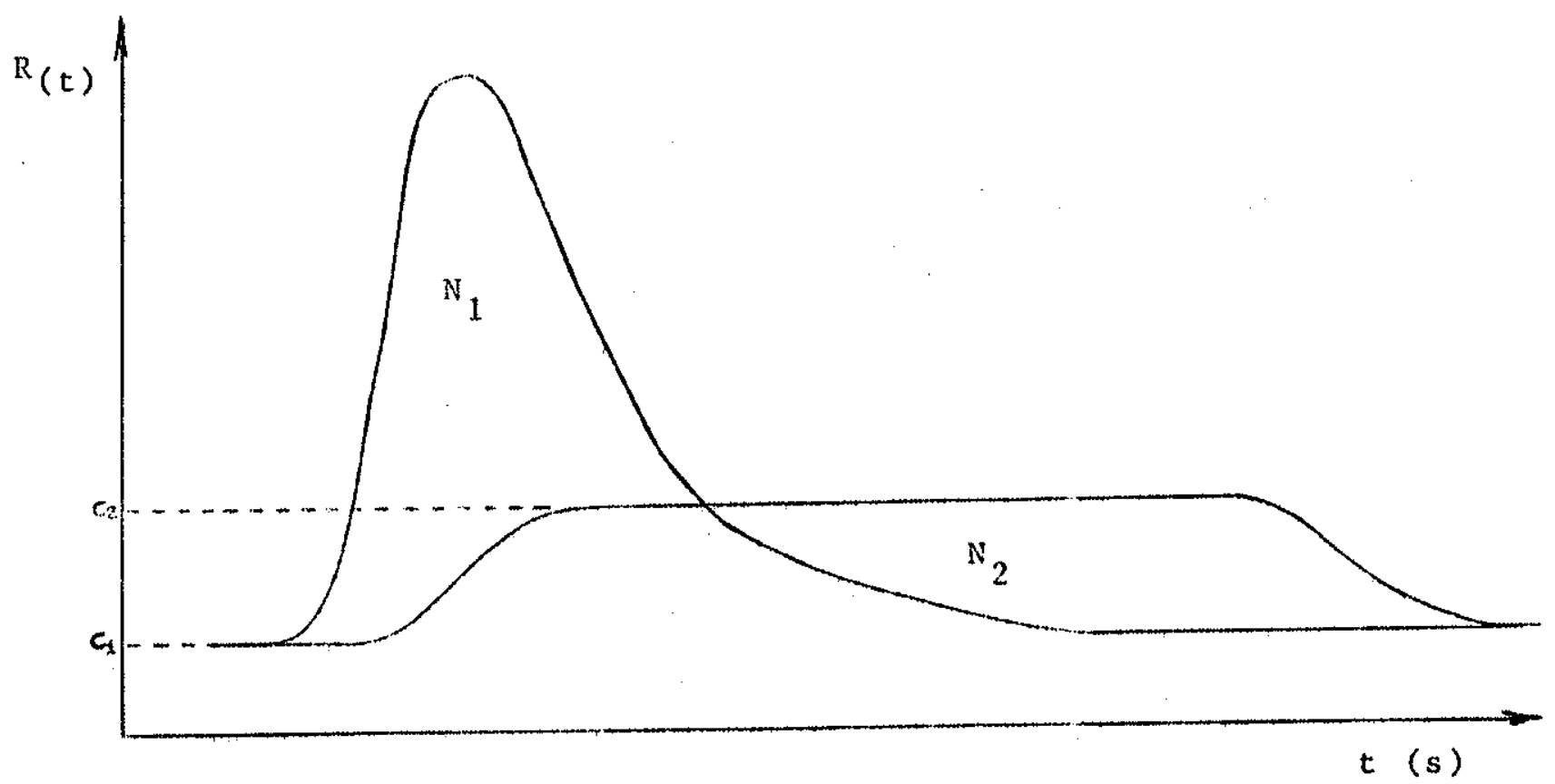

FIGURA 14 - Superposição das curvas de variação da concentração da solução radioativa em função do tempo de contagem, considerando o método da Contagen total $\left(\mathbb{N}_{1}\right)$ e método da Injeção Contínua $\left(\mathrm{N}_{2}\right)$. 
Supondo o mesmo tempo de contagem em (49) e (50), ob serva-se que para obter o mesmo desvio padrão em ambos os casos, necessita-se recolher um volume de água muito grande (fun ção do volume sensivel de deteção do detetor subnerso). 


\section{CAPITULO IV}

\section{: PARTE EXPERIMENTAL}

os mëtodos desenvolvidos no capitulo anterior, as sim como a teoria exposta neste trabalho, foram experimentalmente comprovadas em laboratório e no campo.

Nas medições em tubulações utilizou-se o labo ratörio de hidräulica da D.A.R.E.I. (Djvisão de Aplicação de Radioisótopos na Engenharia e Industria); em canalizações o canal de saída do esgôto de Santos e São Vicente, na Praia Grande e em rios o Rio Pirajussara.

\section{IV.I. MEDIDAS DE VAZAO EM TUBULAÇOES}

Realizaram-se estas medidas utilizando-se o método da Contagem Total e dos Dois Picos, simultaneamente, para comparar o erro relativo e aproveitar ao máximo o traçador ra dioativo usado em cada ensaio.

\section{IV.1.1 METODO DA CONTAGEM TOTAL}

$$
\text { Utilizou-se o } 131 \text {, escolhido por suas caracte - }
$$
risticas apresentadas na tabela IV, e por permitir o uso de aliquotas da mesma solução durante todos os ensaios, facilitando a calibração do sistema detetor.

o conjunto experimental (figura 15) consistiu de:

- um reservatório de 1000 1itros; 


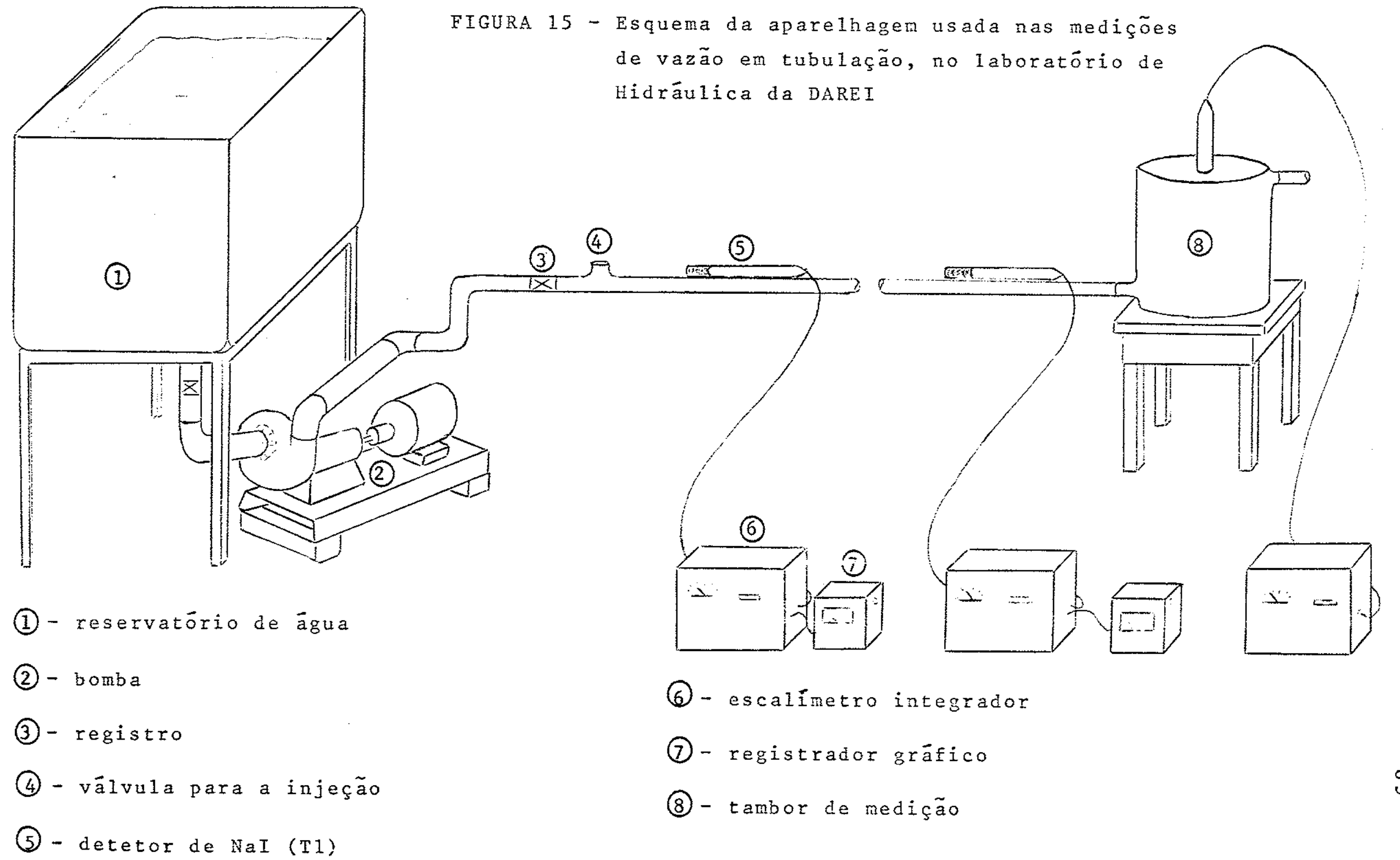


- uma bomba de $1 / 4 \mathrm{HP}$, com vazão mäxima de 100 $1 / \mathrm{min}$;

- 20 metros de cano de $5,08 \mathrm{~cm}$

- vảlvula com membrana de borracha, para permi tir a injeção (figura 16);

- seringa hipodêrmica graduada, por onde se injeta va a solução radioativa;

- tambor de medição com capacidade de 78,5 litros, em cujo centro geometrico foi colocado o detetor (figura 17);

- cintilador com cristal de NaI (T1) de $3,8 \mathrm{~cm}$ de diâmetro por $2,5 \mathrm{~cm}$ de altura;

- escalímetro e integrador BASC;

- registrador gráfico RUSTRAK.

A utilização da equação (26) exige o conhecimento da atividade absoluta, o que é difícil de ser obtido. Assim sendo optamos pela equação (36) modificada, a saber:

- retira-se uma fração $f$ da solução traçadora, a ser injetada no sistema (pode ser em peso ou em volume). Esta fração é diluida no tambor de medi ção, e apōs homogeneização medemse a contagem $\mathrm{N}_{c}$ (cpm) (calibração estätica).

o fator de calibração $F$ é representado pela equação (34)

$$
F=\frac{N_{c} \cdot V_{c}}{f \cdot A}
$$



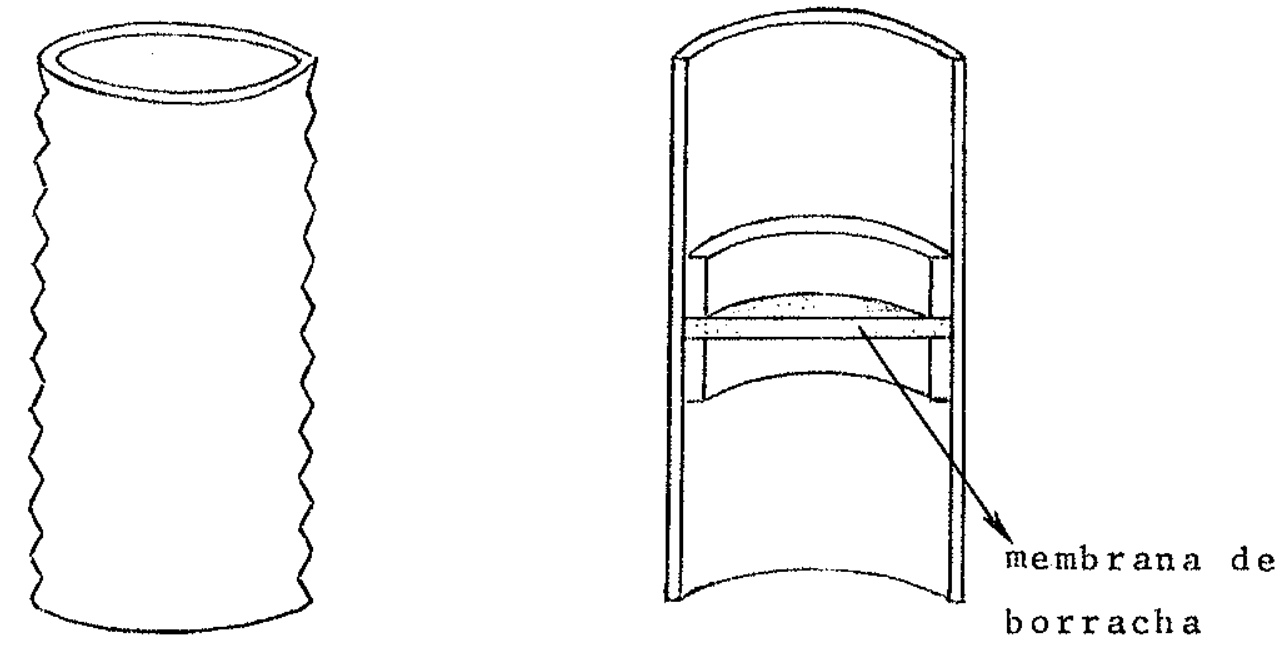

FIGURA 16 - Válvula para a injeção do traçador
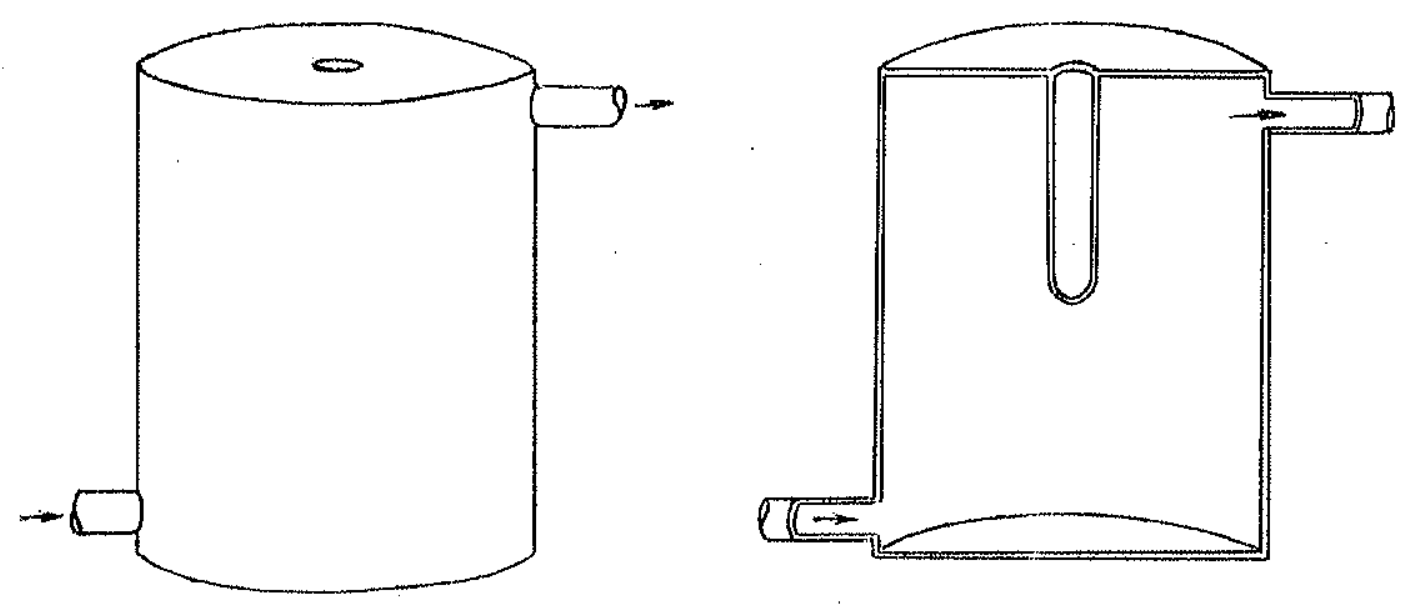

FIGURA 17 - Tambor de medição 
Substituindo $F$ na equação (26), tem-se:

$$
Q=\frac{F \cdot A}{N}=\frac{N_{C} \cdot V_{C} \cdot A}{f \cdot A \cdot N}=\frac{N_{C} \cdot V_{C}}{f \cdot N}
$$

Observa-se que a vazão volumétrica é representada somente em função da contagem de calibração $\left(N_{C}\right)$, do volume do tambor de medição $\left(V_{c}\right)$, da contagem total 1íquida acumu lada durante a medição (N) e da fração (f) da solução traçado ra utilizada nas medições e calibração.

Utilizou-se esta equação, na prätica, para evitar os erros sistemáticos, pois os volumes e pesos podem ser cuidadosamente medidos.

As quantidades de solução traçadora,utilizadas em cada ensaio, foram pesadas em balança analítica com precisão de atê $10^{-4}$ gramas.

Para o cálculo de F realizaram-se seis medições estáticas, para obtenção de um valor mêdio dos resultados (ta bela VI). Pesou-se certa fração da solução traçadora, que em seguida foi injetada no tambor de medição contendo volume conhecido de âgua. Introduziu-se um agitador mecânico no tambor para obtenção de uma homogeneização completa. Contou-se a solução radioativa por dez minutos e dai obteve-se a ativida de em contagens por minuto (cpm), da fração contida no volume do tambor. A seguir acrescentou-se nova fração de mate rial radioativo, e repetiu-se o procedimento anterior.

No total agregou-se tres (3) frações diferentes. Os resultados estão dispostos na tabela VI.

Ajustou-se a vazão por meio de um registro, para permitir a realização de um ensaio completo, sem que se esgotasse a água do reservatörio. Assim, o "background" medido antes e depois de cada experiência era sempre 0 mesmo. 
T A B E L A

CĀLCULO DE $F$ NA MEDIÇÃO DE VAZÃO EN TUBULAÇÕES

\begin{tabular}{|c|c|c|c|c|c|c|c|c|}
\hline $\begin{array}{c}\text { ENSAIO } \\
\text { NO }\end{array}$ & $\begin{array}{c}\Delta t \\
(\min )\end{array}$ & $\begin{array}{c}B G \\
(\text { contagem) }\end{array}$ & ${ }_{t_{(}}^{c}{ }_{(\text {contagem })}$ & ${ }^{C_{t_{\ell}}}{ }_{(\text {contagem })}$ & $\begin{array}{c}\text { PESO DA SOL. } \\
\text { (GRAMAS) }\end{array}$ & $e^{x}$ & ${ }^{C_{t}}{ }_{(\text {contagem })}$ & $\begin{array}{l}\mathrm{F} \\
(\mathrm{cp} \mathrm{m} / \mathrm{g} / \ell)\end{array}$ \\
\hline 1 & 750 & 25.012 & 135.885 & 110.873 & 7,2560 & 0,6274 & 176.718 & 1.911 .847 \\
\hline 2 & 760 & 25.720 & 136.639 & 110.919 & 7,2560 & 0,6270 & 176.830 & 1.913 .059 \\
\hline 3 & 790 & 24.952 & 190.450 & 165.498 & 10,8692 & 0,6259 & 264.416 & 1.909 .676 \\
\hline 4 & 800 & 25.676 & 191.129 & 165.453 & 10,8692 & 0,6255 & 264.513 & 1.910 .377 \\
\hline 5 & 820 & 25.957 & 249.857 & 223.890 & 14,7700 & 0,6247 & 358.396 & 1.904 .813 \\
\hline 6 & 830 & 25.360 & 248.925 & 223.565 & 14,7700 & 0,6244 & 358.047 & 1.902 .958 \\
\hline$F$ & & $R$ DE CALIB & $A C ̧ \tilde{A} O$ & & & & & $\tilde{E}=1.908 .738$ \\
\hline
\end{tabular}

$\Delta t=$ TEMPO TRANSCORRIDO ENTRE $t=0$ E O ENSAIO

$B G=$ "BACKGROUND" OU CONTAGEM DE FUNDO

$\mathrm{Ct}=$ CONTAGEM TOTAL (b=bruta, $\ell=1$ íquida e $c=$ corrigida)

$\mathrm{e}^{\mathrm{x}}=$ FATOR DE DECAIMENTO RADIOATIVO (para um $t=0$ ) 
Confirmou-se portanto que todo o traçador radioativo injetado passou pelo tambor de medição.

Todos os valôres das contagens de radioatividade fo ram corrigidos do fator de decaimento, de acôrdo com a equação (4), para um tempo $t=0$, e os resultados encontram-se na tabela VIT.

\section{IV.1.2 METODO DOS DOIS PICOS}

No circuito descrito anteriormente colocou-se dois cintiladores no exterior da tubulação (conforme figura 15), 1 i gados a dois BASC e dois RUSTRAK, para obtenção do $\Delta t$ entre os picos. Os registradores foram sincronizados antes de cada ensaio para determinação das suas velocidades reais.

Calculou-se a velocidade do papel registrador gräfi co utilizando-se a equação (19), evitando-se erros devido à parte mecânica deles.

Para o cálculo da vazão volumetrica, de acôrdo com a equação (20), consideraram-se os seguintes fatôres:

- distância entre o ponto de sincronização ( inicio do ensaio) no papel e o baricentro da curva que representa o pico de atividade nas duas fitas registradoras (figura 18);

- a velocidade real medida, para cada fita, e o cá1 culo do intervalo de tempo transcorrido entre os dois pontos;

- o tempo de trânsito da frente radioativa entre os dois detetores;

- a velocidade do traçador no interior da tubula ção. 
T A B E L A VII

RESULTADOS OBTIDOS PELO METODO DA CONTAGEM TOTAL EM TUBULACÕOS

\begin{tabular}{|c|c|c|c|c|c|c|c|c|}
\hline $\begin{array}{c}\text { ENSAIO } \\
\text { NO }\end{array}$ & $\begin{array}{c}\Delta t \\
(\min )\end{array}$ & $\begin{array}{c}\mathrm{BG} \\
(\text { contagem })\end{array}$ & $\mathrm{c}_{\mathrm{t}_{\mathrm{b}}}$ & $\mathrm{C}_{\mathrm{t}_{l}}$ & $\begin{array}{c}\text { PESO DA SOL. } \\
\text { (GRAMAS) }\end{array}$ & $e^{x}$ & $\mathrm{c}_{t_{c_{(\text {contagem })}}}$ & $\mathrm{Q}_{(\ell / \mathrm{min})}$ \\
\hline 1 & 675 & 25.006 & 115.320 & 90.314 & 2,8007 & 0,9602 & 94.057 & 56,84 \\
\hline 2 & 720 & 22.121 & 110.430 & 88.309 & 2,8232 & 0,9576 & 92.219 & 58,44 \\
\hline 3 & 785 & 23.280 & 114.460 & 91.080 & 2,8440 & 0,9539 & 95.481 & 56,86 \\
\hline 4 & 870 & 24.570 & 109.580 & 85.010 & 2,7174 & 0,9490 & 89.579 & 57,90 \\
\hline 5 & 1.985 & 24.998 & 106.110 & 81.112 & 2,7375 & 0,8874 & 91.404 & 58,21 \\
\hline 6 & 2.035 & 25.190 & 105.190 & 79.900 & 2,7976 & 0,8848 & 90.303 & 59,13 \\
\hline 7 & 2.075 & 25.772 & 102.120 & 76.348 & 2,7303 & 0,8827 & 86.494 & 60,25 \\
\hline$Q$ & $\mathrm{VAZ}$ & O VOLUMTRR. & $\mathrm{CA}$ & & & & & $\bar{Q}=58,26 \pm 1,22$ \\
\hline
\end{tabular}




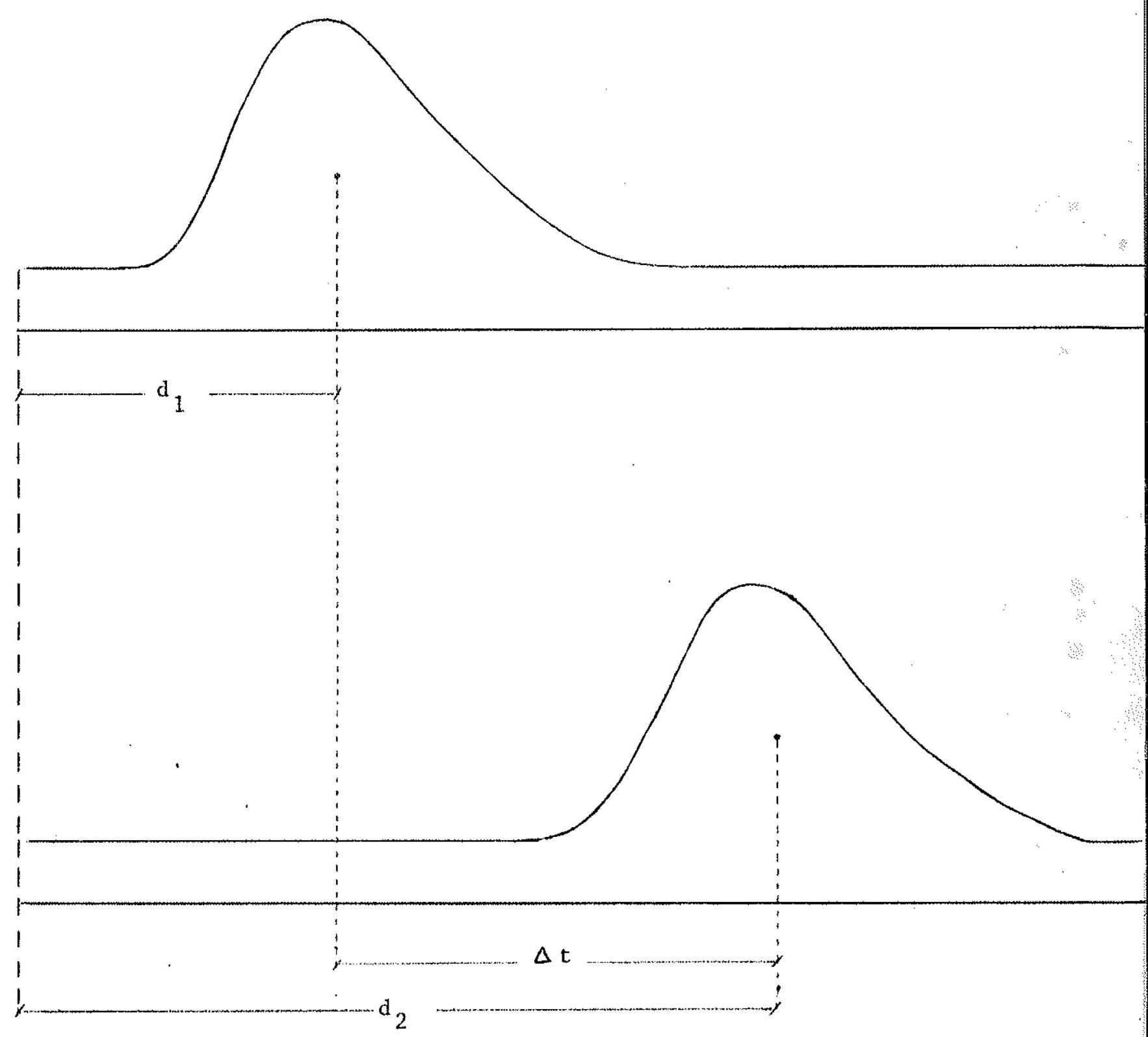

FIGURA 18 - Distância na fita do registrador gräfico entre o ponto de sincronização e o baricentro do pico de atividade. 
Conhecendo-se a velocidade e a seção molhada da tú bulação, calculou-se a vazão volumëtrica, utilizando-se a equação (20), simplificada:

$$
Q_{\text {medido }}=\mathrm{V} \cdot \mathrm{S}
$$

Mediu-se a seção molhada da tubulação (S) utilizando-se um paquímetro. O valor mediclo não correspondeu ao nominal, sendo necessário várias medições para obtermos um valor da seção mêdia.

os resultados obtidos estão representados na tabe 1a VIII.

\section{IV.1.3 COMPARACAO ENTRE OS RESULTADOS OBTIDOS}

Com base nos resultados das tabelas VII e VIII, pode-se afirmar, levando-se em conta que o método da Contagem Total tem uma precisão intrínseca limitada a $1 \%$, pelo nümero de contagens obtido e também pela reprodutibilidade do sistema de deteção utilizado, que as fontes de erro que podem ter afetado os resultados são:

- erros estatísticos de contagem, oriundos do próprio fenômeno de desintegração nuclear;

- pequenas variações de voltagem, alterando o rendí mento da bomba;

- a falta de homogeneidade na seção da tubulação de plástico, que se deforma facilmente. 
T A B E L A A VIII

RESULTADOS OBTIDOS PELO METODO DOS "DOIS PICOS" EM TUBULACÕES

\begin{tabular}{|c|c|c|c|c|c|c|c|}
\hline $\begin{array}{c}\text { ENSAIO } \\
\text { No }\end{array}$ & $\begin{array}{l}\mathrm{d}_{1} \\
(\mathrm{~cm})\end{array}$ & $\begin{array}{l}\mathrm{t}_{1} \\
(\mathrm{~s})\end{array}$ & $\begin{array}{c}\mathrm{d}_{2} \\
(\mathrm{~cm})\end{array}$ & $\begin{array}{c}\mathrm{t}_{2} \\
(\mathrm{~s})\end{array}$ & $\begin{array}{c}\Delta \mathrm{t} \\
(\mathrm{s})\end{array}$ & $\begin{array}{c}\mathrm{v} \\
(\mathrm{cm} / \mathrm{s})\end{array}$ & $\begin{array}{c}Q \\
(\mathrm{l} / \mathrm{min})\end{array}$ \\
\hline 1 & 16,04 & 47,88 & 22,26 & 66,19 & 18,31 & 46,42 & 57,35 \\
\hline 2 & 16,95 & 50,60 & 23,05 & 68,54 & 17,94 & 47,38 & 53,53 \\
\hline 3 & 15,16 & 45,25 & 21,34 & 63,46 & 13,21 & 46,68 & 57,66 \\
\hline 5 & 15,90 & 47,22 & 21,97 & 65,58 & 18,36 & 46,30 & 57,19 \\
\hline 6 & 17,80 & 53,13 & 23,90 & 71,34 & 17,94 & 47,38 & 58,53 \\
\hline 7 & 16,32 & 48,72 & 22,32 & 66,37 & 17,65 & 48,16 & 59,49 \\
\hline
\end{tabular}




\section{IV.2 MEDIDAS DE VAZÃO EM CANALIZACOES}

A oportunidade para a aplicação do método de traçadores radioativos na determinação de vazão volumétrica em canalização, surgiu com um pedido para a medição do escoamen to do esgôto de Santos-São Vicente, por intermêdio de um convênio entre o IEA (Instituto de Energia Atômica) e o CETESB (Centro Técnico de Saneamento Básico). A finalidade das medições era calibrar uma régua linimétrica existente na canalização, próxima à estação experimental de cloração da SBS (Saneamento da Baixada Santista).

0 método escolhido foi o da Contagem Tota1, pois co mo jä foi exposto anteriormente, não se necessita conhecer a seção transversal ou perímetro molhado, nem ser necessärio uma geometria infinita para o sistema detetor (no caso utilizou-se o tambor de medição).

Simultaneamente a estes ensaios com traçadores radioativos, o CETESB realizou medidas com colorantes, que não proporcionaram resultados satisfatōrios, pela existência de muitas partículas sólidas em suspensão tornando turva a coloração do esgôto e tambëm por ser um meio altamente redu tor.

Calculou-se a distância mínima de homogeneização de maneira a ultrapassar em dez vêzes o valor que se obtém utili zando a equação (10). Com este coeficiente de segurança assegurou-se uma perfeita homogeneização.

Utilizou-se $0^{82} \mathrm{Br}$ por suas caracteristicas apresen tadas na tabela VI e calculou-se a atividade pela equação(43). Escolheu-se um trechoretilíneo da canalização para as medições, situado entre a estação experimental de cloração da SBS e o posto de sentinelas do Forte Itaipú (figura 19). O ponto de injeção e o ponto de medição estavam separa dos por aproximadamente 2000 metros.

Para a injeção da solução traçadora utilizou-se um aparelho projetado e fabricado no IEA (figura 20), para injeção instantânea, requisito indispensāvel de validez das equações utilizadas no cálculo da vazão volumétrica pelo më- 


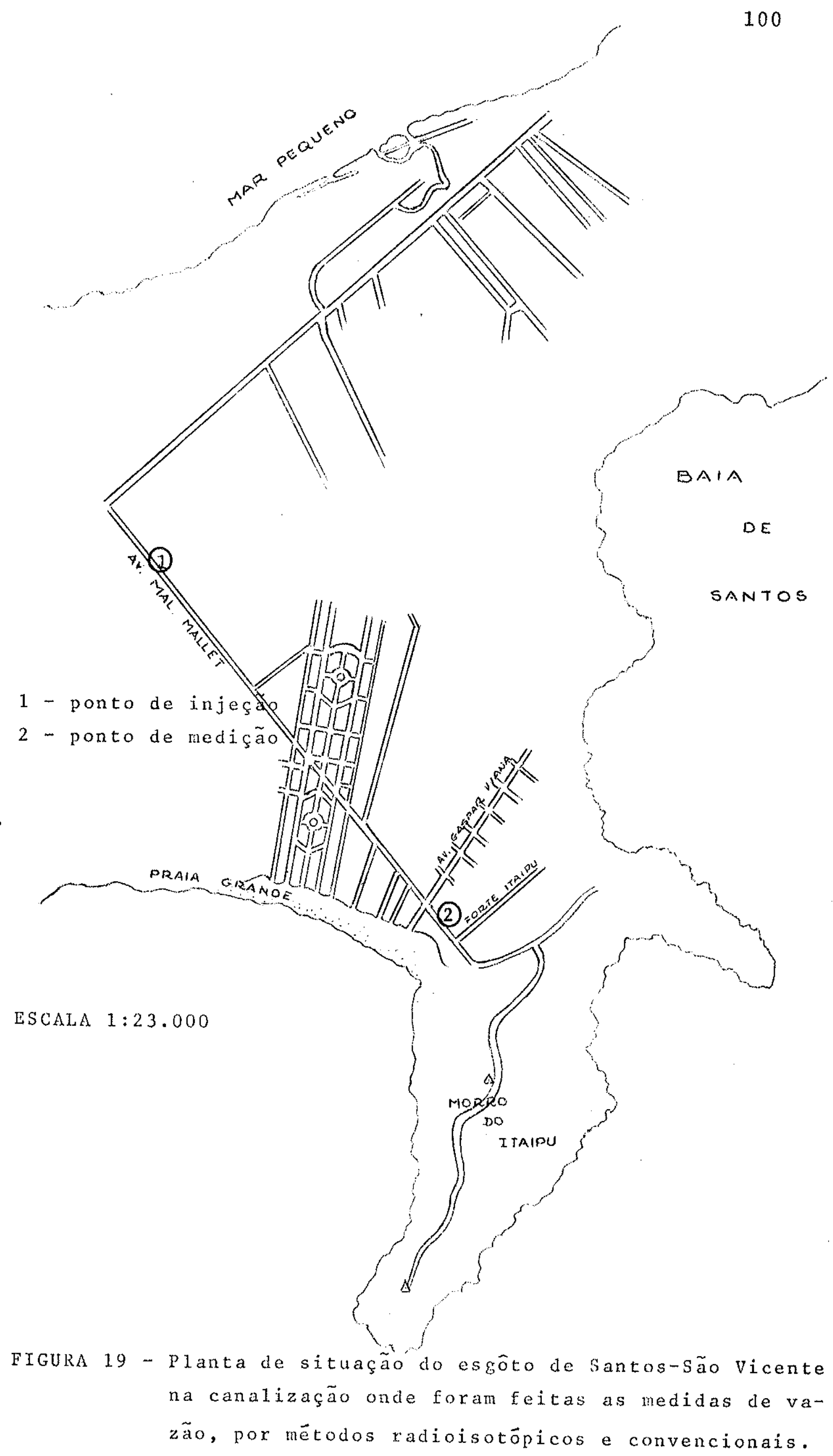




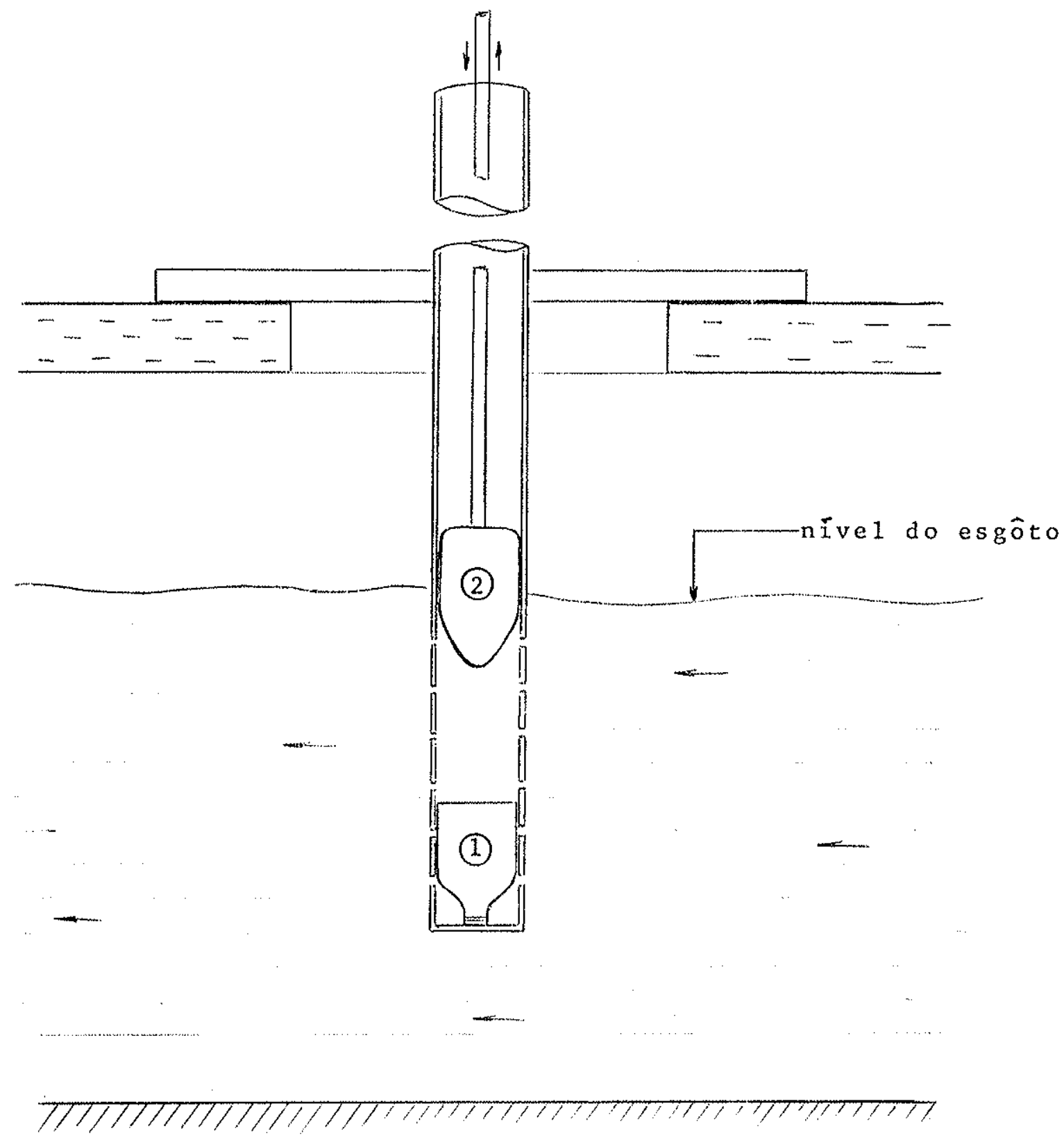

FIGURA 20 - Aparelho para injeção instantânea

(1) - frasco de vidro con solução traçadora

(2) - pistão de impacto 
todo da Contagem Tota1.

Mediu-se a atividade do esgôto utilizando-se a técnica $B$, da figura 2, com um detetor de cintilação com cris tal de NaI (TI) ligado a um escalímetro integrador e a um registrador gráfico (Figura 21). Tambëm faz parte do sistema o tambor de medição (figura 17) e uma bomba de $1 / 4 \mathrm{HP}$ com vazão mâxima de $200 \mathrm{1} / \mathrm{min}$.

0 traçador ${ }^{82} \mathrm{Br}$ foi dissolvido em solução de tios sulfato de sódio e as frações, para cada ensaio, foram acondi cionadas em frascos de vidro de $10 \mathrm{ml}$.

Entre os ensaios mediu-se a taxa de "background" pa ra verificar se o traçador radioativo não havia ficado retido no sistema em medição.

Para cada medição realizada leu-se o nível do esgo to, correspondente a vazão determinada. Os dados obtidos estão dispostos nas tabelas IX e $X$, sendo que a correlação entre eles esta apresentada na figura 22. Pode-se notar que existe uma concordância na forma das curvas, e a pequena variação existente entre elas pode ser atribuida a:

- oscilação do escoamento durante as medições;

- variação de tensão utilizada na bomba;

- leitura da régua na hora do ensaio (divisão minima de $2 \mathrm{~cm}$ );

- sólidos, que arrastados pelo escoamento, poderiam entupir parcialmente o filtro da välvula de sucção ( $f$ igura 23 ).

Os resultados obtidos nas medições, que constam da tabela IX, jā estão corrigidos por decaimento radioativo(equa ção (4) ) a um tempo $t=0$.

Para o cálculo da vazão utilizou-se a equação (36). 
T A B E L A

RESULTADOS OBTIDOS PELO METODO DA "CONTAGEM TOTAL" EM CANALIZAÇÕES

\begin{tabular}{|c|c|c|c|c|c|c|c|c|}
\hline $\begin{array}{l}\text { ENSAIO } \\
\text { NO }\end{array}$ & $\begin{array}{c}\Delta t \\
(\min )\end{array}$ & $\mathrm{c}_{\mathrm{b}_{(\text {contagem })}}$ & $\begin{array}{c}\text { BG } \\
(\text { contagem })\end{array}$ & $\mathrm{C}_{t_{\ell}}$ & $\begin{array}{c}\text { P㝵SO DA SOL. } \\
\text { (GRAMAS) }\end{array}$ & $e^{x}$ & $\mathrm{c}_{\mathrm{t}} \mathrm{c}_{(\text {cont agem })}$ & $Q\left(m^{3} / s\right)$ \\
\hline 1 & 1005 & 175.330 & 47.130 & 128.200 & 12,7829 & 0,727 & 176.341 & 0,989 \\
\hline 2 & 1053 & 161.930 & 29.130 & 132.800 & 13,5872 & 0,716 & 185.475 & 0,999 \\
\hline 3 & 1090 & 157.620 & 37.420 & 126.200 & 13,3214 & 0,703 & 178.249 & 1,019 \\
\hline 4 & 1121 & 173.730 & 31.530 & $\overline{1} 42.200$ & 14,6991 & 0,701 & 202.853 & 0,988 \\
\hline 5 & 1156 & 146.790 & 25.590 & 121.200 & 13,1020 & 0,693 & 174.892 & 1,022 \\
\hline 6 & 1191 & 156.330 & 33.080 & 123.250 & 13,4910 & 0,685 & 179.927 & 1,023 \\
\hline 7 & 1223 & 158.570 & 32.430 & 126.140 & 13,5967 & 0,678 & 186.047 & 0,997 \\
\hline 8 & 1260 & 154.440 & 29.810 & 124.630 & 13,5630 & 0,670 & 186.015 & 0,995 \\
\hline 9 & 1295 & 154.300 & 29.700 & 124.600 & 13,3809 & 0,663 & 187.934 & 0,971 \\
\hline 10 & 1330 & 160.070 & 32.670 & 127.400 & 14,0099 & 0,656 & 194.207 & 0,984 \\
\hline 11 & 1368 & 143.130 & 34.230 & 108.900 & 12,3355 & 0,648 & 168.056 & 1,001 \\
\hline 12 & 1401 & 157.460 & 33.330 & 124.130 & 13,6427 & 0,641 & 193.651 & 0,961 \\
\hline$F=$ & $\times 10^{6}$ & $s / g / l$ & & & & & & $=0,996 \pm 0$, \\
\hline
\end{tabular}


T A B E L A

NIVEIS LIDOS NA REGUA QUANDO DOS ENSAIOS DE MEDICCÃO DE VAZT̃O DO ESGOTO DE SANTOS - ST̃O VICENTE. E A VAZT̃O CORRESPONDENTE MEDIDA PELO METODO DA CONTAGEM TOTAL.

\begin{tabular}{|c|c|c|c|}
\hline $\begin{array}{l}\text { ENSAIO } \\
\text { NO }\end{array}$ & IIORA & $\begin{array}{ll}\text { NIVEL } & \text { NA } \\
\text { REGUA } & (\mathrm{cm}) \\
\end{array}$ & $\begin{array}{c}\text { VAZ } A O O M E I D A \\
\ell / \mathrm{s}\end{array}$ \\
\hline 1 & $9: 43^{\prime}$ & 104 & 989 \\
\hline 2 & $10: 33^{\prime}$ & 106 & 999 \\
\hline 3 & $11: 10^{\circ}$ & 105 & 1019 \\
\hline 4 & $11: 41^{\prime}$ & 104 & 988 \\
\hline 5 & $12: 16^{\prime}$ & 105 & 1022 \\
\hline 6 & $12: 51^{\prime}$ & 106 & 1023 \\
\hline 7 & $13: 23^{\prime}$ & 106 & 997 \\
\hline 8 & $14: 00^{\prime}$ & 105 & 995 \\
\hline 9 & $14: 35^{\prime}$ & 105 & 972 \\
\hline 10 & $15: 10^{\circ}$ & 104 & 985 \\
\hline 11 & $15: 48^{\circ}$ & 104 & 1002 \\
\hline 12 & $16: 21^{\prime}$ & 104 & 961 \\
\hline
\end{tabular}


FIGURA 21 - Esquema da aparelhagem usada na medição da vazão volumêtrica da canalização do esgôto de Santos- Sã Vicente
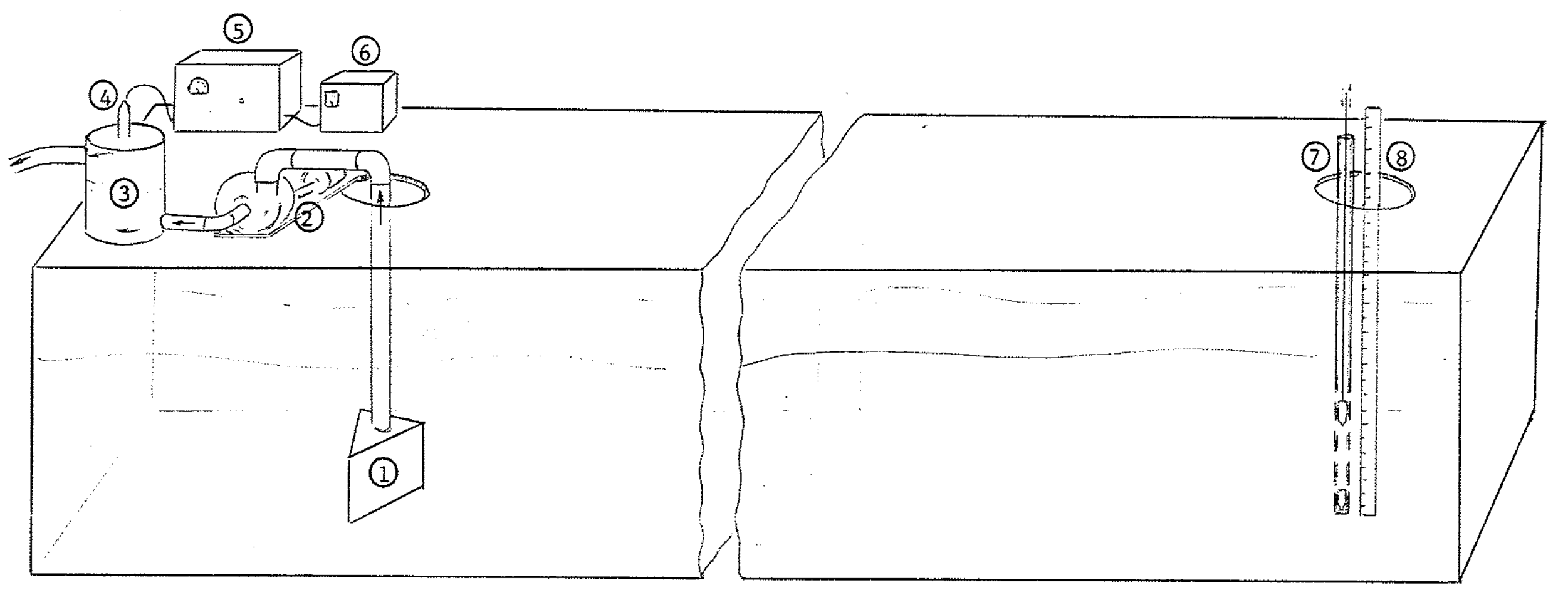

(1) - aparelho protetor da välvuia de sucção

(5) - escalimetro e integrador

(2) - bomba

(6) - registrador

(3) - tambor de medição

(7) - aparelho de injeção instantânea

(4) - detetor de cintilação

(8) - régua linimētrica 


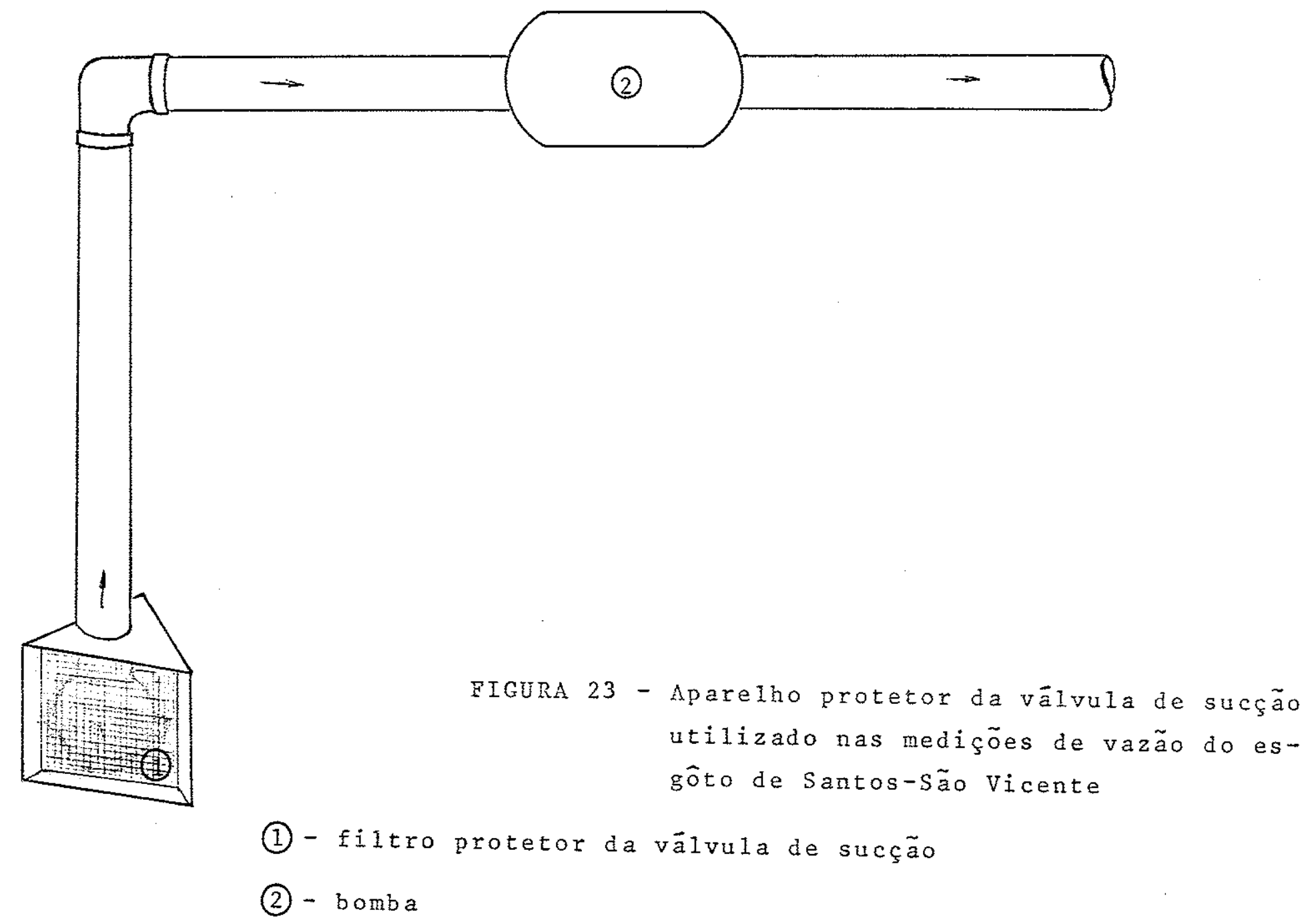




\section{3 MEDIDAS DE VAZÃO EM RIOS}

Para esta experiência escolheu-se o mêtodo da Conta gem Total, por ser o mais acessível e de bôa precisão. A uti1ização deste método em canal aberto foi originalmente empregada por Hull (1958), em um afluente de água salgada de uma refinaria para corrigix um linimetro fixo neste canal.

Para comprovar a eficiência do mëtodo de medições de vazão de pequeno porte, realizaram-se quatro ensaios no Rio Pirajussara (figura 24). A distância entre o lançamento do traçador e a estação de deteção foi de 2000 metros aproximadamente, superior em dez vêzes a distância mínima de homoge neização representada pela equação (10), no caso de uma injeç̃o latera1.

os erros de medição que poderiam ser cometidos esta vam ligados a falta de homogeneização, perda do traçador por precipitação ou adsorção pelo solo e ou algas do leito e baixa atividade do traçador injetado.

o Rio Pirajussara, no trecho escolhido para ensaio (figura 24), corre atravês de um canal aberto. Sua âgua tem. fluxo laminar passando ao regime turbulento em alguns pontos, facilitando assim a dispersão e homogeneização do traça dor injetado.

Lançou-se a solução traçadora em um trecho do rio onde ele está sendo canalizado e detetou-se a onda radioativa à jusante, em uma seção onde a parede do canal tinha sido sol apada por infiltração secundäria de água.

Calculou-se a atividade mínima a injetar pela fórmu la (43), levando-se em conta a tabela $V$.

A solução traçadora foi o ${ }^{82} \mathrm{Br}$ (tabela IV) dissolvi do em solução de tiossulfato de sỏdio. Parte dela foi fracio nada em quatro frascos de aproximadamente $30 \mathrm{~m} 1$, pesados em balança analitica.

Nestas medições utilizaram-se os mesmos equipamentos descritos anteriormente, ou seja, uma bonba de $1 / 4 \mathrm{HP}$ com vazão mảxima de 100 1/min, tambor de mediçäo (figura 17),cin tilador com cristal de NaI (T1), escalimetro integrador $\bar{e}$ 


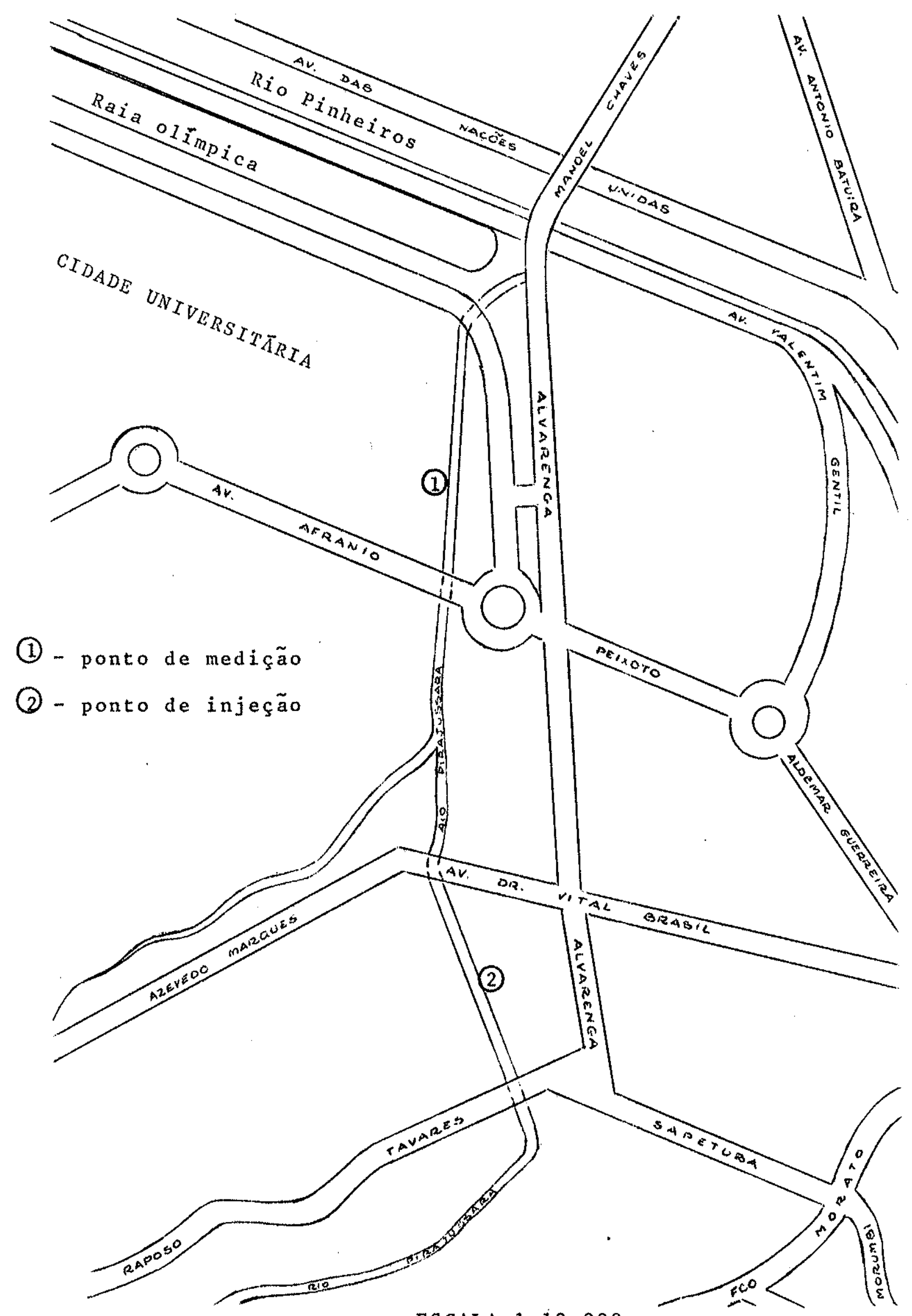

ESCALA 1:10.000

FIGURA 24 - Planta de situação do Rio Pirajussara no local onde foram realizados os ensaios de medição de vazão por método radioisotópico. 
FIgURA 25 - Esquema da aparelhagem usada na medição da vazão volumétrica do Rio Pirajussara

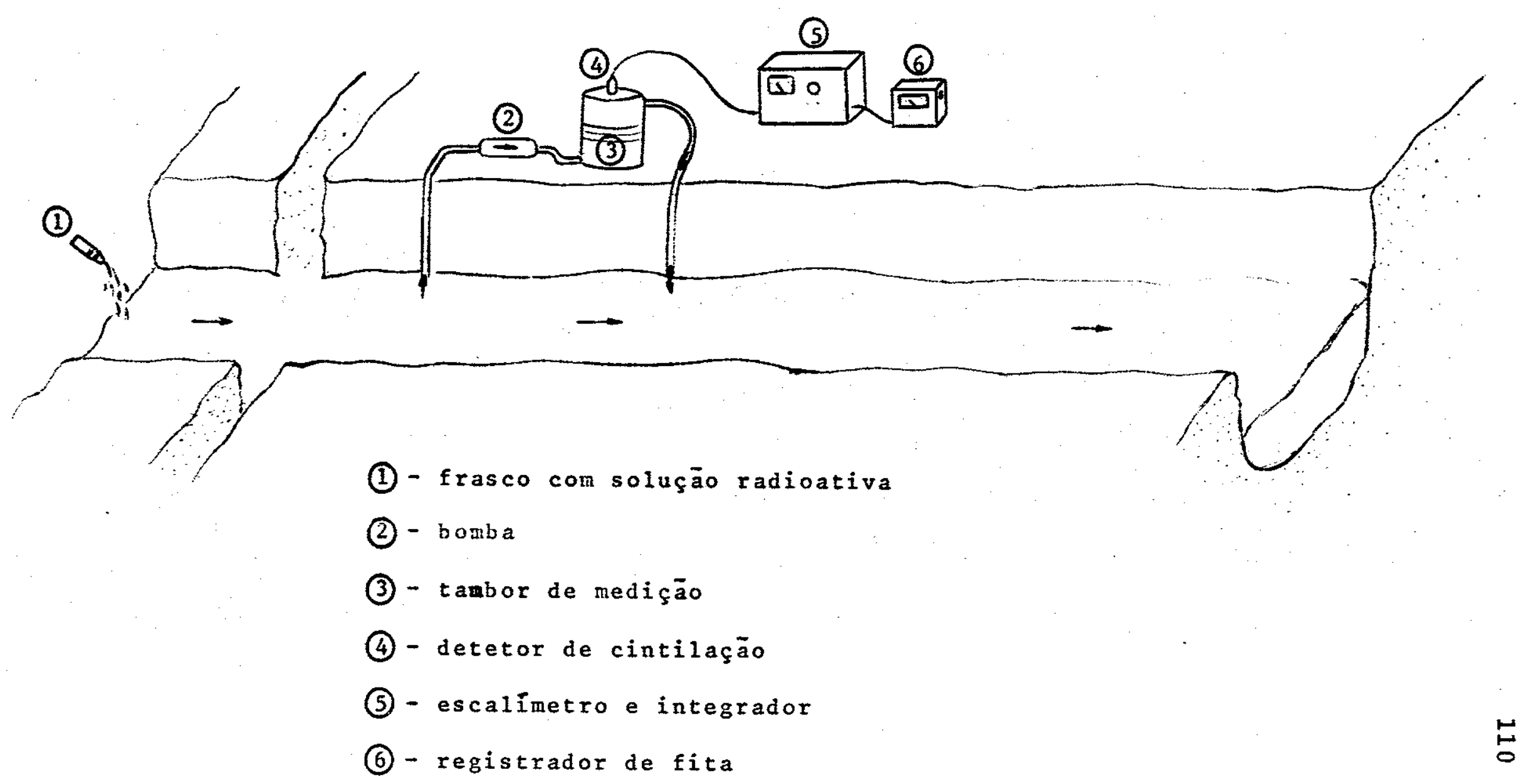


T A B E L A $\quad$ XI

RESULTADOS OBTIDOS PELO MÉTODO DA "CONTAGEM TOTAL" NO RIO PIRAJUSSARA EM 10 DE ABRIL DE 1973

\begin{tabular}{|c|c|c|c|c|c|c|c|c|}
\hline $\begin{array}{c}\text { ENSAIO } \\
\text { NO }\end{array}$ & $\begin{array}{l}\Delta t \\
(\min )\end{array}$ & $\begin{array}{c}\text { BG } \\
(\text { contagem) }\end{array}$ & ${ }_{b} c_{\text {(contagen) }}$ & ${ }^{c_{l}}{ }_{\text {(contagem })}$ & $\begin{array}{l}\text { PÊSO DA SOL. } \\
\text { (GRAMAS) }\end{array}$ & $e^{x}$ & ${ }_{t_{c}}^{c}{ }_{(\text {contagem })}$ & $\begin{array}{c}Q \\
\left(\mathrm{~m}^{3} / \mathrm{s}\right)\end{array}$ \\
\hline 1 & 330 & 101.610 & 281.770 & 180.160 & 36,6821 & 0,899 & 161.916 & 0,850 \\
\hline 2 & 290 & 80.920 & 258.280 & 177.360 & 36,8443 & 0,910 & 161.398 & 0,856 \\
\hline 3 & 210 & 73.532 & 250.800 & 177.268 & 37,9102 & 0,934 & 165.568 & 0,859 \\
\hline 4 & 180 & 84.210 & 253.800 & 169.590 & 36,5562 & 0,943 & 159.923 & 0,857 \\
\hline$F=$ & .987 & cps/g/l & & & & & \multicolumn{2}{|c|}{$\bar{Q}=0,856 \pm 0,0039$} \\
\hline
\end{tabular}


registrador gräfico (figura 25).

Com o uso do registrador gräfico pode-se perce ber visualmente a passagem da onda radioativa até chegar à contagem de fundo.

As contagens obtidas nos ensaios de campo (tabela XI) e as referentes a calibração do cintilador foram corrigi das por decaimento a um tempo $t=0$.

Oteve-se o fator de calibração com o uso de uma alí quota da solução traçadora e calculou-se a vazão pela förmula (36).

\section{IV.4 CONCLUSOES E OBSERVACOES}

Pelos resultados das experiências pode-se observar a validade dos métodos utilizados em diferentes meios. 0 en saio em tubulação. foi feito com água corrente potâvel, o da canalização, no esgoto de Santos e o ültimo no Rio Pirajus sara.

Os dados obtidos em laboratório poderiam ser melhorados, se tivessemos realmente um regime constante (como no caso do Rio Pirajussara) e a bomba utilizada fosse insensí vel às frequentes variações de tensão.

Nos ensaios em tubulação, o método da Contagem Tota1 apresentou um desvio padrão $1 / 3$ superior ao do método do Dois Picos. Isto não significa que este resultado e o mais correto, mas sim o que mais se adaptou às condições da expe riência. Realmente, este ultimo método não foi atingido pelas variações de tensão, por ser o tempo de medição relativamente curto e porque somente nos interessava io intervalo de tempo transcorrido entre a passagem do "pico" pelos dois dete tores.

Na canalização, o desvio padrão também foi elevado, mas se considerarmos o espaço de tempo em que ocorreram os en saios de medição, podemos notar a causa. Durante a realiza ção do trabalho, a vazão variou conforme constatado pela leitura da régua. Fez-se uma comparação entre cada medida e o 
respectivo nível do esgoto lido na régua, de acôrdo com os da dos das tabelas $I X$ e $X$. Dai construiram-se as curvas da (figu ra 21). Observa-se que de fato as duas curvas se comportam de maneira anāloga, com excessão de poucos pontos. Provavelmente, foram estes os que sofreram os efeitos da variação de tensão na bomba ou ainda devido a um parcial entupimento do filtro da välvula de sucção do sistema detetor.

Nas medições realizadas no Rio Pirajussara, a bomba era nova e a eletricidade fornecida vinha direto de um poste com transformador, sendo constatado tambëm que a vazão não se alterou durante o período de ensaios. Com isto alcançou- se um desvio padrão otimo nos ensaios realizados, demonstrando que de fato, o mëtodo da Contagem Total proporciona bôa preci são.

Uma comprovação da inoperância do mẻtodo convencio na1 de colorimetria, quando o meio não è limpido, foi mostrada quando da realização dos ensaios de medição de vazão de esgoto em Santos. Simultaneamente com os traçadores radioativos realizaram-se ensaios com Rodamina $B$, que não chegaram a resul tados reproduziveis, pois o meio não era o ideal ao uso deste traçador.

Nossas experiências tinham por objetivo um melhor co nhecimento dos mëtodos descritos, muito pouco utilizados em nosso país, e das dificuldades a serem enfrentadas na prätica.

Para finalizar, pode-se dizer que o uso sistemātico de métodos radioisotópicos na determinação de vazões volumé tricas, quando convenientemente aplicados, são relativamente simples e de baixo custo. Por isto tudo, é de se esperar que estes métodos tenham seu uso incrementado em futuro próximo. 
BIBLTOGRAF IA

ANDRE, H. - "Hydromêtrie practique des cours d'eau". ENSEHRMA Section Hydraulique, Facultê des Sciences, Grenoble, 88 p.

BALLOFFET, Gotelli, Meoli - "Hidrâulica". Ediar Soc. Anon. Editores, seg. edição (1962).

BAUMEISTER, Marks - "Mechanical Engineers". International Student Edition. McGraw-Hill-book Company, 1958 .

CAstagnet,A.C. - "Curso de Aplicação de Radioisöto pos nas Indústrias de petróleo, Gâs e Petroquimica". Apostila no prelo.

DANIELS,F. e R.A. Alberty "Físico Química". Ao Livro Técnico, 1960.

GARCEZ, L.N. - "Hidrologia". Editôra Edgard BIucher Ltda., 1967.

GARDNER,R.P. and Ra1ph L. E1y, Jr - "Radioisotope Measurement applications in Engineering Reinhold Publishing Corporation, New York. 1967.

GOMEZ, H.R. - "Aplicacion de Radioisotopos en Hidrologia". 6 curso Regiona1, Universidad Nacional de Cuyó, Argentina -1970

GUIZERIX,J., et a11 - "Les mesures de dëbits effectuees en France a 1 'aide de traceurs radioactfs por 1 a methode $d$ ' integration. Radioisotopes in Hydrology (Proc.Symp.Tokyo 1963), 255-279 IAEA 
Viena-1964.

HOLMAN, J.P. - "Experimental Methods for Engenieers". MacGraw-Hi11 Book Company, 1966.

HULL, D.E. - "Dispersion and Persistence of tracer in river flow measurements". Intern. Journal of Applied Radiation and Isotopes, vol.13, pp. $63.73,1962$.

HULL, D.E. - "The Total Count Technique; a new principle in flow measurements". Int. J. App1.Ra diat. Isotops, vol.4, pp.1-15, 1958.

HULL, D.E., et al1 - "Flow measurements by the Total Count method". Repr. from 2nd Un Geneve Conference.

INTERNATIONAL ATOMIC ENERGY AGENCY - "Guide to the Safe Handling of Radioisotops in Hidrology". IAEA, Viena, Safety series, num.6, 1966.

KAPLAN, Irving - "Física Nuclear". Ediciones Aguilar S. A. -1962 .

KAUFMANN, W.J. e Orlob, G.T. - "An Evaluation of Ground-Water Tracer".Trans. Am. Geophysics Union, $n^{8} 37,297-306,1956$.

KORSUNSKY, M. - "The Atomic Nucleus".Foreign Languages Publishing House - 1962.

MASAO, Kato et al1 - "A study in River engineering on the Rad. in Hydrology". Proc. of a Symp. Tokyo, 1962 . 
MOLTNART, J. - "Les traceurs salins et fluorescentes em hidrologie". DR/SAR G/69-15/JM/MCT.

MONDREGO, S.P. e A. Plata - "Radiaciones jonizantes": Ed. E1 Ateneo S.A., Barcelona - 1965.

OHLWETLER, O. Alcides - "Introduçầ à Quimica Geral" Editôra Globo S.A.- 1067.

PLATA, A.B. - "Isotopos en Hidrologia". Editorial Alhambra S.A. 1a. edic. - 1972.

PUTMAN, J.L. - "Isotopes". Ed. Penguin Books Ltd. Baltimore - 1960 .

RUMYANTSEV , S. - "Industrial Raaiology". Foregn Langages Publishing House - Moscow - 1968 .

SIENKO; J. Miche11 e R.A. Plane - "Química". Ediciones Aguilar S.A. - 1966.

SCHOELLER, H. - "Les eaux souterraines". Ed. Masson et Cie, Paris - 1962 .

SANCHEZ, Wladimyr - Tese de doutoramento - IEA - 1973.

TIMBLIN et a11 - "Use of rad. for open channel flow measurements". Proc. of a Symp. Tokyo 1962.

TOSOVAC, T. et al1 - "Study of the dispersion ability and some other characteristics of the Danube by nuclear techniques".SM $129 / 30$. Symp. on the use of isotopes in Hydrology Viena - 1970 . 